\title{
Ergativity and Its Typology: The Trans-Zab Jewish Dialects
}

The Jewish towns to the east of the Greater Zab comprise a separate TransZab Jewish subgroup against the Jewish communities to the west of the Greater Zab and the settlement Barzan. These western Jewish dialects, such as Dohok, Zakho and 'Amedia, known as lishana deni, are closer to the Christian dialects and will be discussed in the following chapter. The Barzani cluster shares a number of features with the Trans-Zab communities.

Mutzafi (2008b) discerns further clusters within the Trans-Zab subgroup displayed on the map below:

- The Western Trans-Zab cluster in the Arbel_or Erbil_-region, between the Great and Little Zab rivers: Dobe, Arbel and Shaqlawa alongside Rewanduz, Rustaqa and Koy Sanjaq in Iraq;

- The Northern Trans-Zab cluster in Iranian Azerbaijan, including Salmas (or Salamas, Duval 1883), Urmi (or Urmia, Garbell 1965; Khan 2008b), Solduz (Naghada; Hopkins 1989b), Shino (Oshnavieh) and Sablagh (Mahabad);

- The Southeastern (SE) Trans-Zab subgroup in the Sulemaniyya region of Iraq and western Iran, with Bijar as the easternmost and Kerend as the southernmost Jewish outpost.

The Trans-Zab dialect bundle is characterized by isoglosses such as final stress, e.g. gorá 'man' vs. góra elsewhere, the merger of interdentals / $/$ / and / $/$ / into /l/, e.g. belá 'house' (< *baytāa) and 'elá 'festival' (< $\left.{ }^{*} e \underline{e} \underline{a}\right)$, lexemes, e.g. băruxa 'friend', the definite suffix - aké borrowed from Gorani and verb-final word order under influence of Iranian. ${ }^{1}$

The SE Trans-Zab cluster stands out in the whole of NENA for its type of ergative morphology, its typology will be the focus of our discussion in this chapter in light of the Trans-Zab Jewish subgroup as a whole.

After introducing some of the unique morphosyntactic features common to most of the Trans-Zab Jewish group, the differences in their nominal marking and verbal person marking will be examined from a typological perspective. Splits between ergative and non-ergative alignment are generally divided according to clause/verb-related factors, such as tense, aspect and mood, and

1 See Mutzafi (2008b) for a discussion of these and more features. 


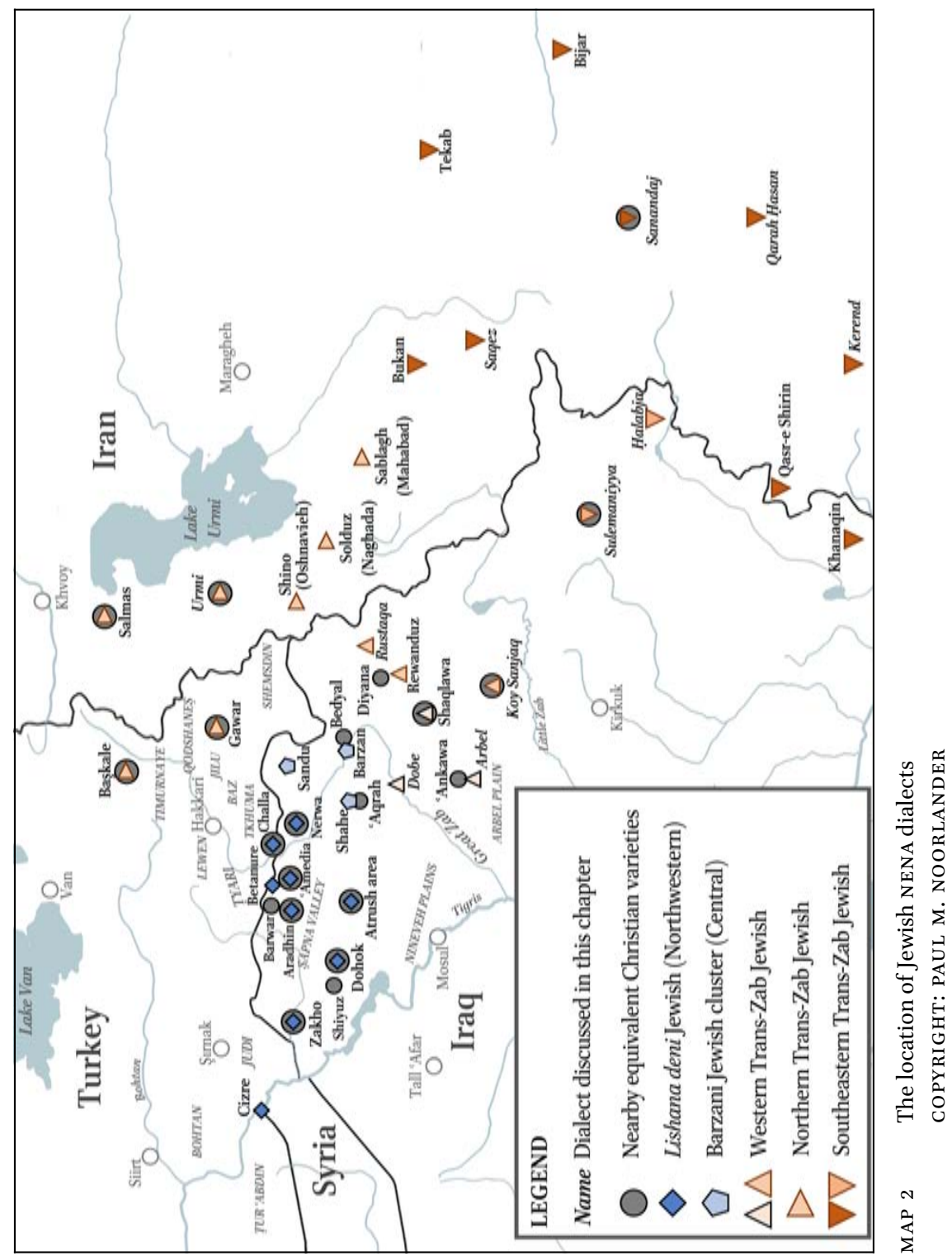


argument prominence-related factors, such as person and definiteness, alongside morphological factors, such as prepositional vs. verbal person marking. These factors tend to be presented as scales or hierarchies. When and in what sense do we find ergative marking in these dialects? Valency alternations, i.e. voice, are also pertinent to ergativity as to how these dialects distinguish between intransitive and transitive verbal predicates or (anti)passive and ergative constructions. The splits in Trans-Zab Jewish are manifold and concern all of these factors. They not only occur in simplex verbal forms, but also in compound verbal constructions based on the resultative participle as well as the infinitive.

What is central to this chapter is not only the question to what extent the properties found for ergativity in the Trans-Zab Jewish cluster are (un)expected typologically, but also to what extent there is a correlation between these properties and ergativity within this group. Some of these properties can seem rather unusual from a functionalist approach, but it will be argued that they make sense from a dialectological perspective.

\subsection{Main Morphosyntactic Hallmarks}

\subsubsection{Verb-Final Word Order}

All Trans-Zab Jewish varieties typically exhibit an Object-Verb, i.e. P-V, sequence as the unmarked word order throughout, ${ }^{2}$ similarly to other NENA varieties in the eastern periphery, for example:

(1) J. Saqez (W Iran; Israeli 1998, 186)

$[\mathrm{P}] \quad[\mathrm{V}]$

a. baxt-év aburw-év labl-a-le

woman:Fs-his dignity:M S-his take ${ }_{\mathrm{IPFV}}-\mathrm{A}: 3 \mathrm{FS}-\mathrm{P}: 3 \mathrm{MS}$

'His wife takes away his dignity.'

$[\mathrm{P}] \quad[\mathrm{v}]$

b. hatán kaldá nəšq-a-le

groom:Ms bride:FS kiss ${ }_{\mathrm{PFV}}-\mathrm{P}: 3 \mathrm{FS}-\mathrm{A}: 3 \mathrm{MS}$

'The bridegroom kissed the bride.'

2 See Noorlander and Molin (forthcoming) for a comparative study of word order typology in NENA. 


\subsubsection{Prepositional Marking of Objects}

3.1.2.1 ('al)l-and Accusative Prepositional Marking

The Trans-Zab Jewish dialects use the preposition $l$ - 'to, for' and its allomorphs, i.e. 'al-/hal-, to mark definite full nominal objects differentially in an accusative fashion. This is regardless of the type of verbal construction and, hence, also occurs together with qtil-, such as (2a) for J. Sanandaj and ( $2 b$ ) for J. Urmi.

\section{(2) Differential prepositional marking}

$$
[\mathrm{A}] \quad[\mathrm{DOM} \rightarrow \mathrm{P}] \quad[\mathrm{V}-\mathrm{A}]
$$

a. bronăké hal- bratăké lá-xe-wa-le ba-'amr-éf

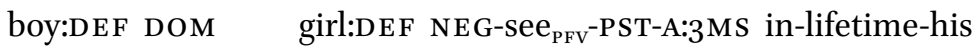

'The boy had never seen the girl in his life.' (J. Sanandaj, W Iran; Khan 2009, 323)

b. +̌̌ültaná ’al-brön-éw nšáq-le

king:MS DOM-son:Ms-his kiss ${ }_{\mathrm{PFV}^{-}} \mathrm{A}: 3 \mathrm{MS}$

'The king kissed his son.' (J. Urmi, Garbell 1965, 170)

\subsubsection{Jall-Series of Person Markers}

Typical of the Trans-Zab Jewish varieties is the use of the same preposition ('al)l- as the basis for object pronouns that we shall refer to as the 'all-series (cf. Khan 1999), which are distinct from the unmarked series, e.g. 'ana 'I', and from suffixal person markers as given in the following example.

(3) J. Arbel (NW Iraq; Khan 1999, 334)
$[\mathrm{P}]$
[V-A]
a. 'วll-ŏ́x-iš
$\dot{g} a z y-a$
OBJ-2MS-ADD see $_{\text {IPFV }}-\mathrm{A}: 3 \mathrm{FS}$
'that she sees you also.'
$[\mathrm{P}] \quad[\mathrm{V}-\mathrm{A}-\mathrm{P}]$
b. ’all-án qațl-i-lan
OBJ-1PL kill ${ }_{\mathrm{IPFV}} \mathrm{-A:3}$ PL-P:1PL
'that they kill (also) us.'

The narrow focus position in these dialects is immediately before the verb (see Noorlander and Molin forthcoming). Object pronouns can thus occupy this focus position, occurring independently of verbal inflection, like full nominals. Pre-verbal position, then, factors in the selection of independent object pronouns, since they provide a pronominal equivalent of full nominals in the verb- 
final word order, characteristic of Trans-Zab Jewish varieties, ${ }^{3}$ as illustrated for Jewish Urmi below.

(4) J. Urmi (NW Iran; Khan 2008b, 448, 300)

a. al-'yalé dah-i-wa 'They would beat the children.'

b. oll-án dah-i-wa 'They would beat us.'

The P-V word order is only possible with the fully independent person form, for example:

(5) J. Kerend (W Iran; Hopkins 2002, 287)

[P] $[\mathrm{V}-\mathrm{A}]$

’alóx graš-li

'I pulled you $_{\mathrm{ms}}$ '.

The default position, however, is immediately after the verb, which tends to be the perfective past form based on qtil-. When the 'all-series is placed after the verb, there is a very strong tendency to cliticize, with syncope of the initial $P /$ after consonants and $/ 2$ a/ after vowels. This coalescence yields another set of dependent person markers alongside the familiar L-suffixes. Thus J. Arbel (Khan 1999, 118-119, 133-134) has for 'We saw him':

$$
\begin{aligned}
& {\left[\begin{array}{lll}
\mathrm{V} & -\mathrm{A} & -\mathrm{P}
\end{array}\right] \quad\left[\begin{array}{ll}
\mathrm{V} & -\mathrm{A}
\end{array}\right] \quad[\mathrm{P}]} \\
& \dot{g} z e ́-\quad-l a n \quad-i l l e u<\dot{g} z e-\quad \text {-lan ill-eu } \\
& \text { see }_{\mathrm{PFV}^{-}}-\mathrm{A}: 1 \mathrm{PL}-\mathrm{P}: 3 \mathrm{MS} \quad \text { see }_{\mathrm{PFV}^{-}}{ }^{-\mathrm{A}: 1 \mathrm{PL}}-\mathrm{OBJ}^{-3 \mathrm{MS}}
\end{aligned}
$$

These pronouns may even attach to inverted qțil-based ditransitive constructions, where the E-set always denotes the theme and the 'all-series the recipient, e.g. J. Urmi (Khan 2008b, 123):

$$
\begin{aligned}
& {\left[\begin{array}{llll}
\mathrm{V} & -\mathrm{A} & -\mathrm{P} & -\mathrm{R}
\end{array}\right]} \\
& \text { hiw } \quad-a \text { a } \quad-l e \quad-l l i \\
& \text { give }_{\mathrm{PFV}}-\mathrm{T}: 3 \mathrm{FS}-\mathrm{A}: 3 \mathrm{MS} \text {-R:1SG }
\end{aligned}
$$

'He gave her to me.'

The preposition 'al- can also be extended by the linker $d$ - or the independent possessive pronominal base did-; the latter can also completely take over the pronominal object form, e.g. J. Sanandaj (Khan 2009, 348)

3 See $§ 3.3 .2 .2$. 


\begin{tabular}{|c|c|}
\hline$[\mathrm{P}]$ & {$[\mathrm{v}$} \\
\hline did-i-čc & qațl \\
\hline
\end{tabular}

'They will kill me also.' (lit. will kill mine also)

\subsubsection{Verbal Inflection and Person Marking}

3.1.3.1 Transitive Verbal Base qațl-

The qțil-base may sometimes display a slight difference in the pattern, i.e. vowel template, of sound verbs when combined with both E-suffixes and L-suffixes in all Trans-Zab Jewish varieties. While the template of the verb on its own is $\mathrm{C}_{1} \mathrm{C}_{2} \partial \mathrm{C}_{3}$ - before suffixes beginning with a consonant, e.g. I nšaq-le 'He kissed', III madmax-la 'She put to sleep', it breaks up the syllable as $\mathrm{C}_{1} \partial \mathrm{C}_{2} \mathrm{C}_{3}$ - when followed by an affix beginning with a vowel before the L-suffix, e.g. nəšq-a-le 'He kissed her' instead of ** $n s ̌ i q-a-l e$ similarly to madəmx-i-la 'She put them to sleep' for **madmix-i-la. ${ }^{4}$ This is presumably at least partially under the influence of the equivalent qatal-based forms that coincide in the syllable structure $\mathrm{C}_{1} \mathrm{VC}_{2} \mathrm{C}_{3}$ in the inflection of final-y verbs, compare J. Saqez (Israeli 1998, 26) xazy-a-le 'She sees him' and xəzy-a-le 'He saw her' and mazdy-a-le 'She frightens him' and mazdy-a-le 'He frightened her' (Khan 2005). ${ }^{5}$

3.1.3.2 Possessive Suffixes and Secondary $\mathrm{L}_{2}$-Suffixes $\left(\mathrm{L}_{2}\right.$-set $)$

The possessive suffixes of the $3 \mathrm{~ms}$. and 3 fs. in Trans-Zab Jewish varieties generally end in a characteristically labial element ranging from $-u,-w,-v$ to $-f$ depending on the dialect, as illustrated in (6) below. They contrast with the L-suffixes 3 ms. -le and 3 fs. -la respectively.

(6) Possessive suffixes vs. L-suffixes

L-SUFFIX

(all)

$3 \mathrm{MS}-l e$

$3 \mathrm{FS} \quad-\mathrm{la}$

POSSESSIVE SUFFIX

J. Urmi J. Saqez J. Sanandaj

vs. bel-éw bel-év bel-éf 'his house'

vs. bel-áw bel-áv bel-áf 'herhouse'

Occasionally, these distinct suffixes also end up on verbal forms through the 'all-series. While the object is normally marked by L-suffixes after E-suffixes in qațal-, such as garš-a-le 'She pulls him' or garš-á-wa-le 'She pulled him' in J. Sanandaj, the first person singular verbal forms of qațal- take object indexes

4 To the best of my knowledge, only J. Rustaqa (Khan 2002b) does not display this shift and maintains the pattern of nšiq-a-le.

5 See also $§ 2 \cdot 3 \cdot 3 \cdot 1$. 
in -ef and - af and after -wa they are -lef and -laf. Thus, the following constructions in (7) below do not contain the expected L-suffixes -le and -la. ${ }^{6}$ Possibly, forms such as *garáš-na-lox underwent anticipatory assimilation garəš-na-nox and syncope, developing into garáš-n-ox. ${ }^{7}$ Then the second affix was reanalyzed as an adnominal suffix, resulting in the use of distinct $3 \mathrm{~ms}$. and $3 \mathrm{fs}$. suffixes identical to the adnominal suffixes -ef and - $a f$.

\section{(7) Distinct L-suffixes after first person singular (Khan 2009, 155-156) PRESENT PAST \\ 3MS garəš $\quad$-n -éf garáš- -na \\ 3FS garəš $\quad-n$-áf garáš- -na}

Similarly, the simplification of originally geminate /ll/ neutralizes the distinction between the L-suffixes and 'all-series attached to the preterit. The following data from Jewish Saqez (W Iran; cf. Khan 2009, 158 for J. Sanandaj) show how the sets of person markers can be neutralized:

(8) Secondary L-set of affixes in J. Saqez (W Iran; Israeli 1998, 30, 113)

\begin{tabular}{llll} 
& L-SET & 'all-SET & POSS \\
1SG & $-l i$ & $-l-i$ & $-i$ \\
$2 \mathrm{MS}$ & $-l o x$ & $-l-o x$ & $-o x$ \\
$2 \mathrm{FS}$ & $-l a x$ & $-l-a x$ & $-a x$ \\
$3 \mathrm{MS}$ & $-l e$ & $-l-e v$ & $-e v$ \\
$3 \mathrm{FS}$ & $-l a$ & $-l-a v$ & $-a v$ \\
\cline { 3 - 4 } 3PL & $-l u$ & $-l-u$ & $-u$
\end{tabular}

The second set in (8) represents the forms that correspond to the 'all-series in closely related dialects of Jewish Saqez. The distinction in (8) between the first set and the second set is minimal in Jewish Saqez and clearly correlates with the 'possessive' suffixes. Hence, all indexes except for the third person singular are identical to the familiar L-suffixes and have arguably merged. The third person singular thus has a unique set of indexes in Trans-Zab Jewish varieties, which characteristically end in a labial sound that can become a special type of $\mathrm{L}_{2}$-suffixes contrasting with the more typical -le and -la.

6 J. Rustaqa (Khan 2002b, 401) is the only dialect known to me that does not show deviant forms, e.g. qațal-n-e ' $\mathrm{I}_{\mathrm{M}}$ kill him'.

7 Similarly to Țuroyo (SE Turkey), e.g. ko-goráš-n-ŭx ' $\mathrm{I}_{\mathrm{MS}}$ pull you $_{\mathrm{M}}$ ', a contraction of ko-gorášno-lux. 


\subsubsection{The Clause-Final Copula and Secondary E-suffixes ( $E_{2}$-set)}

The Trans-Zab Jewish dialects diverge to a great degree in the expression of the perfect and progressive that are generally based on nominal forms of the verb. When dialects use a nominal form of the verb combined with the enclitic copula, the person indexes can convert into suffixes virtually identical to the Eset. The dialects in the Western Trans-Zab region (Khan 1999; Mutzafi 2004b), however, make no use of such nominal based forms, but simply add a preverbal TAM-marker instead, e.g.

$\begin{array}{llll}\text { PROGRESSIVE } & l \bar{a} / n \bar{a} & \text { palax- } \varnothing & \text { 'He is opening' } \\ \text { PERFECT } & l \bar{a} / n \bar{a} & \text { plax-le } & \text { 'He has opened' }\end{array}$

The past copula consists of the qtil- of hwy 'be, become' with L-suffixes in all Trans-Zab Jewish dialects, e.g.

$\begin{array}{ll}\text { wele 'he was' } \\ \text { weli 'I was' } \\ \text { welan } & \text { 'we were' } \\ & \text { etc. }\end{array}$

The shape of the corresponding present enclitic copula can vary significantly across the dialects, as illustrated in (9). Western Trans-Zab dialects such as Arbel have the paradigm that is most common to NENA overall. Northern TransZab dialects such as Urmi stand out because of their generalization of the /1/ from the third to all persons and Southeastern varieties stand out because of their characteristic $-y .{ }^{8}$

(9) The basic clause-final copula in Trans-Zab Jewish ${ }^{9}$

\begin{tabular}{|c|c|c|c|}
\hline & $\begin{array}{l}\text { Arbel } \\
\text { (Khan 1999) }\end{array}$ & $\begin{array}{l}\text { Urmi } \\
\text { (Khan 2008b) }\end{array}$ & $\begin{array}{l}\text { Sulemaniyya } \\
\text { (Khan 2004a) }\end{array}$ \\
\hline $3 \mathrm{MS}$ & -ile & -ile & $-y e$ \\
\hline $3 \mathrm{FS}$ & -ila & -ila & $-y a$ \\
\hline $3 \mathrm{PL}$ & -ilu & -ilü & $-y e n$ \\
\hline $2 \mathrm{MS}$ & $-w a t$ & -ilet & $-y e t$ \\
\hline FS & -wat & -ilat & $-y a t$ \\
\hline & etc. & etc. & etc. \\
\hline
\end{tabular}

8 Khan (2004a, 94) argues the inflection of the originally pronominal copula was verbalized to match that of the final-/y/ verb hwy.

9 Cf. Khan $(2002 b, 408)$. 
Certain contractions of the enclitic copula and the vocalic ending of the predicate can result in person indexes that are (nearly) identical to the Esuffixes. When the preceding word ends in /e/ or /a/, all the copula forms containing /e/, except for the 3ms. -ye, contract completely in SE Trans-Zab Jewish dialects like Sulemaniyya. These are the $3 \mathrm{pl}$., 2ms., 2 pl. and $1 \mathrm{pl}$; thus compare, e.g. J. Sulemaniyya (Khan 2004a, 94-95)

$\begin{array}{rlll}\text { laxxá } & + \text {-yex } & \text { laxx-éx } & \text { 'We are here.' } \\ & -y a & \text { laxxa-ya } & \text { 'She is here.' } \\ \text { naxóš } & -y e x & \text { naxóś-yex } & \text { 'We are ill.' } \\ & -y a & \text { naxóś-ya } & \text { 'She is ill.' }\end{array}$

The same process applies to compound verbal forms consisting of the copula and a nominal element of the verb that typically ends in /e/ or /a/. J. Sulemaniyya contracts progressive forms such as garošéx 'We are pulling' from the infinitive *garošá 'pulling' plus the enclitic copula -yex 'we are' are phonologically identical to the E-suffixes, The progressive garoš-éx is identical to the inflection of qațal- as in garš-éx 'We pull' (Khan 2004a, 100). The difference between the two sets is obsolete with respect to the $2 \mathrm{~ms}$., 2 pl. and ipl., while other person indexes are kept apart, for example:

(10) J. Sulemaniyya (NW Iran; Khan 2004a, 83, 100)

\begin{tabular}{|lll|} 
& HABITUAL & PROGRESSIVE \\
3MS & garəš- $\varnothing$ & garošá-y \\
3FS & garš-á & garoša-ya \\
3PL & garš- $-i ́$ & garoš-én \\
\hline 2MS & garš-ét & garoš-ét \\
2PL & garš-etun & garoš-etun \\
1PL & garš-éx & garoš-éx \\
\hline
\end{tabular}

Among Jewish dialects, contracted forms can thus fall 'out of synch' with their uncontracted counterparts. This is the case in Iranian Azerbaijan, where the synthesis of a formerly analytic construction constitutes the basis of an inflectional paradigm no longer synchronic with the copula, ${ }^{10}$ as compared in (11) below for the first person.

10 Only a non-verbal clause can take the full form of the enclitic copula in J. Urmi (Khan 2008b, 282). 
(11) J. Urmi (NW Iran; Khan 20o8b, 84) PROGRESSIVE +qatöl-én $<$ *qațolá-ilen ' $\mathrm{I}_{\mathrm{M}}$ am killing' COP E-SET +qatöl-án $<$ *qațolá-ilan 'I $\mathrm{I}_{\mathrm{F}}$ am killing' -ilan -an ${ }^{+}$qatöl-áx < *qatolá-ilax 'We are killing' -ilax -ax

These endings are completely identical to the E-set found in the rest of the verbal system. They only differ in the third person morphems $-e$ and $-u$ based on copula forms -ile and -ilu, for example:

\begin{tabular}{|c|c|c|c|c|c|}
\hline PROGRESSIVE & & & & $\mathrm{COP}$ & E-SET \\
\hline${ }^{+}$qatöl-é & $<$ & *qațolá-ile & 'He is killing' & -ile & $-\varnothing$ \\
\hline 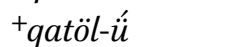 & $<$ & * qatolá-ilü & 'They are killing' & $-i l \ddot{u}$ & $-i$ \\
\hline
\end{tabular}

First and second person agent indexes combine with the L-suffixes to denote the object, for example:

PERFECT + $q$ talt-an-ne < * $q$ țlta + -ilan +-le ' 'I $\mathrm{F}$ have killed him.'

The merger of the compound progressive and perfect with qațl- is virtually complete in dialects like J. Urmi. Only the third person masculine singular and third person plural agent indexes constitute separate set, being -é and -ü, consistent with the copula forms -ile and -ilü from which they derive. Unlike first and second person subject and agent indexes, which are identical to the $\mathrm{E}_{1}$-set, these third person forms combine with an object series that shows secondary gemination of the /l/ like the 'all-series, for example:

PERFECT $\quad+q t ̦ i l-\ddot{u}-l l i<\quad$ *qțilé +-ilü + ’all-i 'They have killed me.'

Negation and past tense are not expressed by special forms of the copula in Urmi. The past convertor $w a$ and negator $l a$ are used instead:

$$
\begin{aligned}
& \text { PERFECT } \quad{ }^{+} \text {qtalt } \text {-an-ne ' 'I } \mathrm{F}_{\mathrm{F}} \text { have killed him.' (present) } \\
& \text { la }{ }^{+} \text {qtalt -an-ne 'I } \mathrm{I}_{\mathrm{F}} \text { haven't killed him.' (negative) } \\
& { }^{+} \text {qtalt -án-wa-le ' } \mathrm{I}_{\mathrm{F}} \text { had killed him.' (past) }
\end{aligned}
$$

The difference between the copula and the E-set, therefore, can be minimal, although a residue of the copula is still observed, especially in the third person. This gives rise to a special secondary $\mathrm{E}_{2}$-set for the third person only, similarly to the 'all-series, while the first and second persons are fully merged with the primary E-set in Jewish dialects of Iranian Azerbaijan. 
When a particular alignment type is restricted to a grammatical domain, we are dealing with an alignment split. This phenomenon has become so closely linked with the typology of ergativity in the literature that when ergative alignment is restricted with respect to the accusative type, as it often is, this is generally called split ergativity (Comrie 1978; Dixon 1979, 1994). In fact, it so common for ergativity to be restricted by various factors, that split ergativity has been considered one of the defining hallmarks of an ergative language. ${ }^{11}$ Labeling this 'split ergative alignment' is not only arbitrary, but also confusing. This terminology is avoided altogether here, as "it is not ergativity that is split, but alignment" (Haig 2008, 9). More specifically, it is not alignment per se that is split, but constructions that instantiate different argument marking strategies.

Alignment splits as such can occur between:

a) clausal categories, e.g. imperfective vs. perfective verbal constructions, or verbal categories, e.g. agentive vs. patientive verbs;

b) morphological strategies, e.g. flagging vs. indexing;

c) argument categories, e.g. first/second vs. third person.

There are at least two major approaches within linguistic typology to account for such splits, which can be divided into functional-communicative and arealdiachronic typology. The difference between the two approaches will become especially apparent in the alignment splits conditioned by the properties of the argument itself, but the difference between the more cognitive and more historical approaches is arguably noticeable for all factors.

Functionalists emphasize an underlying functional-communicative and cognitive basis. They adopt (sometimes universal) functional explanations for why certain patterns are favored cross-linguistically. ${ }^{12}$ It is a common assumption among such typologists, for instance, that cross-linguistic variation is largely not random, but due to general cognitive principles and an iconic relationship existing between the speaker's experience and the constructions they choose (e.g. Givón 1985b). What is more in line with speakers' experiences is easier to process, and, because they are easier to process, constructions that maximally correspond to speakers' experiences are preferred over others.

The other approach emphasizes the role of areal and diachronic factors that contribute to preferences in alignment typology. The historical development of

\footnotetext{
11 See, for instance, Silverstein (1976), Dixon (1979), Givón (1985a).

12 See inter alia Givón (1979, 199o, 1995, 2001), Foley and Van Valin (1984), Langacker (1987), (1991a-b), Croft (1994a, 2001).
} 
the source construction and areal factors concerning replications or transfers from one language to another are considered pertinent. They may be equally or even more germane to why alignment varies or is manifested in this way in a given language (e.g. Creissels 20o8b). While functionalistic approaches do not deny that diachronic factors and language contact play a role, such 'areal-diachronic typologists' ${ }^{13}$ argue that functionalist explanations for typology have been overstated, and historical and area-specific factors have more explanatory scope and power.

When we consider the typology of ergativity and its expected properties based on predications made in the literature, these approaches evidently diverge, but both arguably need to be taken seriously. Therefore, none of the generalizations made here are intended to be taken as universally true, i.e. inferences of universals about human language. When a given property is considered exceptional or unexpected, it is simply contrary to a given predication or expectation found in the relevant typological literature. While communicative efficiency is not considered to be irrelevant, it will become clear that areal and diachronic factors have to be taken into account. The focus here, nevertheless, is on the synchronic variation and its typological properties, not its diachronic development perse.

\subsubsection{Clause- and Verb-Related Factors for Alignment Splits}

The marking of $s$ and alignment of arguments can vary based on verbal semantics, sometimes referred to as "semantic alignment" (Donohue 2008). s can align with either $A$ or $P$, so that we can speak in terms of an $\mathrm{s}_{\mathrm{A}}$ and $\mathrm{s}_{\mathrm{P}}$ form. Lexical verb classes can be open as opposed to closed, so that one construction may be available to all verbs, while another is restricted. Alignment may also differ depending on clause-level grammatical information expressing the categories of tense (such as future, present and past), grammatical aspect (such as imperfective and perfective) and mood (such as realis vs. irrealis) or modality (such as possibility, necessity etc.), often abbreviated to TAM. All of these factors are, broadly speaking, verb-related (e.g. Tsunoda 1981).

13 Bickel (2008), Cristofaro (2013), Bickel et al. (2015) and the contributions to the special issue on hierarchies in alignment in Linguistics 54/3 (Haude and Witzlack-Makarevich 2016) are examples of recent studies and surveys. 


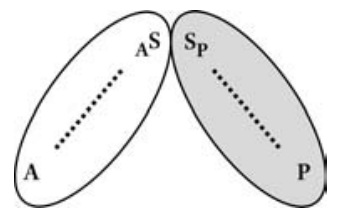

SPLIT-S MARKING

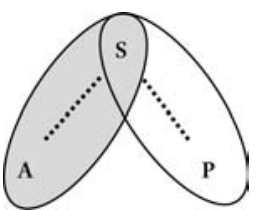

FLUID-S MARKING

FIGURE 2 Split- and fluid-subject marking

\subsubsection{Split and Fluid Subject Marking}

Dixon $(1979,1994)$ distinguishes between split-subject marking and fluidsubject marking. ${ }^{14}$ Figure 2 displays the two types in form of a schema.

The main difference between them is the number of lexemes or verb classes involved. Split-subject marking confines $\mathrm{s}_{\mathrm{A}}$ or $\mathrm{s}_{\mathrm{P}}$ forms to specific verb classes depending on semantic prototypes. In Guaraní, a Tupian language spoken in Paraguay, for example, the $\mathrm{s}_{\mathrm{A}}$ form is limited to verbs that denote an activedynamic situation such as 'go', 'die' or 'sleep', while the $s_{\mathrm{P}}$ form to those that denote a stative situation (like 'be fast', 'be dead' or 'be sleepy'). In the following example, the prefix $a$-marks A as well as the s of dynamic situations and the prefix še- marks P as well as the $\mathrm{S}$ of stative situations.

(1) Guaraní (Tupian, Paraguay; Mithun 1991, 511)

TRANSITIVE

a. a-gwerú aína

A:1SG-bring them

'I am bringing them now.'

TRANSITIVE

b. še-rerahá

P:1sG-carry.off

'It will carry me off.'

\section{INTRANSITIVE}

c. $a-x a ́$

S:1SG-go

'I go.'

INTRANSITIVE

d. še-ropehï

s:1SG-be.sleepy

'I am sleepy.'
$\left(\mathrm{s}_{\mathrm{A}}\right.$, dynamic $)$

$\left(s_{\mathrm{P}}\right.$, stative $)$

Sometimes there is an open as opposed to a closed verb class, so that one form is more common overall than the other. Fluid-subject marking, however, allows a single verb class to occur in both $\mathrm{s}_{\mathrm{A}}$ and $\mathrm{s}_{\mathrm{P}}$ forms. In Guaraní, for example, some verbs can occur in both the $s_{A}$ and $s_{P}$ form. Mithun (1991, 13), for instance, demonstrates that "the verb $k a^{\prime} u$ means 'to get drunk' " in the $\mathrm{s}_{\mathrm{A}}$ form "but 'to be a drunkard, to be drunk'" in the $\mathrm{s}_{\mathrm{P}}$ form. A language, therefore, may

14 This is sometimes also called split intransitivity (e.g. Payne 1997; Andrews 2007; Creissels 2008a). See also Klamer (2008) for more examples of overlap between the two. 
show both split- and fluid-subject marking, a situation that also holds for NeoAramaic languages.

NENA dialects may exhibit $\mathrm{s}_{\mathrm{A}}$ or $\mathrm{s}_{\mathrm{P}}$ forms, i.e. for the third person, in qtilbased constructions in a similar way, in particular the Northern Trans-Zab Jewish varieties. $S$ aligns with $A$ in the perfective aspect, i.e. with dynamic action focus, but with $\mathrm{P}$ in the resultative or retrospective aspect, i.e. with result state focus. ${ }^{15}$

(2) J. Urmi (NW Iran; Garbell 1965; Khan 2008b)
a. ${ }^{+} d m \partial x-l a^{16}$
( $\mathrm{s}_{\mathrm{A}}$ intransitive: perfective past) sleep $_{\mathrm{PFV}}-\mathrm{S}: 3 \mathrm{FS}$
'She went to sleep.' (lit. 'Her slept')

b. ${ }^{+}$dmix $-\boldsymbol{a}$

$\left(\mathrm{s}_{\mathrm{P}}\right.$ intransitive: realis perfect $)$

sleep $\mathrm{PFV}_{\mathrm{PF}} \mathrm{S}: 3 \mathrm{FS}$

'She has gone to sleep.' (lit. 'She slept')

The patient-like inflection (i.e. E-set) for s serves to denote an observed state resulting from a prior event. This can generally encompass stative, resultative or retrospective (i.e. perfect) aspect, all of which are properly subsumed under the imperfective aspect focusing on a continuous result state against the perfective past representing the event as a whole completed in the past. This co-variation is a fluid type of subject-marking, in which the $\mathrm{s}_{\mathrm{A}}$ form, i.e. L-set, expresses the perfective past, i.e. wholly completed dynamic event, and the $\mathrm{s}_{\mathrm{p}}$ form, i.e. E-set, the perfect or resultative, i.e. an enduring result state.

Various factors may be involved in split- and fluid-subject marking. The type exemplified in Guaraní above is on the basis of aspect and also known as activestative alignment. A dynamic situation or action is generally distinguished from a stative situation or inaction by the occurrence or absence of change. Activities like 'walk' or processes like 'grow' are dynamic, since they presuppose a change, while a state like 'be sleepy' does not. The opposition between action and inaction of the intransitive situations correlates with the agent as instigator or initiation phase and patient as endpoint or result-state phase of a transitive situation (e.g. DeLancey 1981). Another type of split- and fluid-subject marking is known as an agent-patient split (Nichols 1990), where the degree of agentivity

15 The corresponding transitive construction of the resultative or perfect varies considerably across these dialects, see Subsection 3.4.

16 The symbol + indicates suprasegmental pharyngealization of the following word or syllable. 
or affectedness determines the grouping of $s$. If $s$ is in control and thus instigating like an agent (such as the subject of 'walk', 'swim' etc.), it shares its coding properties with A, but if s lacks control and is affected like a patient (such as the subject of 'fall', 'die'), it shares these with P. The telic-atelic split also exists, where, for example in Georgian, telic verbs will align their S with $P$ and not with A, which indicates that telicity outranks volitionality (Arkadiev 2008). A telic situation is characterized by a change of state that reaches its natural endpoint or result phase after Greek telos 'goal, end', such as I sat down, I went to the market and the like (Comrie 1976, 45), whereas the counterpart is known as atelic.

The split and fluid-s marking found in the indigenous languages of the Americas, as discussed in the seminal study by Mithun (1991), is sometimes referred to as an alignment type of its own, being essentially not a split between ergative and accusative marking but a system sui generis. The dynamic-stative or rather perfective-resultative fluid-s marking in (2) would accordingly not be a subtype of ergativity, but of semantic alignment. With respect to (2), however, this is further complicated by the fact that forms like $d m i x-a$ in (2b), i.e. the realis perfect or resultative, also have a transitive counterpart belonging to the same clause type where $s$ may not be treated like A and/or P. If there is a transitive counterpart to $(2 b)$ with the same or a similar TAM value, I will consider the $\mathrm{S}_{\mathrm{P}}$ form also part of that system.

Furthermore, split intransitivity is a common feature of languages with ergative alignment because of the differential treatment of $\mathrm{A}$; a feature that is generally not apparent in an accusative pattern. ${ }^{17}$ Basque, for instance, is a wellknown example of a language with ergative morphosyntax, but the $s$ of a few intransitive verbs, such as 'boil' in (3c), takes ergative case-marking, and the verb takes transitive coding instead of the expected absolutive, such as the $s$ of 'come' in (3b) (Creissels 2008a, 143).

(3) Basque (Creissels 2008a, 143, glossing slightly adapted)

a. Gizon-ak ur-a edan du man-SG:ERG water-SG:ABS drink $\mathrm{PFV}_{\mathrm{PUV}}$ AUX:PRS:P:3SG:A:3SG

'The man has drunk the water.'

b. Gizon-a etorri da

man-SG:ABS come PFV $_{\text {AUX:PRS:S:3SG }}$

'The man has come.'

17 Nevertheless, this distinction may be reflected elsewhere, for example in the different selection of auxiliaries, such as HAVE vs. BE, in the various European perfects. 
c. $\boldsymbol{U}$ r-ak irakin $d u$
water-SG:ERG boil
PFV AUX:PRS:P:3SG:A3SG 'The water has boiled.'

Thus, the grouping of s, especially as manifested through verbal person marking, can vary between an ergative and an accusative pattern, and align with either $\mathrm{P}\left(\mathrm{s}_{\mathrm{P}}\right)$ or $\mathrm{A}\left(\mathrm{s}_{\mathrm{A}}\right)$, respectively. In Southeastern Trans-Zab Jewish dialects of NENA, which show third person ergative morphology in the preterit, most intransitive verbs are incompatible with A-like subject coding, but a few classes of intransitive verbs are compatible, as illustrated in (4) below. Contrast $n w x$ 'bark' with 'by 'swell' in J. Sulemaniyya:

(4) J. Sulemaniyya (NW Iraq; Khan 2004a, 298-300)

a. kalbá nwax-le

( $\mathrm{s}_{\mathrm{A}}$ intransitive: $n w x^{\prime}$ 'bark') dog:Ms bark PFv $^{-S}: 3 \mathrm{MS}$

'The dog barked.' (lit. 'Him barked')

b. zbot-i 'aby-a

( $\mathrm{s}_{\mathrm{p}}$ intransitive: 'by 'swell')

finger:FS-my swell ${ }_{\mathrm{PFV}}-\mathrm{S}: 3 \mathrm{FS}$

'My finger swelled.' (lit. 'She swelled')

Although intransitive verbs mainly belong to stem I, other stems may also be intransitive, e.g. gandar- $\varnothing$ ' It $\mathrm{M}_{\mathrm{M}}$ rolled' vs. zarzar-re '(The horse) neighed' (Khan 2004a, 300). Fluid-subject marking may also be found in these dialects: a single verb may occur in either $\mathrm{s}_{\mathrm{A}}$ or $\mathrm{s}_{\mathrm{P}}$ forms, e.g. nqas-la 'She pricked' and nqis-a ' $\mathrm{It}_{\mathrm{F}}$ pricked' (Khan 2009, 304).

The Southeastern Jewish Trans-Zab dialects that show third person ergative morphology are generally referred to as "split-s dialects" in the literature, ${ }^{18}$ because the marking of $s$ is split depending on various factors, as shown in (4) above. If this is correct, such a system would have to be subsumed under semantic alignment, rather than a subtype of ergativity. The ultimate analysis depends on whether our goal is to explain the structure found in Southeastern Trans-Zab Jewish dialects, illustrated in (4), which is like that of Basque, in light of the accusative pattern or from the perspective of a fluid-s system such as the one found in dialects like Jewish Urmi, illustrated in (1). While the boundary between ergative alignment and split- or fluid-s systems can be vague

18 For instance, Doron and Khan (2012), Barotto (2015), Khan (2017). 
(Comrie 2005, 399), it may be argued ${ }^{19}$ that splits of the kind in (4) can be considered a hallmark of the typology of transitivity alternations or lexical verbal classes in general, which could only manifest itself in an ergative morphological pattern because of the differential treatment of A. In fact, it so common for 'ergative languages' to show variation in the marking of $s$ depending on lexical transitivity that this has even been considered one of their defining hallmarks (e.g. Givón 1985a). It also depends on how much weight is given to the number of subsets of $\mathrm{s}_{\mathrm{A}}$ and $\mathrm{s}_{\mathrm{P}}$ verbs or verbal forms. This is radically different from the type in (2), since, there, both situations are equally intransitive and pertain to the same intransitive verb. For this reason, I will avoid subsuming the type in (4) under semantic alignment and consider it possible for verbs like (4a) to show transitive morphology but intransitive semantics.

Finally, although semantic factors may be discerned in the classification of verbs and splits in subject coding, there is ample room for language-specific arbitrariness (e.g. Dixon 1994, 74-75; Creissels 2008a, 150-151). There appears to be no obvious semantic reason for the $\mathrm{s}_{\mathrm{A}}$ coding in Basque, for example. It appears to be a recent, increasingly common shift that is spreading from Western to Eastern Basque (Aldai 2008).

Hence, semantic criteria can be ambiguous, and lexicalization often obscures semantic tendencies. What favors $\mathrm{s}_{\mathrm{A}}$ or $\mathrm{S}_{\mathrm{P}}$ coding is ultimately construction-specific and language-specific. ${ }^{20}$

\subsubsection{Tense, Aspect and Mood}

Alignment may also differ depending on clause-level grammatical information expressing the categories of tense (such as future, present and past), aspect (such as imperfective and perfective) and mood (such as realis vs. irrealis) or modality (such as possibility, necessity etc.), often abbreviated to TAM. There are noteworthy cross-linguistic preferences for the grouping of $\mathrm{s}$ and $\mathrm{A}(\mathrm{s}=\mathrm{A})$ in the irrealis, non-past, and/or imperfective constructions against the grouping of $\mathrm{s}$ and $\mathrm{P}$ in the realis, past, and/or perfective constructions. $\mathrm{s}$ aligns either with $\mathrm{P}$ or A depending on the TAM category expressed by the construction.

In the Standard Kurmanji variety of Northern Kurdish, for example, past tense constructions show ergative alignment, while non-past tense constructions show accusative alignment. Example (5) illustrates this split: the verb always indexes (e.g. $-\hat{\imath})$ only the argument in the 'nominative' case (e.g. $e z$, $t u$ ); this is $\mathrm{P}$ in the past and $\mathrm{A}$ in the present. The 'oblique' case (e.g. min, te), in

\footnotetext{
19 See further Section 3.5.

20 See, for example, Dixon (1994, 74-75), Creissels (2008a, 150-151).
} 
TABLE 12 Alignment split conditioned by TAM in Standard Kurmanji

\begin{tabular}{l|c|c|c}
\hline \multicolumn{2}{c|}{$\begin{array}{c}\text { Non-past } \\
\text { accusative } \\
(\mathbf{S}=\mathbf{A})\end{array}$} & $\begin{array}{c}\text { Past } \\
\text { ergative } \\
(\mathrm{s}=\mathbf{P})\end{array}$ & \multirow{2}{*}{ Gloss } \\
\hline $\mathrm{A}$ & $e z$ & $\min$ & \multirow{2}{*}{ 'I, me' } \\
$\mathrm{s}$ & $e z$ & $e z$ & \\
\cline { 2 - 3 } $\mathrm{P}$ & $\min$ & $e z$ & \\
\hline
\end{tabular}

turn, marks $\mathrm{A}$ in the past, but $\mathrm{P}$ in the present. The word order is consistent in both past and present transitive constructions, where A precedes $P$. The coding properties, by contrast, are inverted, in which s aligns ergatively with $\mathrm{P}$ in the past, but accusatively with A in the present. Table 12 above represents this in a schema for the first person singular.

(5) Kurmanji (Northern Kurdish, Turkey; Matras 1997, 617-618)
PAST: ERGATIVE $(\mathrm{S}=\mathrm{P})$
PRESENT: ACCUSATIVE $(S=A)$
[A] [P]
$[\mathrm{V}-\mathrm{P}]$
[A] $[\mathrm{P}$
[V-A]

a. $\min \boldsymbol{t u} d \hat{\imath} t-\hat{\imath}$

d. $\boldsymbol{e z}$ te di-bîn-im

I:OBL you:NOM saw-2SG

I:NOM you:OBL PROG-see-1SG

'I saw you.'

'I see you.'
[s]
[V-s]
[s]
[V-s]

b. $t u \quad c ̧ \hat{u}-y \hat{\imath}$

e. $t u$

$d i-c ̧-\hat{\imath}$

you:NOM went-2SG

you:NOM PROG-go-2SG

'You went.'

'You are going.'
c. $e z$
$c ̧ \hat{u}-m$
I:NOM went-1SG
'I went.'
f. $\boldsymbol{e z} d i-c ̧-i m$
I:NOM PROG-go-1SG
'I am going.'

Resultative, perfect and preterit are associated with ergative alignment: if ergative alignment is found in the preterit, it will also be expected be found in the perfect and resultative (Malchukov 2015). The dividing line between accusative and ergative alignment in languages such as Kurmanji is non-past 
vs. past. In Indo-Aryan languages such as Hindi and Mayan languages such as Chorti, the dividing line is between perfective and imperfective aspect (Dixon 1994, 100; cf. Comrie 1978, 351-352).

Although such TA-conditioned splits are commonly between accusative and ergative alignment in the imperfective/non-past and perfective/past, other oppositions are also found. The imperfective in Gujarati, for instance, follows a neutral case-marking pattern against ergative case-marking in the perfective (DeLancey 1981, 628-631). Furthermore, it has been claimed for some Cariban languages (Amazonia) that it is rather the imperfective/non-past conditions that favor an ergative pattern (Gildea and de Castro Alves 2010).

Mood is also a category that correlates with accusative or ergative marking and indirectly with tense (e.g. future) and possibly aspect (e.g. proximative). The future/irrealis or imperative/hortative mood favors accusative marking in some languages that manifest a split (Dixon 1994, 101). Dixon (ibid.) points out that moods such as the imperative focus on a controllable activity, which would typically target $\mathrm{A}$ and/or $\mathrm{S}$ and, hence, disfavor a grouping of $\mathrm{s}$ with P. Nevertheless, it may also be the other way around. Ergative alignment, for instance, is found for the future/irrealis and past and perfect in Newari (Tibeto-Burman, Nepal, Givón 1985a, 93).

Some scholars ${ }^{21}$ argue that the features associated with the accusative alignment entail a viewpoint of the event from the perspective of the agent and the features associated with the ergative alignment a viewpoint from the perspective of the patient. The perfective aspect, then, entails a viewpoint of the event that is ultimately oriented towards a definite result terminating in and affecting the patient. This readily combines with the past tense, since completeness and completion neatly go hand in hand. Aspect defines where the situation unfolds over time within its temporal structure in a part-whole relationship (Shibatani 2006, 220-221). The event is viewed as a complete whole from beginning to end in the perfective aspect, but viewed from a specific point or several points of the temporal phase (such as habits) between beginning and end in the imperfective. The perfective past, for instance, expresses complete, bounded events in the past and aligns $S$ with $P$ distinct from the accusative alignment in the imperfective past, which expresses ongoing or iterated events. Since the manner in which the activity or process unfolds through time is more central to the imperfective aspect, this is mainly dependent on the agent's involvement, which would be conventionalized in accusative alignment (e.g. Comrie 1981, 69; DeLancey 1982).

21 See inter alia DeLancey (1981), Givón (1984a, 156-158), Dixon (1994, 100-101), Lazard (1998, 214-217) and Næss (2007, 118-119). 
Nevertheless, it seems more plausible that this patient-orientation is merely an epiphenomenon of diachrony. There is no a priori reason why perfective past constructions should favor ergative alignment or disfavor accusative alignment. Indeed, ergative constructions in tense-aspectual splits are well-known to originate historically in resultative constructions involving an adjectival form of the verb that expresses the state of a patient. ${ }^{22}$ Interestingly, the aspect scale of resultative, perfect and preterit in Malchukov (2015) represents diachronically the grammaticalization of resultative to perfective past via the perfect (e.g. Bybee and Dahl 1989):

stative $>$ resultative $>$ perfect $>$ perfective past

It is thus more likely that the ergative construction in a TAM alignment split is at least in some cases the outcome of a historical development of originally intransitive resultative participial constructions that grammaticalized to and were conventionalized as the main expression of the perfective past. Conversely, in other cases, it is the progressive that is based on an intransitive construction, where $s$ typically marks the agent of an activity in progress. This can further grammaticalize to an accusative pattern alongside the predominant ergative alignment in the rest of the language (e.g. Creissels 2008b).

\subsubsection{Argument-Related Factors for Alignment Splits: Prominence}

Alignment splits based on properties of the argument itself rather than the verb mainly hinge on the special treatment of either A or P. The opposition between zero and overt coding of an NP depending on such properties is generally known as differential argument marking and is mainly associated with objects (e.g. Bossong 1985, 1998). Argument salience has been argued to correlate with associated roles and alignment typology by various functionalist approaches (e.g. Givón 1976; Croft 1988). Lower ranking arguments are associated with the P role, while higher ranking arguments with the A role. Similarly, the ergative type $(\mathrm{s}=\mathrm{P})$ is associated with lower ranking arguments, while the accusative $(\mathrm{s}=\mathrm{A})$ is associated with higher ranking ones.

\section{(6) Role hierarchies}

a. SALIENCE: high > low

b. FUNCTION: A $>$ P

22 See inter alia Anderson (1977), Trask (1979), Creissels (2008b). Cf. Haig (2008) on Iranian. 
The features that determine the inherent and/or discourse salience of a nominal are generally broken down into the following distinct subscales, listed in (7), ${ }^{23}$ where the terminology differs for the overarching scale that merges them. What is commonly known as "the nominal hierarchy" (Dixon 1994), is variously also referred to as the animacy, agency, empathy, individuation, topicality and salience scale/hierarchy. Aissen (2003) adopts the more general term "prominence hierarchy". These features are generally subsumed under a single prominence hierarchy with first and second person pronouns as the highest ranking type and inanimate, non-specific (indefinite) common nouns as the lowest ranking type.

\section{(7) Prominence hierarchy}

$\begin{array}{lll} & \text { MORE PROMINENT } & \text { LESS PROMINENT } \\ \text { a. PERSON: } & \text { first, second } & \text { > third } \\ \text { b. NOMINAL: } & \text { pronoun } & \text { > full nominal } \\ \text { c. ANIMACY: } & \text { human } \quad \text { > animate } & \text { > inanimate } \\ \text { d. REFERENTIAL: } & \text { definite } \quad \text { > specific indefinite > non-specific }\end{array}$

Which particular pragmatic and/or semantic features of the prominence hierarchy demarcates the marking of an argument differs from language to language. Topicalization constructions can also trigger differential marking. ${ }^{24}$ There is a cross-linguistic tendency to distinguish speech act participants, i.e. the (1p.) speaker and/or (2p.) addressee, against non-speech act participants (3p), i.e. somebody other than speaker or addressee (DeLancey 1981, 645-646; Dahl 2000), ${ }^{25}$ so that a basic discourse distinction exists between third and non-third, i.e. first/second person.

Recent large-scale typological surveys, however, show there is no conclusive evidence that demonstrates the universal validity of the correlation between argument salience and indexing, and such correlations are possibly better explained as side-effects of areal diffusion or historical contingencies within languages.

23 See for instance Croft (1990, 116, 127), Bossong (1991, 160), Siewierska (2004, 149). Other categories not listed in (7) may obviously also be involved. Hopper and Thompson (1980, 253), for example, also include the properties number (singular vs. plural), countability (count vs. mass) and concreteness (concrete vs. abstract).

24 See Givón (1979), Lazard (2001, 878), Iemmolo (2010, 2013).

25 First and second person, if so subsumed under one term, are generally referred to as SAP s after speech act participants. This abbreviation is not used here, since it may lead to confusion with $\mathrm{S}, \mathrm{A}$, and $\mathrm{P}$. 


\subsubsection{Divergence between Morphological Properties}

Cross-linguistic typological surveys ${ }^{26}$ show that ergative alignment is rarer than neutral and accusative alignment, and ergative verbal person marking even rarer still (though see further below). In terms of geographical distribution, ergativity is significantly rarer in Europe, virtually absent in Africa, but common in the Americas and Australia as well as the Austronesian language family (Comrie 2005, 401; Siewierska 2005, 407).

We have seen in the previous chapter how distinct morphological strategies such as nominal or verbal person marking can instantiate the same alignment pattern in a language. Both case and agreement are accusative in Modern Standard Arabic, for example. Constructions, however, can also consist of a combination of distinct alignment types through different morphological properties, having, for instance, ergatively aligned nominal marking and accusatively aligned verbal person marking. Comrie (1978, 340; original source cited therein) offers the following example from an Australian language called Walbiri (PamaNyungang):

(8) Walbiri (Pama-Nyungang, Central Australia; glossing adapted)

a. gaty $k a \quad$-na pulami.

I:ABS TENSE -1SG:S shout

'I shout.'

b. yatyululu ka -na $\quad-\eta k u \quad n^{y}$ untu $n^{y} a n^{y}$ i.

I:ERG TENSE -1SG:A -2SG:P you:ABS see

'I see you.'

c. $n^{y} a t^{y} u l u l u k a \quad-n p a \quad-t^{y} u \quad$ gat ${ }^{y} u n^{y} a n^{y} i$.

you:ERG TENSE -2SG:A -1SG:P I:ABS see

'You see me.'

The dependent person markers for the first person singular show accusative morphology in grouping $\mathrm{s}$ and $\mathrm{A}(-n a)$, but isolating $\mathrm{P}\left(-t^{y} u\right)$, while the independent pronouns group $\mathrm{s}$ and $\mathrm{P}\left(\eta a t^{y} u\right)$ ergatively and isolate $\mathrm{A}\left(\eta a t^{y} u l u l u\right)$. Hence, verbal person marking aligns accusatively, whereas the nominal marking aligns ergatively.

Similarly, Stilo (p.c.) explains that the Northwest Iranian language Vafsi may manifest a horizontal pattern $(\mathrm{S} \neq \mathrm{A}=\mathrm{P})$ for case-marking, while the person indexing may be ergative:

26 Cf. Siewierska (2004, 2005), Comrie (2005), Croft (2012, 259), Velupillai (2012, 243). 
(9) Vafsi (Northwest Iranian, Tat, Iran; Stilo p.c.)

$[\mathrm{s} \leftarrow \mathrm{DIR}] \quad[\mathrm{V}]$

a. hascen- $\varnothing$ dá-kctte

(intransitive)

PRN-NOM PVB-fell

'Hasan fell.'

$[\mathrm{A} \leftarrow \mathrm{OBL}][\mathrm{P} \leftarrow \mathrm{OBL}]-[\mathrm{A}] \quad[\mathrm{V}]$

b. hasén-i tamen-s bá-xcendena (monotransitive)

PRN-OBL 1SG:OBL-A:3SG:II PUNC-made.laugh

'Hasan made me laugh.'

The first form in (9a) is known as the 'direct' case, the other nominal forms in ( $9 \mathrm{~b})$ and (9c) as the 'oblique'. Both A and P are marked by the 'oblique', 27 but $\mathrm{s}$ is in the 'direct' case. Only A features as dependent person marker, so that $\mathrm{s}$ and $\mathrm{P}$ are grouped ergatively in not triggering overt indexing.

Dixon (1979, 92, 1994, 95-96) claims that ergative dependent person markers never combine with accusative nominal marking, and Comrie $(1978,340)$ states it is "rare or nonexistent". The possible combinations of ergative and accusative strategies are given below. The dependent person markers tend to pattern accusatively, even when the full nominals pattern ergatively, but the other way around is exceptional (Dixon 1994, 95-96).

(10) Ergative and accusative person and/or nominal marking

\begin{tabular}{|lll|} 
DEPENDENT & INDEPENDENT & FULL \\
PERSON MARKERS & PERSON MARKERS & NOMINALS \\
ACC & ACC & ACC \\
ACC & ACC & ERG \\
ACC & ERG & ERG \\
ERG & ERG & ERG \\
\hline$\left(^{* *}\right)$ ERG & ERG & ACC \\
$\left({ }^{* *}\right)$ ERG & ACC & ACC \\
\hline
\end{tabular}

The prominence hierarchy has been postulated by functional typologists to make implicational predictions regarding nominal marking and verbal agreement patterns across languages with reference to several grammatical functions. ${ }^{28}$ Functional typologists often differentiate arguments that are more topic-worthy than others, i.e. more readily considered salient in the discourse.

27 This alignment pattern only applies to animate NPs.

28 See Keenan (1976), Silverstein (1976), Givón (1976, 1984), Comrie (1989), Croft (1988, 1990 
Such topic-worthy arguments instantiate the higher ranking properties that make them more eligible to be selected as the agent-like topic in the transitive clause (e.g. Givón 1979, 1994; Comrie 1989). Given that A is more often human or first/second person pronoun, the higher ranking properties are associated with $\mathrm{A}$. The lower ranking properties, in turn, are associated with $\mathrm{P}$, since they are more often inanimate and full nominals:

\section{(11) Expected role ranking associations}

$\begin{array}{ll}\text { a. RANKING: high }>\text { low } \\ \text { b. ROLE: } & \text { A }>\text { P }\end{array}$

The zero-marking on the (pro)noun and the potential for the overt person indexing would correlate with a higher ranking of A as well as a lower ranking of P. In accordance with such scales, pronouns, for example, favorably occur as $\mathrm{A}$, while nouns favorably occur as $\mathrm{P}$. This functional principle thus predicts that dependent person markers can show ergative morphology only when lower ranking arguments also do so.

Verbal person marking itself, however, can also be broken down into morphological marking, position and trigger potential and therefore show combinations of alignment types on these levels. Concerning affix order, Siewierska $(2004,167)$ observes that a V-P-A sequence is more commonly combined with accusative rather than ergative morphological marking. Recently, Bickel et al. (2013) showed that, cross-linguistically, there is essentially no strong preference for a particular agreement pattern ${ }^{29}$ in terms of morphological marking alone. Thus, a preference for accusative morphological person marking does not appear to be supported. Nevertheless, they indicate there is a strong avoidance of the grouping of $\mathrm{S}$ and $\mathrm{P}($ or $\mathrm{A}$ and $\mathrm{P})$ in terms of what triggers verbal person marking, i.e. the trigger potential. Ergative and horizontal alignment thus appears to be strongly disfavored only in this latter respect.

\subsubsection{Differential Marking and Split Case Marking}

The most well-known effects of the prominence hierarchy are found in differential object marking (henceforth Dом). Aramaic, Hebrew and Ethiopic, for

1994a), Bossong (1991, 160), Aissen (1999, 2003), Haspelmath (2004b, 2007), Næss (2007), among many others.

29 Accusative indexing is still favored slightly (37\% against $21 \%$ for ergative). Bickel et al. (2013) exclude tripartite alignment from their study, but do include horizontal alignment $(\mathrm{S} \neq \mathrm{A}=\mathrm{P})$. 
instance, differentiate between definite and indefinite $P$ arguments by means of overt flagging. Strictly speaking, neutral alignment $(\mathrm{A}=\mathrm{S}=\mathrm{P})$ is found for indefinite NPS in these languages because they lack nominal case morphology in general, while accusative alignment $(\mathrm{A} \neq \mathrm{S}=\mathrm{P})$ is found for definite NPS, since these are only marked by a preposition in the $\mathrm{P}$ role. Generally, the pattern with overt marking is taken to be the more basic alignment type, ${ }^{30}$ so that we would characterize the alignment in Hebrew and Ethiopic, for instance, as basically accusative. Thus DOM, much like the other phenomena we have observed in previous sections, first and foremost involves a constructional split, not an alignment split per se.

Differential argument-marking need not be sensitive to all the subscales of prominence. Dом, for example, solely depends on definiteness or information structure, i.e. identifiability in the discourse, and covers the whole range from personal pronouns to definite NPs in Hebrew (Givón 1982) and Amharic (Amberber 2005), but excludes indefinite NPs altogether.

Furthermore, differential marking can be obligatory or optional. Some languages such as Sinhalese (Indo-Aryan, Sri Lanka; Næss 2004, 1196) optionally mark animate NPs, while inanimates are never marked. By the same token, definite NPs may not be obligatorily marked in a language, suggesting that speakers need not bind themselves to a definite reading of the object, if they do not feel such a need. In Classical Syriac, for example, differential marking of definite object NPS is not obligatory. Speakers can increase an argument's identifiability through Dом as they feel necessary to signal what they, for whatever reason, find salient in the discourse. ${ }^{31}$

Moreover, coding properties that are sensitive to the prominence of the $\mathrm{P}$ arguments can override other alignment splits. Hindi has a TAM-sensitive alignment split: ergative in the perfective (and the perfect), but accusative in the imperfective (and future). $\mathrm{A}$ is distinguished by the postposition $=n e$ in the perfective; $\mathrm{S}$ and indefinite Ps are zero-marked. When, however, $\mathrm{P}$ is definite inanimate, such as hār 'necklace' in (12b) below, or animate, such as bacce 'child' in (12c), it is marked by the postposition $=k o$. Hindi, therefore, shows a tripartite case-marking pattern $(\mathrm{A} \neq \mathrm{S} \neq \mathrm{P})$ with respect to higher ranking NPs, while the ergative case-marking pattern is manifested only for lower ranking NPS.

$30 \quad$ Thus Comrie (2005), Siewierska (2005), Malchukov (et al. 2010).

31 Cf. Khan (1988, 139-140), Joosten (1996, 45). 
(12) Hindi (Indo-Aryan, India; Mohanan 1994, 180, glossing slightly modified, transcription adapted)
a. Ilā=ne hār
$u t^{h} \bar{a}-y \bar{a}$
(indef. inanimate $\mathrm{P}$ )
Ila=ERG necklace-NOM lift-PERF
'Ila lifted up a/the necklace.'
b. Ilāane hār=ko ut ${ }^{h} \bar{a}-y \bar{a}$
Ila $=$ ERG necklace $=$ DOM lift-PERF
'Ila lifted up the necklace.'
c. Ilā=ne bacce=ko $u t^{h} \bar{a}-y \bar{a}$
Ila=ERG child=DOM lift-PERF
'Ila lifted up the/a child.'

(def. inanimate $\mathrm{P})$

Similarly, the prominence scale has been used to explain alignment splits based on argument properties. Dyirbal, an Australian Aboriginal language, is an oftcited example, where first/second person markers follow an accusative pattern, while all other (pro)nominals follow an ergative pattern (Dixon 1979, 63-64). Table 13 illustrates this split for 'we all' and 'father'. ${ }^{32}$ There are languages where the cut-off point is between pronouns and full nominals, pronouns being neutral or accusative and nouns ergative (Comrie 1989, 131; Dixon 1994, 95-96). The same tendencies for accusative and ergative alignment have been argued to hold for verbal person marking (e.g. Siewierska 2005). Again, accusative alignment is associated with the higher ranking first/second persons and ergative with lower ranking third persons. There appears to be no correlation between person reference and other alignment types than ergativity (Siewierska 2004, 63). Accordingly, first/second person arguments are predicted to show ergative alignment only when third person arguments also do so.

In addition, split-subject marking can be limited to non-third person markers in languages such as Lakota (Siouan, Dakota, United States) or to pronouns against full N Ps in Koasati (Muskogean, Louisiana, United States; Mithun 199o).

A functional-communicative motivation for the special marking of higher ranking Ps and special marking of lower ranking As offered by functional typologists is that the unexpected candidates would favor morphology to disambiguate them from the more expected candidates with the properties associated with the opposite role:

32 Essentially, only A and P are affected, while $\mathrm{s}$ is not. Dyirbal may express actual transitive clauses where both A and $\mathrm{P}$ are marked by ergative and accusative case or both zeromarked (Comrie 1989, 131; Croft 2001, 309-310),. 
TABLE 13 Split conditioned by argument properties in Dyirbal

\begin{tabular}{|c|c|c|c|c|}
\hline \multicolumn{3}{|c|}{ Non-third } & \multicolumn{2}{|l|}{ Third } \\
\hline & $\begin{array}{c}\text { Accusative } \\
\qquad(\mathrm{S}=\mathrm{A})\end{array}$ & Gloss & $\begin{array}{l}\text { Ergative } \\
\qquad(\mathrm{S}=\mathbf{P})\end{array}$ & Gloss \\
\hline A & yana & 'we all' & yuma-ygu & 'father' \\
\hline$S$ & yana & & yuma & \\
\hline $\mathrm{P}$ & yana-na & & yuma & \\
\hline
\end{tabular}

AFTER DiXON (1979, 63)

\section{(13) Unexpected role ranking associations}

$\begin{array}{ll}\text { a. RANKING: high }>\text { low } \\ \text { b. ROLE: } & \mathrm{P}>\mathrm{A}\end{array}$

Unexpected Ps are morphosyntactically distinguished from the expected A, and overt nominal marking tends to be limited to one argument for economy (e.g. Comrie 1975, 1978). Similarly, functional typologists (e.g. Givón 1976; Croft 1988) have argued that argument salience, i.e. what is central to the speech situation and the speakers' experience, enhances the trigger potential for person indexing. Speakers tend to limit person indexing to what they consider the most important referents, applying this limitation to both monotransitive and ditransitive clauses (e.g. Haspelmath 2007) along the cline from higher to lower ranking arguments and associated syntactic roles. Haspelmath (2004b) explains this tendency on the basis of frequency-driven grammaticalization, arguing that the more frequent and more harmonic combinations of argument types and associated roles are more likely to be grammaticalized, while disharmonic combinations, such as the combination where P outranks A, are disfavored and therefore less likely to be grammaticalized.

The higher ranking topic-worthiness of $\mathrm{A}$ is often used as an explanation for its cross-linguistic tendency to be grouped with $s$ in accusative indexing (e.g. Comrie 1989). Topic referents expressed through person markers are mainly found in S and A function (e.g. Cooreman et al. 1984; Dixon 1994, 54-55). On the other hand, corpus-based studies indicate that $\mathrm{P}$ and $\mathrm{s}$ rather than $\mathrm{A}$ are the more likely bearers of new information expressed by full nominals, so that these discourse properties would group s and p ergatively (ever since e.g. 
DuBois 1987). Thus, in the functionalist approach, NPs that are overtly marked and do not trigger agreement are the less likely arguments. ${ }^{33}$ This is the higher ranking argument type in the $\mathrm{P}$ function, but the lower ranking argument in A function. A pronoun ranks higher than a common full NP on the nominal hierarchy. And first/second person referents rank higher than third person referents on the person scale. Hence, when there is a split in alignment based on the referential properties of the NP, the absolute higher ranking arguments have often been said to associate with accusative alignment, while the lower ranking arguments associate with ergative alignment. ${ }^{34}$

Nevertheless, there are numerous exceptions that run counter to these functional principles and are more likely to be based on areal-diachronic contingencies. Siewierska $(2005,407)$, for instance, points out that it is equally possible for the third person only to trigger indexing either accusatively or ergatively; cf. English, for example, where the accusative agreement affix $-s$ is confined to third person referents and Trumai, a language isolate in Upper Xingu, Brazil, which expresses overt ergative verbal person marking that is confined to the third person. This is contrary to the functional principle that predicts verbal person marking is associated with lower ranking arguments.

There also examples where differential object marking does not serve a discriminatory function (Payne 1980, 149-150; Bossong 1985), and need not be an unstable system (Haig 2008, 197). Morphological identity between A in the past tense and salient Ps is found in some Iranian languages. In Vafsi (Northwest Iranian), for example, salient NPs follow a horizontal pattern $(\mathrm{S} \neq \mathrm{A}=\mathrm{P})$, as illustrated below. The 'direct' case $(\varnothing)$ not only neutrally subsumes s, A and P in the present, but also groups ergatively $s$ and non-salient Ps in the past. The 'oblique' case $(-i)$ is used for A of the past tense as well as for salient Ps in all tenses. Hence, one finds the term 'double oblique alignment' for horizontal alignment in the literature.

(14) Vafsi (Northwest Iranian, Tati, Iran; Stilo p.c.)

$[\mathrm{S} \leftarrow \mathrm{DIR}] \quad[\mathrm{v}]$

a. hrescen- $\varnothing$ dce-kcet-tce

(direct)

PRN-DIR PVB-fall:PST-PPT

'Hasan fell.'

33 See further § 4.1.1. on typological markedness in relation to the NENA dialects.

34 Cf. inter alia Silverstein (1976), Silvertein $(1976,122-129)$, Comrie $(1978,1989)$, Dixon (1995, 83-94). 


$$
[\mathrm{A} \leftarrow \mathrm{OBL}][\mathrm{P} \leftarrow \mathrm{DIR}] \quad[\mathrm{V}]
$$

b. tine yey dánce yú-ce-s dard-ce (ergative) he:OBL one CLF heifer-DIR-A:3SG:II have:PST-PL

'He had a heifer'. (Stilo 2004b, B1.2)

$$
[\mathrm{A} \leftarrow \mathrm{OBL}][\mathrm{P} \leftarrow \mathrm{OBL}] \quad[\mathrm{V}]
$$

c. hæesén-i mæhmud-i-s bá-xœend-en-a

PRN-OBL PRN-OBL-A:3SG:II PUNC-laugh-CAUS-PST

'Hasan made Mahmud laugh.'

Recently, Bickel (2008) and Bickel et al. (2015) have tested the significance of referential hierarchies for alignment split tendencies in large language databases. First/second person, for example, would not be expected to pattern ergatively, unless all other argument types also do so. Accusative for the third person and ergative for the first/second person would be unexpected. Nevertheless, Bickel (2008) and Bickel et al. (2015) evince such reverse splits do occur. Bickel (2008) offers examples from Kiranti languages (Sino-Tibetan), where the first person (singular) aligns ergatively and the third person accusatively, while the other persons align neutrally. Table 14 below illustrates this for the Kiranti language Puma.

Bickel et al. (2015) argue that accusative-ergative splits in accordance with higher ranking As and lower ranking Ps cannot be considered universally valid, as much of the provided evidence is ambiguous or leaves room for alternative analyses, leading to their conclusion that person-based splits are an epiphenomenon. ${ }^{35}$ Bickel et al. (2015) show on the basis of survey of 46 o case systems around the world that the languages that fit with the aforementioned predictions are common in the macroareas of Eurasia and New-Guinea and Ausralia, but not outside of these areas. Hence, they conclude that such hierarchical effects are prone to areal diffusion. Furthermore, Gildea and Zúñiga (2016) explain these effects on the basis of their historical source rather than underlying cognitive principles.

Finally, person-conditioned splits can also be restricted by TAM. Balochi, a Northwest Iranian language, for example, manifests a person and nominal rolebased split in the past (Korn 2009). Some (Eastern) Balochi dialects express ergative agreement with higher ranking full nominal ps only, while this is expected for lower ranking arguments. Moreover, the higher ranking persons optionally trigger agreement only with A in these Balochi dialects. 
TABLE 14 Person split in Puma

\begin{tabular}{|c|c|c|}
\hline & $\begin{array}{c}\text { 1SG } \\
\text { Accusative } \\
\qquad(\mathrm{S}=\mathbf{A})\end{array}$ & $\begin{array}{c}3^{S G} \\
\text { Ergative } \\
(\mathrm{S}=\mathrm{P})\end{array}$ \\
\hline A & $-\eta(>3),-n a(>2)$ & $\varnothing-\left(p \Lambda^{-},>1\right)$ \\
\hline s & 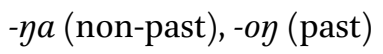 & $\varnothing-$ \\
\hline $\mathrm{P}$ & 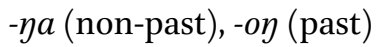 & $u-, i^{-}$ \\
\hline
\end{tabular}

AFTER Bickel $(2008,197)$

Recent cross-linguistic studies indicate, therefore, that there is no conclusive evidence for the predictions regarding alignment splits based on the prominence scales. Since areal diffusion or historical contingencies could equally account for the various alignment splits, functional principles do not hold for alignment splits in human language in general. What does appear to hold crosslinguistically, is that the higher ranking A or the lower ranking $\mathrm{P}$ are associated with zero NP-marking. That is, if arguments are zero-marked by default, this will tend to be animate and/or definite as and inanimate and/or indefinite Ps. Also, $\mathrm{S}$ and A tend to be grouped in trigger potential. That is, if there is obligatory-agreement at all, this will be more likely triggered by s and A than by $\mathrm{P}$.

\subsection{Ergativity and Patient-Related Splits in Trans-Zab Jewish NENA}

In Northeastern Neo-Aramaic dialects, there are three competing constructions, i.e. coding strategies, involved in differential object marking, i.e. higher ranking Ps. As in the qatel-based constructions, differential object marking in qtil- typically involves, depending on the dialect:

- nominal marking, i.e. flagging: differential prepositional marking;

- verbal person marking, i.e. indexing: differential object indexing;

- or a combination of the above.

NENA dialects can even have more than one construction for each of these DOM strategies. The Trans-Zab Jewish dialects are so similar in this respect that a correlation with a particular alignment type and coding strategy cannot be established, nor a particular alignment type associated with a higher ranking 
of $\mathrm{P}$ per se. The usage of a construction is dialect-specific rather than motivated by underlying communicative-functional principles. The alignment type, therefore, is more aptly described as incidental dialectal variation. While there are notable differences, these cannot be linked to the grouping of grammatical functions in themselves, and points to the autonomy of certain transitive construction types across and within dialects. Considering verbal person marking, we concentrate here on morphological marking, i.e. phonological form, since the trigger potential is accusative throughout. After all, $\mathrm{P}$ is clearly the only argument whose indexing and/or flagging is optional and conditioned in contradistinction to the obligatory and unconditioned indexing of $\mathrm{s}$ and $\mathrm{A}$.

\subsubsection{Alignment of qtịl- in Southeastern Trans-ZabJewish Dialects}

The flagging and indexing systems diverge most sharply in the alignment typology of the Southeastern Trans-Zab Jewish varieties. The nominal prepositional marking is accusative $(\mathrm{A}=\mathrm{S} \neq \mathrm{P})$, whereas verbal person marking is ergative $(\mathrm{A} \neq \mathrm{S}=\mathrm{P})$ and tripartite $(\mathrm{A} \neq \mathrm{S} \neq \mathrm{P})$ or horizontal $(\mathrm{S} \neq \mathrm{A}=\mathrm{P})$ in phonological form. We will observe that what constrains the E-suffixes as object-markers also constraint ergative indexing. At the same time, prepositional marking overlaps with verbal person marking. The system found in these NENA dialects is thus typologically rather unusual.

\subsubsection{1 $\quad$ Ergative Verbal Person Marking}

First, $\mathrm{P}$ and $\mathrm{s}$ are grouped ergatively in qtil- by means of the E-set, while A is distinguished by the L-series:

(1) J. Kerend (W Iran; Hopkins 1989a, 428; 2002)

\begin{tabular}{|c|c|c|c|}
\hline \multicolumn{2}{|l|}{ INTRANSITIVE } & \multicolumn{2}{|l|}{ TRANSITIVE } \\
\hline . plat- $\varnothing$ & $-l i$ & c. palt -a & $-l i$ \\
\hline move.out $_{\mathrm{PFV}}-\mathrm{P}: 3 \mathrm{MS}$ & -A:1SG & move.out $_{\mathrm{FV}}-\mathrm{P}: 3 \mathrm{FS}$ & -A:1SG \\
\hline $\begin{array}{l}\text { 'I took him out.' } \\
\text { (lit. Him moved I ol }\end{array}$ & & $\begin{array}{l}\text { 'I took her out.' } \\
\text { (lit. Me moved sh }\end{array}$ & out) \\
\hline
\end{tabular}
b. plit- $\varnothing$
move.out $_{\mathrm{PFv}}$-S:3MS
'He went out.'
d. plit-a
move.out $_{\mathrm{PFv}} \mathrm{-S}: 3 \mathrm{FS}$
'She went out.'

Secondly, ergative morphological marking is restricted to third person indexes. A and $s$ are contrastive for all persons, including first/second person markers, e.g. 


$$
\begin{aligned}
& \begin{array}{ll}
\text { e. plit-na } & \text { f. plat-li }
\end{array} \\
& \text { move.out }_{\mathrm{PFV}} \text {-S:IMS } \text { move.out }_{\mathrm{PFV}}-\mathrm{S}: \mathrm{SG} \\
& \text { 'I } \mathrm{M}_{\mathrm{M}} \text { went out.' 'I took out.' } \\
& \text { (lit. I moved out) (lit. Me moved out) }
\end{aligned}
$$

By contrast, no s-like realization of $\mathrm{P}$ is accepted by speakers of these dialects for non-third persons, so that forms like

$$
\begin{array}{ll}
\text { g. } & \text { *** plat-na } \quad-l e \\
\text { move.out }_{\mathrm{PFv}}-\mathrm{P}: 1 \mathrm{MS} & -\mathrm{A}: 3 \mathrm{SG} \\
\text { 'He took } \mathbf{m e}_{\mathrm{M}} \text { out.' (lit. Him moved I out) }
\end{array}
$$

do not occur. Khan $(2009,159)$, however, mentions one informant of Sanandaj that does use a similar qtil-based formation for the first feminine singular, as given in (2) below.

(2) J. Sanandaj (W Iran; Khan 2009, 472.2)

$$
\begin{aligned}
& \text { hiy -ăna, labl -ăna -nu bimaristấn-e Hădasá } \\
& \mathrm{COME}_{\mathrm{PFV}} \text {-S:1FS take } \mathrm{PFV}_{\mathrm{PF}} \text {-P:1FS -A:3PL hospitial-EZ Hadasa } \\
& \text { 'I } \mathrm{FS}_{\mathrm{FS}} \text { came (and) they took me to Hadasa hospital.' }
\end{aligned}
$$

This construction has not been attested for other Trans-Zab Jewish dialects. Since these forms do not occur in elicitation, but only in texts, their status remains unclear. The forms used by this informant are also rather unusual in their inflection, given that they involve a secondary suffix of the 'all-series to express A, e.g. 'axoní labl-ăna-nef 'My brother took me' (Khan 2009, 472.2) instead of the form with the expected L-suffix **labl-ăna-le or **labl-án-ne. It is possible this is ultimately formed in analogy to qatal-, where such 'all-series can attach to indicate the reverse role, e.g. labl-ăna-nef 'I take him' (cf. Khan 2009, 159). These special third person indexes are only found in combination with the first person singular E-suffixes (Israeli 1998, 116). ${ }^{36}$

Apart from this general person restriction, the E-suffixes are used in differential indexing. (3) below illustrates how the E-set cross-references a prominent NP xalistá 'sister' in either the S or P function. The L-suffixes index A referent, such as -le cross-referencing ahmád in (3a). 
(3) J. Saqez (W Iran; Israeli 1998, 103)

a. ahmád xalist-év xəzy $-\boldsymbol{a} \quad$-le

Ahmad sister-his see $\mathrm{PFV}_{\mathrm{PF}}-\mathrm{P}: 3 \mathrm{FS}$-A:3MS

'Ahmad saw his sister.'

b. lima xalist-i maty $-\boldsymbol{a}$ bel-óx?

when sister-my arrive $\mathrm{PFV}_{\mathrm{PF}}-\mathrm{S}: 3 \mathrm{FS}$ at.house-your:MS

'When did my sister arrive at your ${ }_{\mathrm{MS}}$ house?'

The differential indexing is only ergative in phonological form in qțil-. The trigger potential of indexing is accusative $(\mathrm{A}=\mathrm{S} \neq \mathrm{P})$ in both inflectional systems, as illustrated for J. Sulemaniyya below. P differs from $S$ and A only in trigger potential. $s$ and $\mathrm{A}$ arguments are always indexed, while P is indexed only when it is definite (Khan 2007a, 154). The indexing of full nominal Ps is more restricted and context-dependent than the indexing of s. This limits the manifestation of the ergative pattern even further, but to a similar degree as the accusative pattern in qațal-.

(4) J. Sulemaniyya (NE Iraq; illustration based on Khan 2004a, 2007a, 154) PERFECTIVE (PRETERIT) IMPERFECTIVE (PRESENT)

a. baxta nšaq-le 'He kissed a woman.'

e. baxta năšáq- $\varnothing$ (indef. P) 'He kisses a woman.'

b. baxta qim-a 'A woman rose.'

c. baxt-i nəšq-a-le 'He kissed my wife.'

\section{d. baxtaké qim-a} 'The woman rose.' f. baxta qem-á 'A woman rises.'

g. baxt-i năšzq- $\varnothing-l a$ 'He kisses my wife.'

h. baxtaké qem-á 'The woman rises.' (indef. s) (def. $\mathrm{P})$

All else being equal, the coding of $s$ is the same across both systems. What is peculiar to qțil-against qațal- is marking A in a way distinct from s, reserving the more marked set of argument indexes, i.e. L-series, for A. Of course, the morphological alignment of $\mathrm{s}$ with $\mathrm{P}$ is also peculiar to qțil- but its manifestation is more restricted than the coding of A. There is thus a degree of diffusion of agreement properties across the grammatical functions for qțil-. $\mathrm{S}$ and $\mathrm{P}$ align morphologically, both are marked by the E-set, but not in terms of trigger potential, i.e. the marking of $s$ is unconditioned, but that of $P$ conditioned, 
whereas $\mathrm{S}$ and A align in terms of trigger potential, both are unconditioned, but not morphologically, i.e. E-suffixes mark s, but L-suffixes mark A.

The Southeastern Trans-Zab Jewish varieties, however, have also lexicalized certain intransitive verbs as transitive, so that they also exhibit constructions whereby s may also align with A, sometimes depending on semantic and/or morphological factors. ${ }^{37}$ This is obviously not apparent in the qatalbased 'imperfective' constructions, since there is no morphological distinction between $\mathrm{s}$ and $\mathrm{A}$, i.e. intransitive and transitive constructions:

\section{i. baxtá šahal-la j. baxtá šahl-á \\ 'A woman coughed.' 'A woman coughs.'}

All else being equal, ergative alignment is thus evidently a rather restricted phenomenon in these dialects, being confined to third person indexes. In terms of differential marking, it is striking that only higher ranking full nominals are marked ergatively, while NPs of lower ranking in prominence, such as indefiniteness, proceed on a tripartite basis, since the expression of $\mathrm{P}$ is zero, but $\mathrm{S}$ and $\mathrm{A}$ are distinct.

The unfolding distribution, therefore, is somewhat unusual. Topic-worthy full nominal ps trigger differential marking that patterns ergatively, while the most topic-worthy arguments, namely the first and second person, are generally precluded from such ergative person marking (qim-na: $\left.{ }^{* *} n s ̌ a q-n a-l i\right)$, contrasting with the accusative person marking in qațal-.

\subsubsection{Tripartite or Horizontal Person Marking}

In the inflection of the perfective past, first/second person markers can occur only in their independent prepositional form, e.g. J. Sulemaniyya nšaq-li ’all-ax 'I kissed you $_{\mathrm{FS}}$ '. This prepositional 'all-series ${ }^{38}$ expresses both third and nonthird person referents, like J. Sulemaniyya 'all-i 'me' and 'all-éw 'him', but the E-suffixes are confined to the third person. The independent object person markers, however, do not have the same status as the E-set. They are not used to differentially index nouns, for instance.

Strictly speaking, the independent person markers would seem essentially accusative like prepositional marking of full nominals. When we consider nonthird person markers in qțil- only, however, a tripartite subsystem unfolds. As there is no dependent person form available for $\mathrm{P}$, an independent one is

37 See further Section 3.5.

$38 \quad$ See $§ 3$ 3.1.2.1. 
selected instead. Nevertheless, combined with other person indexes, this gives rise to a tripartite alignment type for all first/second person markers in contradistinction to the ergative third person morphology. In our approach, this is strictly speaking not an accusative pattern (pace Barotto 2015, 240, 243), since S and $\mathrm{A}$ are still differentiated. This is illustrated below for first person masculine singular $\mathrm{S}$ and $\mathrm{A}$ and second person feminine singular $\mathrm{P}$.

(5) Tripartite alignment (J. Sulemaniya NW Iraq; Khan 2004a)

a. kwiš-na

(intransitive)

descend $_{\mathrm{PFV}}$-S:1MS

' $\mathrm{I}_{\mathrm{M}}$ descended.'

b. qtal-li ’all-áx

(transitive)

$$
\begin{aligned}
& \text { kill }_{\mathrm{PFV}}-\mathrm{A}: 1 \mathrm{SG} \text { OBJ-2FS } \\
& \text { 'I killed you }{ }_{\mathrm{FS}} \text { '. }
\end{aligned}
$$

Nevertheless, although the split is strictly conditioned by the absolute properties of the argument in terms of person or nominal type, it has the effect that distinct combinations are possible in actual transitive clauses. When $\mathrm{P}$ and $\mathrm{A}$ are both full NPs, the construction is evidently accusative, and when both are third person pronouns, it is evidently ergative. The cut-off point is between dependent person markers and independent nominals, both belonging to the third person, while the first and second persons seem to have a mixed subsystem of their own. Essentially, however, only A and P are affected, while $s$ is not. When $P$ is non-third person, but $A$ is third person, the transitive construction is identical to $(5 \mathrm{~b})$ above:

$$
\begin{aligned}
& \text { [A:3] [P:2] } \\
& \text { c. qtal-la ’all-áx } \\
& \text { kill }_{\mathrm{PFV}}-\mathrm{A}: 3 \mathrm{FS} \text { овJ-2FS } \\
& \text { 'She killed you }{ }_{\mathrm{Fs}} \text { ' }
\end{aligned}
$$

When $\mathrm{A}$ is non-third person, but $\mathrm{P}$ is third person, the transitive construction is consistent with (3a) above:

[P:3-A:2]

d. qatl-a-lax

kill $_{\mathrm{PFv}}-\mathrm{P}: 3 \mathrm{FS}-\mathrm{A}: 2 \mathrm{FS}$

'You ${ }_{\mathrm{FS}}$ killed her.' 
Both patterns may also occur when both arguments are third person.

For completeness sake, I also mention a possible instance of horizontal grouping in the SE Trans-Zab dialects. The attachment of the 'all-series may end up as a secondary $\mathrm{L}_{2}$-set and merge with the L-suffixes, for example in Jewish Saqez (Israeli 1998) and Jewish Sanandaj (Khan 2009, 158). The independent object person markers ultimately based on the preposition $l$ - attach to the immediately preceding verbal form and are phonologically non-distinct from the agent markers, except for the third person singular. ${ }^{39}$ Thus the equivalent of ( 5 b) qtal-li'sllax would be in J. Saqez:

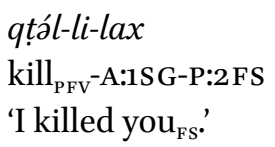

Here, -lax from 'alax 'you' is identical to the corresponding L-suffix. A distinction between the L-suffixes and the 'all-series is limited to the third person in Jewish Saqez. The object person markers -lav 'her' and -lev 'him' comprise another special $\mathrm{L}_{2}$-set corresponding to the 'all-set (i.e. alav, alev) in other dialects and are distinct from the agent person markers - $l a$ and - $l e$ belonging to the L-suffixes. Since the /a/ of the preposition $a l$ - is absent in the forms that have undergone coalescence (Israeli 1998, 115), so that only the third person singular forms are indicative of another series of person markers, ${ }^{40}$ e.g.

nšáq-la-lav

kiss $_{\mathrm{PFV}}$-A:3FS-P:3FS

'She kissed her.'

This form corresponds to nšiq-le ilav 'He kissed her', and not **nšáq-le-la, as we would expect for L-suffixes. By contrast, the other person affixes for J. Saqez are effectively nondistinct from L-suffixes.

Hence, one could argue that the merger of the all-series and the L-suffixes results in another alignment pattern, namely a horizontal one, where P and A are marked alike, as given below.

40 See $§$ 4.2. for similar phenomena in Christian dialects. 
(6) Horizontal alignment (1/2 and 3pl.) in Jewish Saqez

a. dmix-an

(intransitive)

sleep $\mathrm{PFV}-\mathrm{S}: 1 \mathrm{FS}$

'I $\mathrm{F}_{\mathrm{F}}$ went to sleep.'

b. nšáq-li-lax

(transitive)

kiss $_{\mathrm{PFV}}$-A:1SG-P:2 FS

'I kissed you $_{\mathrm{Fs}}$ '

Ergative third person marking (dmix-a 'She slept': nəšq-a-le 'He kissed her') thus co-varies with tripartite third person singular marking (dmix- $a$ 'She slept':

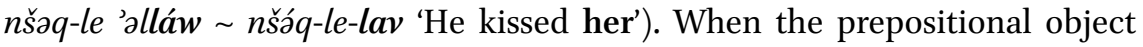
indexes attach to the verbal form, however, there is only a single L-set for first and second person, such as -li,-lan,-lox etc., as well as the third person plural, i.e. - $l u$. A and $\mathrm{P}$ are thus identical in phonological form in these constructions and are arguably expressed by means of the same set of person indexes.

\subsubsection{Combining Prepositional and Verbal Marking}

The system that ultimately unfolds from these diverse strategies is represented in Table 15 below. Full nominals can be marked differentially by flagging and/or indexing. First and second person markers are ultimately derived from the same preposition that marks full object NPS.

Differential prepositional marking and indexing of full nominals can also be combined. Thus, remarkably, it is possible, though highly exceptional, for differential object marking to involve both ergative indexing and accusative prepositional marking of the object. Khan (2004a) offers the following example, unique within his entire corpus. Although, strictly speaking, the verb is ditransitive, it proves the possible combination for transitive verbs. This is thus far only documented for the Sulemaniyya dialect. Khan (2009, 319-320) does not mention an example for Sanandaj, for instance, and neither does Israeli for Saqez (Israeli 1998).

(7) J. Sulemaniyya (W Iran; Khan 2004a, 326, 514.141)

\begin{tabular}{|c|c|c|c|}
\hline$[\mathrm{DOM} \rightarrow \mathrm{T}]$ & {$[\mathrm{V}-\mathrm{T}$} & $-\mathrm{A}]$ & \\
\hline lă-yalé & $l a b l-i$ & $-l e$ & ta-bag்dád \\
\hline
\end{tabular}

(transitive) 
TABLE 15 Argument coding strategies in Southeastern Trans-Zab Jewish NENA

\begin{tabular}{|c|c|c|c|c|c|}
\hline & Nominal marking & Gloss & \multicolumn{2}{|c|}{ Verbal person marking } & Gloss \\
\hline A & baxtaké & \multirow[t]{3}{*}{ 'the woman' } & & & \multirow{3}{*}{$3^{\mathrm{fs}}$} \\
\hline$S$ & baxtaké & & & & \\
\hline $\mathrm{P}$ & 'al-baxtaké & & $-l a v$ & $-a$ & \\
\hline
\end{tabular}

Independent

Dependent

\begin{tabular}{|c|c|c|c|c|}
\hline A & ana & 'I, me' & $-l i$ & $1 \mathrm{~ms}$ \\
\hline $\mathrm{s}$ & ana & & $-n a$ & \\
\hline $\mathrm{P}$ & 'alli & & $(-l i)$ & \\
\hline
\end{tabular}

$[\mathrm{s}] \quad[\mathrm{v}-\mathrm{s}]$

yalé... zil-i ta-maktab-i hulaye (intransitive) child:MPL $\mathrm{gO}_{\mathrm{PFV}}$-S:3PL DAT-school-EZ Jew:MPL

'The children ... went to the school of the Jews.'

The difference, then, is merely one of morphological strategies. Prepositional marking has a wider range on the prominence hierarchy than verbal person marking, which just happens to be ergative. Prepositional marking results in a tripartite or horizontal pattern for non-third person markers and in an accusative pattern for nouns, while dependent third person markers are ergative or tripartite.

In some respects, this alignment system is contrary to Dixon's (1994) and Comrie's (1978) observations. ${ }^{41}$ Ergative dependent person markers tend to combine with ergative nominal morphology, but not with accusative. Moreover, it is not expected for alignment splits sensitive to the referential hierarchy of NPs to favor ergative indexing for higher ranking full nominals. Rather, the higher ranking nominal is expected to align accusatively.

41 See $\$ 3 \cdot 2.2 .1$. 
The ergativity in Trans-Zab Jewish dialects seems to constitute a noteworthy counterexample to these tendencies. The dependent person markers pattern ergatively, while the independent person markers and full nominals do not. The lower ranking full nominals follow a tripartite cross-indexing pattern, while the higher ranking ones an ergative cross-indexing pattern. This tripartite-ergative split conditioned by the referentiality of the full nominal is the exact mirror image of the ergative-tripartite split conditioned by the person reference of the person marker:

TRIPARTITE INDEXING : (high) 1st/2nd person (low) indefinite NPS ERGATIVE INDEXING: (low) 3rd person (high) definite NPS

Person indexing is thus not confined to the most salient arguments. It is the first/second person markers that are most salient, and these are not marked as such in the P function for these NENA dialects.

Finally, it has been argued that cross-linguistically object person markers tend to be coded more readily independently than the agent and subject, especially when they have human referents (Siewierska 2004, 46-47, 6o-61). It is possible this tendency may play a role here, but the prepositional object series can also attach to the immediately preceding verbal form in some dialects of NENA in western Iran and become dependent person markers like the Lsuffixes.

The other Trans-Zab Jewish varieties will provide further evidence for why the alignment split, particularly ergativity, is most likely not motivated by functional-communicative factors.

\subsubsection{Comparative Syntax of Trans-ZabJewish Dialects}

Object marking in other Trans-Zab Jewish dialects shares the following tendencies:

a) verbal person marking that is inverted in relation to qatal-is limited to the third person;

b) prepositional person markers are used to mark objects independently of the verb;

c) if dependent, the set that marks P is added after the affix that marks A in accordance with the qațal-based affix order;

d) and the object is normally in pre-verbal position, i.e. P-V.

As we will see, none of these constructions group $\mathrm{S}$ and $\mathrm{P}$ ergatively, yet the distribution of these constructions is strikingly similar. These tendencies hold irrespective of the alignment type, and thus have no connection with ergativity in itself. The Trans-Zab Jewish varieties make use of common transitive 
constructions as differential object marking strategies regardless of how intransitive constructions are treated in the preterit or elsewhere in the system, e.g. a dynamic-stative split as found in J. Urmi.

\subsubsection{Verbal Person Marking and/or Nominal Marking}

The Western and Northern Trans-Zab dialects mainly differ from the Southeastern ones in only one respect, namely the coding of $s$. This is represented by the following examples in (8) from Jewish Arbel for Western Trans-Zab dialects, where $s$ is marked by the L-suffixes. The E-series is confined to the third person. Another 'all-series derived from prepositional person markers is necessary to express non-third person objects.

(8) J. Arbel (NE Iraq; Khan 1999)

a. dmix-le (intransitive) sleep $\mathrm{PFv}-\mathrm{S}: 3 \mathrm{MS}$

'He slept.' (lit. Him slept)

b. $\dot{g} \partial z y-a-l e$ (dependent $\mathrm{P}$ ) see $_{\mathrm{PFv}}-\mathrm{P}: 3 \mathrm{FS}-\mathrm{A}: 3 \mathrm{MS}$

'He saw her.' (lit. Him saw she)

$\begin{array}{ll}\text { c. } \dot{g} z e-l e \quad \text { ’oll-í } \\ \text { see }_{\mathrm{PFV}} \mathrm{A} \mathrm{A}: 3 \mathrm{MS} & \text { овJ-1SG }\end{array}$ (independent $\mathrm{P}$ )

'He saw me.' (lit. Him saw to-me)

Both flagging and indexing pattern accusatively in dialects like Jewish Arbel. Full nominal $P$ arguments receive special treatment in either cross-referencing through the E-set or prepositional marking by ('al)l-. There is no clear-cut distribution for either of these constructions (Khan 1999, 289-291). In addition, accusative prepositional marking and indexing of full NPs can, sporadically, be combined, as illustrated below.

(9) J. Arbel (NE Iraq; based on Khan 1999, 288-29o)

[s] [v-s]

a. kābrá dmix-le

man:Ms sleep ${ }_{\mathrm{PFV}^{-}}-\mathrm{S}: 3 \mathrm{MS}$

'The man slept.' 

[A] $\quad[\mathrm{DOM} \rightarrow \mathrm{P}]$
[V-P-A]
b. kābrá lo-’anne
be'é zabn-i-le
man:MS DOM-DEM:PL egg:PL sell PFV $-\mathrm{P}: 3 \mathrm{PL}-\mathrm{A}: 3 \mathrm{MS}$
'The man sold those eggs.'

The 'all-series is generally attached to an immediately verbal form, e.g. $\dot{g} z e ́ l o x=a l l e u$ 'You ${ }_{\mathrm{MS}}$ saw him' for ġzelox 'alléu. The third person $\varnothing$-morpheme from the E-set is not used in Jewish Arbel, but the corresponding person form of the 'all-series must be used instead, i.e. 'alléu -lleu 'him'. Jewish Arbel has adopted this in the cross-indexing system and can even be combined with differential prepositional marking. It is the only means to index a masculine singular NP, for example:

(10) J. Arbel (NE Iraq; Khan 1999, 498.83, 484.546)
$[\mathrm{V}$
$-\mathrm{A} \quad-\mathrm{P}]$
$[(\mathrm{DOM} \rightarrow) \mathrm{P}]$
a. xíp -la $\quad$-ll - eu bron-í
wash $_{\mathrm{PFV}}-\mathrm{A}: 3 \mathrm{FS}-\mathrm{OBJ}-3 \mathrm{MS}$ son-my
'She washed (lit. him) my son.'
b. $\dot{g} z e ́ \quad-l e \quad-l l \quad-e w \quad$ al-xalonad $\boldsymbol{b} \bar{a} \boldsymbol{b}$-í
see $_{\mathrm{PFV}}-\mathrm{A}: 3 \mathrm{MS}$-OBJ -3MS DOM-uncle.of father-my
'He saw (lit. him) the maternal uncle of my father.'

The difference between indexing and prepositional marking could also hinge on the relative iconicity-related morphological markedness of the patient (Mengozzi 2005; Barotto 2015). Prepositional marking shifts the morphological markedness more definitively to $\mathrm{P}$ over $\mathrm{S}$ and $\mathrm{A}$, especially with respect to the third person in the inverted qtil-construction, where the E-suffix for the $3 \mathrm{~ms}$. denoting $\mathrm{P}$ is realized as zero $(\varnothing)$, but, using prepositional marking, $\mathrm{P}$ receives distinct overt coding. The E-set may still be preferred for feminine singular and plural nominals, so that we obtain the following verbal person marking in the preterit:

$\begin{array}{lll}\text { baxta } & \dot{g} \partial z y-\bar{a}-l o x & \text { 'You } \\ \text { nāše } & \dot{g} z \text {-éni-lox } & \text { 'You (lit. her) the woman' } \\ \text { kābra } & \dot{g} z \text { sé-lox-əlleu (lit. them) the people' } & \text { 'You } \\ & \end{array}$

Another difference is that the object indexes of the 'all-series immediately follow subject and agent coding when they attach to the verb, which is in accordance with qatal-. Although all person referents are marked accusatively, the 
heavier coding is reserved for the first and second person, and in Jewish Arbel, also the third masculine singular. This suggests that Jewish Arbel is in the process of levelling the object coding from the E-set to the 'all-set and independent prepositional person markers have grammaticalized to a new set of dependent person markers.

Essentially, the same holds for the Jewish dialects of Iranian Azerbaijan (e.g. Khan 2008b, 298-301). Differential prepositional marking through ('al)land/or differential indexing is accusative, for example:

(11) J. Urmi (NW Iran; transcription modified)

$[\mathrm{s}] \quad[\mathrm{v}-\mathrm{s}]$

a. +̌̌ültaná ${ }^{+} d m a x-l e$

king:Ms sleep ${ }_{\mathrm{PFV}}-\mathrm{S}: 3 \mathrm{MS}$

'The king slept.'

$$
[(\mathrm{DOM} \rightarrow) \mathrm{P}][\mathrm{V}-\mathrm{P}-\mathrm{A}]
$$

b. tar-é palx-i-le

door-PL $\quad$ open $_{\mathrm{PFv}}$-P:3PL-A:3MS

(differential indexing only)

'He opened (lit. them) the doors.' (Garbell 1965, 150)
c. 'al-d-ö baxt-éw šiwq-a-le (combined)
DOM-LK-DEM:SG woman-his leave $\mathrm{PFV}_{\mathrm{PF}} \mathrm{P}: 3 \mathrm{FS}-\mathrm{A}: 3 \mathrm{MS}$
'He left (lit. her) his wife.' (Garbell 1965, 157)

The Jewish dialects of Iranian Azerbaijan, however, can also mark such crossindexing by means of additional L-suffixes on the qțil-based preterit verbal form and combine this with prepositional marking just as the other strategy

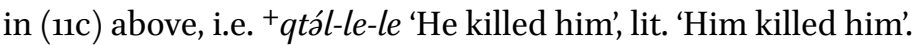

\section{d. tará pláx-le-le}

(differential indexing only)

door:Ms open PFv $^{-A: 3 M S-P: 3 M S ~}$

'He opened (lit. it ${ }_{\mathrm{M}}$ ) the door.' (Garbell 1965, 140)

e. +šültaná ’al-brön-éw nšáq-le-le

(combined)

king:MS DOM-son:Ms-his kiss ${ }_{\mathrm{PFv}}-\mathrm{A}: 3 \mathrm{MS}-\mathrm{P}: 3 \mathrm{MS}$

'The king kissed (lit. him) his son.' (Garbell 1965, 178)

Thus, just as in the dialect of Arbel, there is a more elaborate indexing system than in the SE Trans-Zab dialects, where the person marking strategies distinct from the E-set are not included in the indexing of full nominals. Speakers 
do not seem to have strong preferences for a particular strategy (Khan 2008b, 297-300). This, however, does not mean that the verbal person marking constructions have the same status, and the alignment typology of the dialects of Azerbaijan is somewhat different from that of Arbel.

First of all, the two transitive verbal forms result in two distinct alignment patterns in terms of phonological form/morphological marking. Verbal person marking inflection in the perfective past varies between accusative, as illustrated in (12) below, and neutral, i.e. phonologically non-distinct, as shown in (13).

(12) Third person only (J. Urmi NW Iran; Khan 20o8b)
sleep ${ }_{\mathrm{PFV}}-\mathrm{S}: 3 \mathrm{FS}$
'She fell asleep.' (lit. Her fell asleep)
a. ${ }^{+} d m \partial x-l a$
b. xazy-a-le
see $_{\mathrm{PFV}}-\mathrm{P}: 3 \mathrm{FS}-\mathrm{A}: 3 \mathrm{MS}$
'He saw her.' (lit. Him saw she)
(intransitive)
(transitive)

(13) First and second person (J. Urmi NW Iran; Khan 2008b)
a. ${ }^{+}$dmax-lan
sleep $\mathrm{PFv}_{\mathrm{PF}} \mathrm{S}: 1 \mathrm{PL}$
'We fell asleep.' (lit. Us fell asleep)
b. xzé-lax-lan
see $_{\mathrm{PFv}}$-A:2 F S-P:1PL
'You ${ }_{\mathrm{FS}}$ saw us.' (lit. Your $\mathrm{FS}_{\mathrm{S}}$ saw us)

(intransitive)

(transitive)

First/second person indexes, however, necessarily manifest neutral phonological form, as shown in (13). The difference from the horizontal morphological marking in certain SE Trans-Zab Jewish Dialects like Saqez ${ }^{42}$ is only the expression of $s$ in the perfective past. First and second person references are thus excluded from the accusative verbal morphology in (12) above, just as they are from the ergative verbal morphology in SE Trans-Zab Jewish dialects. Another difference between the accusative and neutral coding is affix order. In the accusative pattern, $\mathrm{P}$ is suffixed immediately to the inflectional base and pre- 
cedes A, i.e. V-P-A. In the neutral pattern, A always comes before $\mathrm{P},{ }^{43}$ i.e. V-A-P, so that forms like ** $x z e$-lax-li for 'You ${ }_{\mathrm{FS}}$ saw me' do not occur. ${ }^{44}$

Finally, independent object person markers seem to follow the same pattern as full NPs. There is free alternation between dependent and independent person markers in J. Urmi. The independent 'all-series in pre-verbal position are given in (14a) and (14b) below, and the suffixal L-series are given in (14c) and (14d) below. This applies to both qațal- and qțil-. Independent pronominal objects can also be indexed like full nominal objects. This is the regular construction for demonstrative pronouns with human referents (Khan 2008b, 299), such as $o$ in (14e) below. Independent first and second person markers are regularly expressed without additional indexing (Khan 2008b, 301), as illustrated in (14f.).

(14) J. Urmi (NW Iran; Khan 20o8b, 426.137, 428.148, cf. 329)

$\mathbf{P}=$ all -

$$
\mathbf{P}=\mathrm{L} \text {-set }
$$

$[\mathrm{P}] \quad[\mathrm{V}-\mathrm{A}(-\mathrm{P})]$

[V-A-P]

a. all-án dah-i-wa

DOM-1PL beat ${ }_{\text {IPFV }}$-A:3PL-PST

c. dah-í-wa-lan

'They would beat us.'

beat $_{\mathrm{IPFV}}$-A:3PL-PST-P:1PL

b. all-i ambal-lu

DOM-1SG take ${ }_{\mathrm{PFv}}-\mathrm{A}: 3 \mathrm{PL}$

d. ambál-lu-li

'They took me.' take PFV A:3PL-P:1SG

$[\mathbf{P}] \quad[\mathrm{V}-\mathrm{A}-\mathrm{P}]$

e. al-d-ö löka ${ }^{+}$plát-le-le

DOM-LK-DEM:SG there release ${ }_{\mathrm{PFV}}-\mathrm{A}: 3 \mathrm{MS}$-P:3MS

'He had him released from there.' (Khan 2008b, 298)

f. all-án löka ${ }^{+} p l a ́ t-l e\left(-{ }^{* * *} l a n\right)$

OBJ-1PL there release ${ }_{\mathrm{PFV}}-\mathrm{A}: 3 \mathrm{MS}(-\mathrm{P}: 1 \mathrm{PL})$

'He had us released from there.'

43 How this aligns with the L-suffix marking s immediately following the verbal base is a moot point, see $\S 2 \cdot 3 \cdot 2 \cdot 3$.

44 Khan's (2008b, 259) informants for Jewish Urmi say the two transitive constructions are not entirely functionally equivalent, $x z z y-a$-le expressing rather recent past 'He saw her just now'. The speakers' attempt to explain the difference could be connected with the dynamic-stative split in these varieties, ${ }^{+} d$ mix $-a$ 'She has gone to sleep' vs. ${ }^{+} d m a x$-la 'She went to sleep'. However, it is clear from the texts that both xəzy-a-le and $x z e$-le-la express narrative perfective past without a tense-aspect distinction between the two. 
TABLE 16 Morphosyntax of qțil- in Western and Northern Trans-Zab Jewish NENA

\begin{tabular}{|c|c|c|c|c|c|}
\hline & Independent & Gloss & \multicolumn{2}{|c|}{ Dependent } & Gloss \\
\hline A & baxtaké & 'the woman' & \multicolumn{2}{|c|}{$-l a$} & $3^{\text {fs. }}$ \\
\hline S & baxtaké & & \multicolumn{2}{|c|}{$-l a$} & \\
\hline $\mathrm{P}$ & 'al-baxtaké & & $-l a$ & $-a$ & \\
\hline A & baruxaké & 'the friend' & \multicolumn{2}{|c|}{-le } & $3 \mathrm{~ms}$. \\
\hline S & baruxaké & & \multicolumn{2}{|c|}{$-l e$} & \\
\hline \multirow[t]{2}{*}{$\mathrm{P}$} & 'al-baruxaké & & -le (Urmi) & -alleu (Arbel) & \\
\hline & Independent & Gloss & \multicolumn{2}{|c|}{ Dependent } & Gloss \\
\hline A & 'ana & 'I, me' & \multicolumn{2}{|c|}{$-l i$} & 1sg. \\
\hline $\mathrm{s}$ & 'ana & & \multicolumn{2}{|c|}{$-l i$} & \\
\hline $\mathrm{P}$ & 'alli & & -li (Urmi) & -alli (Arbel) & \\
\hline
\end{tabular}

Notes: Forms in darker gray shade in the dependent column only occur in dialects like Jewish Arbel, whereas their alternative in the same row only occurs in dialects like Jewish Urmi.

Morphologically non-distinct verbal person marking is presumably the result of levelling the L-set of object indexes throughout the verbal system in analogy with qațal-. 45

In terms of transitive morphosyntax, therefore, the differences among the Western and Northern Trans-Zab Jewish dialects are marginal, as well as their differences from the Southeastern Trans-Zab varieties treated in the previous section. In all of them the transitive inverted V-P-A qțil-forms with the E-set as object indexes are disfavored for the first/second persons regardless of alignment type. A construction, where the inversion is uplifted is favored overall, as the alternative coding strategies show a V-A-P order of affixes or require an inde-

45 See Subsection 4.3.3. for further argumentation, including other NENA dialects. 
pendent pronominal object. The systems that unfold across these Trans-Zab varieties are summarized in Table 16 above. The third person dependent forms are also used to differentially index full NPs. This leads to a salient morphological distinction between third masculine singular objects, e.g. 3ms. -alleu, and third non-masculine singular objects, e.g. 3 fs. - $a$, 3 pl. $-i$, in J. Arbel not found in other dialects as such.

\subsubsection{Object-Verb Order}

Word order usually varies depending on the discourse properties of arguments irrespective of alignment type manifested in verbal person marking or prepositional marking. It can also lead to ambiguity in determining alignment. ${ }^{46}$

There are nevertheless evident dialect-specific word order preferences in Neo-Aramaic. The NENA dialects in the eastern periphery, including all TransZab Jewish varieties, typically exhibit an Object-Verb (i.e. P-V) arrangement as the unmarked word order throughout. The word order is irrespective of the clausal properties (i.e. TAM), for example:

(15) J. Saqez (W Iran; Israeli 1998, 186)

$[\mathrm{P}] \quad[\mathrm{V}]$

a. baxt-év aburw-év labl-a-le

(qațal-)

woman:Fs-his dignity:MS-his take ${ }_{\mathrm{IPFV}}-\mathrm{A}: 3 \mathrm{FS}-\mathrm{P}: 3 \mathrm{MS}$

'His wife takes away his dignity.'

b. hatán kaldá nəšq-a-le

groom:Ms bride:Fs kiss ${ }_{\mathrm{PFV}}-\mathrm{A}: 3 \mathrm{FS}-\mathrm{P}: 3 \mathrm{MS}$

'The bridegroom kissed the bride.'

Moreover, while the SE Trans-Zab Jewish dialects do show some degree of ergativity, it is not ergativity per se that correlates with a particular dialectological word order preference. Trans-Zab NENA dialects with a different alignment typology in qțil-may also have this particular arrangement, such as Jewish Arbel and Jewish Urmi, cf. (16) below.

(16) J. Urmi (NW Iran; Garbell 1965, 197)

$\begin{array}{lll} & {[\mathrm{P}]} & {[\mathrm{v}]} \\ \text { hatán } & \text { reš-éw } & \text { glé-le-le }\end{array}$

groom:Ms head:Ms-his reveal ${ }_{\mathrm{PFv}}-\mathrm{A}: 3 \mathrm{MS}-\mathrm{P}: 3 \mathrm{MS}$

'The bridegroom uncovered his head.'

$46 \quad$ See $§ 2 \cdot 3 \cdot 2 \cdot 3$. 
Thus, although the Trans-Zab varieties with ergativity in qțil-prefer P-V order, this preference is not specific to this alignment type, but to the Trans-Zab dialect bundle as a whole. This is borne out by the fact that the same word order preference is found for the qatel-based clauses and that related dialects with other alignment typology betray the same word order preference.

\subsubsection{Person Restrictions in Relation to Compound Verbal Forms}

Compound verbal forms can also be restricted by person in NENA dialects, similarly to qțil-. This shows that person constraints are regardless of the alignment constellation we consider them part of.

Dependent first/second person object markers, for example, cannot be combined with dependent A markers in the Jewish dialect of Sulemaniyya (Khan 2004a), which is part of the Southeastern Trans-Zab cluster. When the object is of first or second person reference, it must be expressed independently. Two types of object coding occur in the present progressive, namely a) independent 'all-series and b) 'possessive' suffixes restricted to the third person:

(17) J. Sulemaniyya (NE Iraq; Khan 2004a, 139)

\begin{tabular}{|c|c|c|c|c|}
\hline $3 \mathrm{PL}$ & $\begin{array}{l}\text { INDEPENDENT } \\
\left(\text { garošá- } \nu^{\prime} \partial l l-u ́\right)\end{array}$ & $\begin{array}{l}\text { DEPENDENT } \\
\text { garoš- } u \text { - } y e\end{array}$ & "He is pulling & them' \\
\hline $3 \mathrm{FS}$ & (garošá-y ’all-áw) & garoš-aw-ye & etc. & her' \\
\hline $3 \mathrm{MS}$ & (garošá-y ’all-éw) & garoš-ew-ye & & him' \\
\hline $1 S G$ & garošá-y ’all-í & - & & me' \\
\hline $2 \mathrm{PL}$ & $\begin{array}{l}\text { garošá-y ’all-ăxún } \\
\text { etc. }\end{array}$ & - & & $\begin{array}{l}\text { you }_{\mathrm{PL}} \text { ' } \\
\text { etc. }\end{array}$ \\
\hline
\end{tabular}

Only third person referents can occur as dependent object person markers. They are suffixed between the verb (garošá 'pulling') and the coding for A $(-y(e)$ 'He is') in construction type II (second column). By contrast, the progressive combines with all persons when the object is not dependent, but expressed independently by a preposition instead (e.g. 'all-i, first column). This parallels the person restrictions on the E-suffixes that mark $\mathrm{P}$ before agent indexes in qțil- such as:

(18) J. Sulemaniyya

$\begin{array}{llll}\text { INDEPENDENT } & \text { DEPENDENT } & & \\ (\text { graš-le ’all-aw }) & \text { garš-a-le } & \text { 'He pulled } & \text { her' } \\ \text { graš-le 'all-i } & - & & \text { me' } \\ \text { etc. } & & \end{array}$


Moreover, the person restriction on qtill-forms can be motivated by the perfect in the Northern Trans-Zab Jewish dialects such as J. Urmi. The transitive realis perfect assimilates almost fully to qațal- apart from the third person. The morphemes and stress pattern ${ }^{47}$ of first/second person indexes is indistinguishable from qațl-. Importantly, then, the compound verbal construction's merger with qatal-would potentially also affect the interpretation of the inflection of qțil-, being liable to role reference inversion. Supposing qțil-forms like ${ }^{* *+}$ qtil-an-ne for 'He killed me' had been used, they would have completely converged with the masculine singular forms of first and second person in the realis perfect. The J. Urmi perfect and pluperfect ms. forms, for instance, would have been phonologically identical to preterit and plupreterit ms. forms, but with inverted morphosyntax (as qațal-), for example:

(19) PERFECT $\left({ }^{+} q\right.$ tila $+\mathrm{E}_{1 / 2}$-set) ${ }^{+}$qtil-an-ne

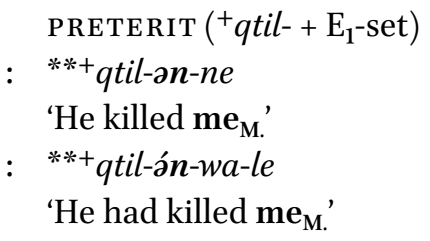

It is conceivable that these two constructions would be incompatible and therefore increase the pressure to constrain the constructions with inverted role reference. There is only a subtle difference, so that a construction based on the resultative participle ${ }^{+}$qtila like ${ }^{+}$qtil-án-ne ' $\mathrm{I}_{\mathrm{M}}$ had killed him' that potentially could be conflated with an instance of ${ }^{+} q$ til- together with the $\mathrm{E}_{1}$-set can neatly co-exist with inverted preterit forms based on ${ }^{+} q$ til- of the third person like ${ }^{+}$qtil-a-le 'He killed her.'48

Furthermore, in J. Koy Sanjaq (NE Iraq), a Western Trans-Zab Jewish variety, the marking of $\mathrm{P}$ shifts depending on the coding of A. $\mathrm{s}$ and $\mathrm{A}$ are always marked by the copula, but the copula marking A either follows or precedes object suffixes. When A is first/second person, $\mathrm{P}$ is expressed by L-suffixes, following the copula, whereas, when A is third person, P is expressed by 'possessive suffixes', preceding the copula. This is a constructional split first and foremost, and does not affect the alignment:

47 Ultimate stress on nominal forms facilitates this analogy in J. Urmi, i.e. ${ }^{+}$qtilá 'killed one'.

48 These two are incompatible in the Christian dialect of Borb-Ruma (Bohtan) where the transitive realis perfect is fully based on qțil-, i.e. qțil-ən-na 'I have killed her' and qțil-a-li 'She has killed me' (both qtil- $+\mathrm{E}_{1}$-set), see $§$ 4.4.3.2. 
(20) J. Koy Sanjaq (Mutzafi 2004a, 100-101)

\begin{tabular}{|c|c|c|c|c|}
\hline & {$[\mathrm{v}$} & A: 1,2 & P: L-S & iffix] \\
\hline PROGRESSIVE & $n \check{a} a q a ́$ & $-w \partial n$ & $-n e$ & 'I $\mathrm{I}_{\mathrm{M}}$ kiss him.' \\
\hline \multirow[t]{2}{*}{ PERFECT } & nšiqá & $-w a n$ & $-n e$ & 'I $\mathrm{I}_{\mathrm{M}}$ have kissed him.' \\
\hline & {$[\mathrm{V}$} & P: POSS & A: 3$]$ & \\
\hline PROGRESSIVE & $n s ̌ a q$ & -án & -ile & 'He kisses us.' \\
\hline PERFECT & $n s ̌ i q$ & -án & -ile & 'He has kissed us.' \\
\hline
\end{tabular}

The person constraints in Trans-Zab Jewish dialects therefore do not correlate with a particular alignment type per se (i.e. ergativity) or with a particular Tense-Aspect-Mood property per se. They are presumably based on a specific combination of dependent person markers, possibly in a specific order, namely V-P-A like qțil-or V-A-P like qațal-. The 'all-series and/or L-suffixes, especially in the preterit, are ideal alternatives for object indexes following the agent indexes just as they do in the rest of the verbal system, particularly qatal- 49

All in all, ergativity in itself is not what triggers this person restriction, nor another alignment type. It is simply a combination of dependent person markers in the inflection of transitive verbs that is disfavored or impossible for first/second person objects.

\subsection{Ergativity and Splits along the Tense-Aspect-Mood Scale}

Drawing on cross-linguistic studies, Malchukov (2015) proposes an implicational Tense-Aspect-Mood scale for alignment splits conditioned by TAM. Resultative and perfect are the most likely to pattern ergatively against the perfective past and especially the imperfective present and imperative. Once the ergative pattern is manifested in the perfective past, it will also tend to be in the perfect and resultative, but not vice versa. NENA data, as we will see, however, run counter to this tendency. The perfective past can pattern accusatively, while the perfect and/or resultative patterns ergatively.

The degree of grammaticalization of intransitive resultative-stative to transitive perfective past seems to me more fundamental to the microvariation found in NENA than a particular alignment pattern and/or functional category. In terms of grammatical aspect, for instance, the E-set of subject indexes, if employed, will be further removed from the perfective past than the L-set of

49 See further Section 4.3. on the typology of person-role constraints in NENA. 
agent indexes on the TAM scale in (1), where L-set becomes less likely and E-set more likely from right to left. The patient-like E-set (minimally for s), if it exists in a NENA variety, will therefore not be more grammaticalized to the right of this scale than the agent-like L-set (minimally for A).

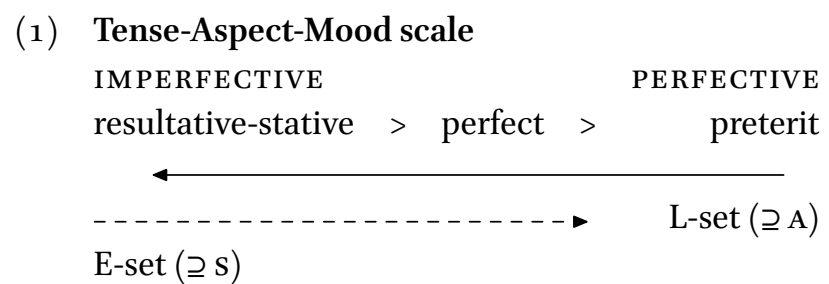

Trans-Zab Jewish dialects vary greatly in their treatment of intransitive verbs in general as well as the transitive realis perfect. ${ }^{50}$ The morphosyntax of $q t i l$-based constructions that normally express the perfective past (see Subsection 3.3.) can differ from that of those that typically denote the realis perfect (see below). It is the transitive realis perfect that stands out in all of them and displays the greatest diversity. Historically, there existed a gap for a transitive counterpart to the perfect that is filled differently by each dialect. We will compare to what extent the alignment in verbal person marking of the 'realis perfect' differs from that of the 'preterit' and sometimes the 'irrealis perfect'.

\subsubsection{Filling the Gap of the Transitive Perfect}

In NENA dialects in general, the participle is inflected for number and gender like adjectives in compound verbal forms (see § 2.2.4.). Compound verbal forms in Trans-Zab Jewish varieties distinguish transitive from intransitive verbs by means of a shift in syllable structure, where the intransitive base consistently maintains the long vowel /i/. Thus, while transitive bases alternate between $q t a l$ - before a consonant, e.g. fs. qtaltá, and qaț- before a vowel, e.g. pl. qațlé, the intransitive remains stable as qțil-in the verbal inflection, for example šql 'buy' and $\operatorname{sm} x$ 'wait':

(2) J. Sulemaniyya (NE Iraq; Khan 2004a, 98; 2005) SIMPLEX COMPOUND

TR. $\quad$ šqal- $\varnothing$-le 'He bought $\mathrm{it}_{\mathrm{M}}$ ' šaqlá-y 'He has bought' šaql-a-le 'He bought it $_{\mathrm{F}}$ ' šqaltá-ya 'She has bought' šaql-i-le 'He bought them' šaql-én 'They have bought'

$5^{\circ} \quad$ See Khan (2008b, 2-7, 146-148; 2009, 5-9, 327-329). 


\begin{tabular}{|c|c|c|c|c|}
\hline \multirow{4}{*}{ INTR. } & SIMPLEX & & COMPOUND & \\
\hline & $\operatorname{smix}-\varnothing$ & 'He waited' & smixá-y & 'He has waited' \\
\hline & $\operatorname{smix}-a$ & 'She waited' & smixtá-ya & 'She has waited' \\
\hline & smix $-i$ & 'They waited' & smix-én & 'They have waited' \\
\hline
\end{tabular}

The transitive stem I verbs conjugate similarly to the equivalent stem III verbs, e.g. preterit $m r a d x$-a-le 'He boiled it ${ }_{\mathrm{F}}$ ' and perfect mradxá-y 'He has boiled'.

Unlike J. Sulemaniyya, illustrated in (2) above, Northern Trans-Zab Jewish dialects do show the qtal-/qațl-pattern in the preterit, e.g. J. Urmi ${ }^{+} q a t l-i-l e$ 'He killed them', but not in the participle, e.g. pl. qțile 'killed'. The Jewish dialect of Rustaqa (Khan 2002b, 403-405) has /CCiC/ throughout, i.e. qțil-i-le and qțile, respectively. Also, the shape of the copula can differ from dialect to dialect. The simplex verbal forms pattern ergatively throughout the Southeastern TransZab varieties, including Sulemaniyya (NE Iraq) and Sanandaj (W Iran). The alignment of the compound verbal forms, however, need not do so, and even if they do, the conditions are generally different as well.

Broadly speaking, verbal constructions overlap in the expression of perfect and preterit. Both simplex constructions based on qțil- and compound constructions based on the resultative participle can be used to express either of these. Occasionally, the differences between the two can be very subtle. Khan (2004a, 306, 314-318) observes in J. Sulemaniyya, for instance, that qtil-based forms such as qim- $\varnothing$ 'I arose' can also express the perfect and serve as the dynamic counterpart to the participle-based constructions such as qimá-y 'I have arisen' focus on the state resulting from an action. This notwithstanding, there are three main construction types that typically express the realis perfect:

- distinct preverbal TAM-marking added to qțil-;

- distinct subject marking added to qțil- (L-set vs. E-set);

- compound perfect based on the resultative participle (qțila) and a copula. It is an important distinction whether dialects prefer preverbal TAM-marking or TAM-marking via distinct sets of subject indexes. Dialects may even mix these constructions across intransitive and transitive verbs.

This applies in particular to dialects with a dynamic-stative type of fluid subject coding. This occurs further to the northwest among Northern Trans-Zab Jewish and some Western Trans-Zab Jewish varieties. These dialects minimally group together $\mathrm{S}$ and A through the L-set (dmax-lan 'We slept': nšaq-lan 'We kissed'), but they differentiate between E-suffixes and L-suffixes to mark the subject depending on aspect, as illustrated below. 
(3) J. Urmi (NW Iran; Garbell 1965; Khan 2008b)

a. ${ }^{+} d m a x$-le 'He went to sleep.'

b. ${ }^{+} d$ mix $\quad-\varnothing$ 'He is asleep, has gone to sleep.'

The result-oriented $s_{\mathrm{P}}$ form (E-set) interacts with a fundamental distinction between transitive and intransitive realis perfect constructions. As a realis perfect, it is generally confined to the expression of result states, of which its continuation in the actual present is inferred from direct perceptible evidence. In expressing the transitive counterpart, the 'dynamic-stative dialects' must have recourse to other means of coding, since the coding for the intransitiveresultative (e.g. qim- $\varnothing$ ) creates a gap for the transitive counterpart:

\begin{tabular}{|c|c|c|c|}
\hline & PRETERIT & PERFECT & \\
\hline & qțal-le 'He killed' & & 'He has killed' \\
\hline TR. & qim-le 'He rose' & qim- $\varnothing$ & 'He is/has risen' \\
\hline
\end{tabular}

All else being equal, it is the morphosyntax of the transitive realis perfect that stands out. Compound verbal forms (e.g. qimá or qațlá + copula) may interact with the simplex ones based on qțil- (e.g. qim- or qațl-) and manifest converging or diverging alignment patterns depending on the dialect.

\subsubsection{Arbel: Accusative}

Several dialects have grammaticalized preverbal TAM-markers to indicate the realis perfect. These are, for example, the particles $n \bar{a}$ in J. Dobe and $l \bar{a}$ in $\mathrm{J}$. Arbel. ${ }^{51}$ The object marking is the same throughout (see $\S 3.3 .2$ ), thereby yielding no split alignment but consistent accusative alignment:

\section{(5) Jewish dialects on the Arbel Plain}

J. Dobe (N Iraq; J. Arbel (NE Iraq;

Mutzafi 2004b) Khan 1999)
a. (Ø) 'alye-le
(Ø) 'alye-le
(Ø) palx-a-le
(Ø) palx-a-le
'He came.'
(preterit)
b. $\boldsymbol{n} \overline{\boldsymbol{a}}$ 'alye-le lā 'alye-le
'He has come.'
(perfect)
$n \bar{a} \quad p a l x-a-l e$ la $\quad p a l x-a-l e$
'He has opened it.'

$5^{1} \quad$ These are presumably fossilized forms of a deictic copula (Khan 2007d), i.e. hola 'here she/ $\mathrm{it}_{\mathrm{F}}$ is', hona 'here they are'. 
The resultative participle has not grammaticalized to a perfect in J. Arbel (NE Iraq; Khan 1999, 284-285) and its usage is mainly confined to intransitive verbs, e.g.
rkiwa-wen 'I am riding.' (lit. am mounted)
skina-wet 'You ${ }_{\mathrm{MS}}$ dwell.' (lit. are settled)

Both $l \bar{a}$ and the participle can be used to express a present result state, e.g. (Khan ibid. 269)
xmila-wen 'I am standing.' (lit. am stood)
lāxmal-li 'I am standing.' (lit. Here-now me stood)

The intransitive verb pyš 'remain' retains an $\mathrm{s}_{\mathrm{P}}$ form denoting a continuous state, e.g. (Khan ibid. 284).

'o-la-piš- $\varnothing \quad$ 'He is not alive.' (lit. He not remained)

This is a relic of an earlier dynamic-stative distinction still preserved more extensively in the following Trans-Zab dialects.

\subsubsection{Rustaqa: Ergative and Tripartite Resultative}

Jewish Rustaqa and Rewanduz, dialects bordering Arbel and Urmi, combine two strategies. The same particle generally and redundantly accompanies the $\mathrm{s}_{\mathrm{P}}$ form ( $q$ im- $\varnothing$ 'He is risen') in fluid-s marking. The actualizer $l \bar{a}$ together with E-suffixes to mark the subject ( $l \bar{a}$ qim- $\varnothing$ 'He is risen') shifts the event viewpoint to a state resulting from prior action (Khan 2002b, 404) against the $\mathrm{s}_{\mathrm{A}}$ form, as compared below. There appears to be no semantic difference between the presence or absence of the actualizer $l \bar{a}$; it always combines with the $\mathrm{s}_{\mathrm{P}}$ form.

(6) J. Rustaqa (NE Iraq; Khan 2002b, 404)

a. $(\varnothing)$ dye-le 'He came (but might not be here).'

(dynamic)

b. $l \overline{\boldsymbol{a}} \quad d y e-\emptyset \quad$ 'He has come and is here now.'

There is no distinction in agent coding between the preterit and perfect. $l \bar{a}$ expresses the realis perfect for transitive verbs, where the L-suffixes mark the agent: 
(7) J. Rustaqa (NE Iraq; Khan 2002b, 404)
a. (Ø) qțal-le 'He killed.'
(preterit A = L-set)
b. (Ø) qim-le 'He stood up.'
(preterit $\mathrm{S}=\mathrm{L}$-set $)$
c. $l \bar{a} \quad q t a l-l e$ 'He has killed.'
(perfect A $=$ L-set)
d. $\boldsymbol{l} \overline{\boldsymbol{a}} \quad$ qim- $\emptyset$ 'He is (risen and now) up.'
(perfect $\mathrm{s}=\mathrm{E}$-set $)$

The choice of subject coding between E-suffixes and L-suffixes would be enough for intransitive verbs, but the TAM-marking regularly precedes intransitive verbs just as their transitive counterparts. The only difference is the use of the E-set for subject person marking in the realis perfect.

Just as in J. Arbel, the role inverted construction is limited to the $3 \mathrm{fs}$. and $3 \mathrm{pl}$. objects in J. Rustaqa, while non-third person arguments require an independent prepositional object (Khan 2002b, 405), for example:

(8) (lā) qțil-ā-le 'He (has) killed her.'

(9) (lā) qțal-le 'ill-i ' 'He (has) killed me.'

Consequently, we not only have a split between qațal-and qțil-but we also have a split within the inflection of qtil- that is sensitive to TAM.

There are thus two subsystems that each have their own variation in alignment patterns. The dynamic and perfective aspect exhibits a markedness shift in accusative alignment depending on the type of patient-marking. The prepositional marking complements the verbal person marking system. The system in the preterit is largely indistinct from that of J. Arbel:

(10) Accusative: Preterit (J. Rustaqa, NE Iraq; Khan 2002b)

a. praq-le

(intransitive) finish $_{\mathrm{PFv}}-\mathrm{S}: 3 \mathrm{MS}$

'He finished.'

b. qțil-i-le

(transitive, 3 fs. and $3 p l$. patient) kill $_{\mathrm{PFv}}$-P:3P L-A:3MS

'He killed them.'

c. qțal-le 'all-ox

kill $_{\mathrm{PFV}}-\mathrm{A}: 3 \mathrm{MS}$ OBJ-2MS

(transitive, non-third person

'He killed you ${ }_{\mathrm{Ms}}$ ' or third person patient) 
The alignment, however, is largely the same as the preterit of Southeastern Trans-Zab Jewish dialects in the realis resultative or perfect of J. Rustaqa (see §3.3.1). J. Rustaqa similarly evinces an ergative and tripartite pattern conditioned by person. While the tripartite pattern is available for all persons, the ergative type is limited to the 3 fs. and 3pl. This is illustrated in (11) and (12) below. Importantly, then, ergative alongside tripartite alignment is found in the realis perfect rather than the preterit in this Jewish dialect:

(11) Ergative: Realis perfect (J. Rustaqa, NE Iraq; Khan 20o2b)

a. $l \bar{a}$ priq-i

(intransitive) ACTZ finish ${ }_{\mathrm{PFV}} \mathrm{S}: 3 \mathrm{PL}$

'They are finished.'

b. $l \bar{a} \quad q t ̦ i l-i-l e$

ACTZ kill ${ }_{\mathrm{PFV}}$-P:3PL-A:3MS

(transitive, 3 fs. or $3 p l$. patient)

'He has killed them.'

(12) Tripartite: Realis perfect (J. Rustaqa, NE Iraq; Khan 20o2b)

a. $l \bar{a}$ priq-et

(intransitive)

ACTZ finish ${ }_{\mathrm{PFV}}-\mathrm{S}: 2 \mathrm{MS}$

'You ${ }_{\mathrm{MS}}$ are finished.'

b. $l \bar{a} \quad q t a l-l i \quad$ ’all-ox

ACTZ kill ${ }_{\mathrm{PFV}}$-A:1SG OBJ-2MS

'I have killed you $_{\mathrm{MS}}$ '

(transitive, non-third person or third person patient)

Once again, the coding strategies of the transitive verbs do not hinge on a particular alignment pattern. The role inverted construction with dependent person marking is person-restricted regardless of either ergative alignment in the resultative or perfect or accusative alignment in the preterit. What differs are the intransitive constructions, where the E-set of subject indexes are lagging behind, as it were, on the grammaticalization from resultative-stative to preterit.

Finally, in many respects, intransitive resultative or perfect forms like $d m i x$ $\varnothing$ are akin to compound verbal forms based on the enclitic copula and resultative participle found in the same dialect. The same sense of the intransitive resultative-stative is available for a construction based on the participle: 
(13) J. Rustaqa (NE Iraq; Khan 2002b, 404) ${ }^{52}$
a. $\mathbf{l a}$ xmil-et
'You ${ }_{\mathrm{MS}}$ are standing.'
$($ TAM + qțil- + E-set $)$
b. xmil-a-wet 'id.'
(RPP qțila + encl. copula)

Based on Khan (2002b), we can assume the following system for J. Rustaqa. The schema below gives the first person masculine forms for the two types of resultatives and the preterit; one ('resultative I') based on qțil-, the other ('resultative II' represented in gray shade) based on the resultative participle (qțila):

(14) Two resultatives in J. Rustaqa (NE Iraq; Khan 2002b)

PRETERIT RESULTATIVE I RESULTATIVE II

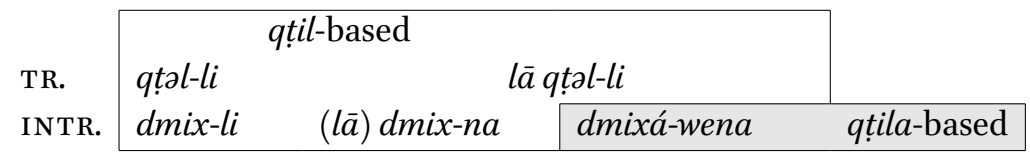

Note how it is the intransitive constructions that show distinct verbal inflection. In principle, the transitive resultative lā qțil-li with preverbal TAMmarking functions as the transitive counterpart to both 'resultative I' $(l \bar{a}) d m i x$ $n a$ and 'resultative II' dmixá-wena.

\subsubsection{Koy Sanjaq: Competing Resultatives}

Jewish Koy Sanjaq (NE Iraq) is closely related to J. Rustaqa (NE Iraq), but there are notable differences. The TAM-marker $l \bar{a}$ is absent, but 'resultative I' forms like r $x i s ̌$ - $\varnothing$ 'He has walked' (Mutzafi 2004a, 82) do occur. They are marginal and are largely supplanted by the second resultative construction, i.e. compound verbal form. Compound verbal forms like dmixe-lu 'They are asleep' (qțila + COPULA) are more common than 'resultative I' forms like $d m i x-i$ 'They are asleep' (qțil- + E-set) (Mutzafi 2004a, 78, 105, 108). The compound perfect is, however, fully available for transitive verbs, so that we obtain the following system:

(15) Two resultatives in J. Koy Sanjaq (NE Iraq; Mutzafi 2004a)

\begin{tabular}{|c|c|c|c|c|}
\hline \multirow{4}{*}{$\begin{array}{l}\text { TR. } \\
\text { INTR. }\end{array}$} & PRETERI & RESULTATIVE I & \multirow[t]{2}{*}{ RESULTATIVE II } & \\
\hline & \multicolumn{2}{|c|}{ qțil-based } & & \\
\hline & qțil-li & \multicolumn{2}{|c|}{ qțilá-wen $(a)$} & \\
\hline & $d m i x-l i$ & dmix-en $(a)$ & dmixá-wen $(a)$ & qțila-based \\
\hline
\end{tabular}

52 Third person enclitic copula forms (-ile, -ila, -ilu) presumably undergo contraction (e.g. $d m i x$-ele $\left.<{ }^{*} d m i x a-i l e\right)$. Khan (2002c) does not provide an example of this contraction, but we can infer this from the contraction with noun phrases elsewhere. 
It is the second resultative (qtilá-wena) that serves as the transitive counterpart to the 'resultative I' based on qtil- (dmix-ena) in J. Koy Sanjaq.

Certain typical change-of-state verbs belonging to stem I, however, are essentially voice-neutral in their resultative construction. A verb like $t w r$ 'break' can therefore express the following semantic ambiguity in Jewish Koy Sanjaq. The resultative participle twirta agrees with the subject expressed by the enclitic copula -ila 'She is'. It can express an intransitive state that is either patient-oriented (imply some external cause) or subject-oriented (anticausative, spontaneous), or a transitive perfect that is agent-oriented:

(16) J. Koy Sanjaq (NE Iraq; Mutzafi 2004a, 106)

twir-té-la $\left(<{ }^{*}\right.$ twirtá-ila $)$

broken-Fs-she.is

a. 'She is broken.'

(patient or subject-oriented, intr., stative)

b. 'She has broken.'

(agent-oriented, tr., dynamic)

The aspectual opposition between the intransitive stative-resultative and transitive perfect also correlates with their integration into the verbal system. ${ }^{53}$ The difference is partly found in agreement pattern and negation in J. Koy Sanjaq. The resultative-stative conforms to other adjectives by expressing agreement in the plural, while the perfect lacks this. As illustrated in (17) below, the participle šwiqé is in the plural and agrees with the first plural subject in the resultative šwiqe-wex 'We are left', while in the corresponding perfect, it takes the unmarked masculine singular form šwiqa-wex 'We have left'. The agentoriented perfect of transitive verbs will therefore lack agreement as opposed to the patient-oriented resultative of transitive verbs: nšiqa-wex 'We have kissed' as opposed to nšiqe-wex 'We are kissed'.

(17) pl. šwiqé + -wex šwiqe-wex 'We are left'
sg. šwiqá + -wex šwiqa-wex 'We have left'

The alignment of verbal person marking is partly accusative and partly tripartite in J. Koy Sanjaq. Moreover, the coding strategy for P depends on the person of A. The copula indexes A and the participle agreement always groups $\mathrm{S}$ and $\mathrm{A}$ in accusative fashion. The coding strategy for $\mathrm{P}$, however, depends on the person of $\mathrm{A}$; its marking is sensitive to the properties of a co-argument. ${ }^{44}$ When $\mathrm{A}$ is

53 See Kapeliuk (2008); cp. Mutzafi (2004a, 105-109) and Khan (2008a, 653-659).

54 See $\S$ 4.4.1.1. on the issue of co-argument sensitivity raised by Witzlack-Makarevich et al. (2016). 
first/second person, P is expressed by L-suffixes. Somewhat confusingly, when A is third person, $\mathrm{P}$ is expressed by 'possessive suffixes' attached to the participle instead, ${ }^{55}$ e.g. (Mutzafi 2004a, 100-101)

$$
\begin{aligned}
& {\left[\begin{array}{llll}
\mathrm{V} & -\mathrm{A} & -\mathrm{A} & -\mathrm{P}
\end{array}\right]} \\
& \text { nšaq } \quad \text {-t }- \text {-ewan } \quad \text {-ne 'I } \mathrm{I}_{\mathrm{FS}} \text { have kissed him.' (lit. I am kissed him) } \\
& {\left[\begin{array}{llll}
\mathrm{V} & -\mathrm{A} & -\mathrm{P} & -\mathrm{A}
\end{array}\right]} \\
& n s ̌ a q ~-t-e ́ w \quad-i l a \quad \text { 'She has kissed him.' (lit. She is kissed his) }
\end{aligned}
$$

While there is a clear difference in construction preference depending on the person of A, there is ultimately no distinction in alignment. However, a tripartite alignment unfolds when we consider simplex 'resultative I' dmix-en based on qțil-, where s, marked by the E-set, aligns with neither A nor P in the compound transitive perfect. This is similar to the system we find in the Jewish dialect of Urmi.

\subsubsection{Urmi: Mixing Resultatives}

3.4.5.1 Complementary Simple and Compound Verbal Forms

There is some overlap between qțil-and the resultative participle $q t ̦ i l a$ in either direction in both J. Rustaqa and J. Koy Sanjaq. A mixed system with complete complementary distribution between the two types of resultatives occurs in dialects further north in Iranian Azerbaijan, such as J. Urmi (Khan 2008b, 8283 ). Here, intransitive verbs are inflected for the familiar $\mathrm{E}_{1}$-set ( $p$ lix $\varnothing \varnothing \mathrm{It}_{\mathrm{M}}$ opened'), while transitive verbs have a complete system of their own based on the resultative participle and a secondary $\mathrm{E}_{2}$-set ultimately based on but not identical to the enclitic copula: plix-é < ${ }^{*}$ plix-elé $<$ "plixa-ile 'He has opened' (see §3.1.3.3).

(18) J. Urmi (NW Iran; Khan 2oo8b, 263, 83)
a. xa tara plix-é 'He opened a door.'
(tr., qțilá, $\mathrm{A}=\mathrm{E}_{2}$ )
b. tara plix- $\varnothing$ 'The door has opened.'
(intr., qtill-, $\mathrm{s}=\mathrm{E}_{1}$ )
c. $\ddot{\text { o-tara }}$ plix-ele 'The door is open.'
(adj., qțilá, s = COP)

55 Although I cannot fully address this here, there could be a correlation with ditransitives, where the third person copula marks the theme and attaches to a preceding L-set. See also parallels in Christian dialects of NENA in $§ 4 \cdot 3 \cdot 2 \cdot 3$. 
The two systems complement each other entirely and constitute a paradigmatic relation, as illustrated in (19) below. The feminine forms highlight the difference between the verbal bases. The construction based on the resultative participle inflects for gender like the nominal form, e.g. fs. qtalta 'killed', and is combined with the $\mathrm{E}_{1}$-series for the first and second person, but the $\mathrm{E}_{2}$-series for the third person. If the intransitive form had the same basis, it would inflect in the same way, i.e. **dmixt-án 'She has slept', but this is impossible.

(19) Two resultatives mixed in J. Urmi (NE Iraq; Khan 20o8b)

\begin{tabular}{|c|c|c|}
\hline & PRETERIT & PERFECT \\
\hline TR. & $\begin{array}{l}q t \text { til-BASED } \\
{ }^{+} q t a l-l i\end{array}$ & $\begin{array}{l}\text { qtila-BASED } \\
{ }^{+} q \text { talt-án }\end{array}$ \\
\hline INTR. & $+d m \partial x-l i$ & ${ }^{+}$dmix-an \\
\hline
\end{tabular}

This also applies to the relative past tense forms that take the past convertor -wa instead of the past copula. Compare:

(20) Equivalent forms with 'past convertor'

\begin{tabular}{|c|c|c|}
\hline & PRETERIT & RESULTATIVE I+II \\
\hline & qțil-BASED & qțila-BASED \\
\hline & ${ }^{+} q t a ́ l-w a-l i$ & ${ }^{+} q t a l t-a n-w a$ \\
\hline INTR. & ${ }^{+} d m a ́ x-w a-l i$ & ${ }^{+} d m i x-a n-w a$ \\
\hline
\end{tabular}

3.4.5.2 Ergative Feminine Gender and Tripartite Person Marking The subsystem in Jewish Urmi is further characterized by a split between accusative and tripartite alignment depending on mood; realis as opposed to irrealis. Whenever the verb takes an object index in the perfect, this is marked by the L-suffixes analogically to qațl-, e.g. ${ }^{+} q t a l t-a n-n e ~ ' I_{F}$ have killed him' (see § 3.1.3.3.)

A more analytic construction is preferred in the irrealis mood, however. The auxiliary verb hwy 'be' is employed together with the participle, both agreeing with the subject and agent. The unmarked qațal-form of hwy, i.e. $\varnothing$-hawe, expresses the subjunctive. The intransitive and transitive verbs pattern alike in this analytic construction, for example:

(21) Irrealis perfect in J. Urmi (NE Iraq; Khan 2008b, 82, 142) RESULTATIVE II

$\begin{array}{llllll}\text { TR. } & { }^{+} q \text { tal } & -t a ́ & -h a w y & -a & \\ & +q t a l & -t a ́ & -h a w y & -a & -l e \\ \text { INTR. } & +d \operatorname{cox} & -t a ́ & - \text { hawy } & -a & \end{array}$


In terms of alignment, then, the irrealis perfect is accusative, and this is expected, because the inflection is fully based on the qatal-form of hwy 'be'. When we confine ourselves to the realis perfect, however, the alignment pattern is best considered to be tripartite for the third person indexes and accusative only for the first and second person indexes. The first and second person subject and agent indexes are expressed by the $\mathrm{E}_{1}$-set, e.g. ${ }^{+} d$ mix-an ' $\mathrm{I}_{\mathrm{F}}$ have slept' : ${ }^{+}$talt-an ' $\mathrm{I}_{\mathrm{F}}$ have killed', while third person $\mathrm{s}$ and $\mathrm{A}$ are differentiated by the primary $\mathrm{E}_{1}$-set, e.g. plix- $\varnothing$ ' $\mathrm{It}_{\mathrm{M}}$ is opened', and secondary $\mathrm{E}_{2}$-set, e.g. plix-é 'He has opened (sth.)'. The patient index may be a primary $\mathrm{L}_{1}$-set or secondary $\mathrm{L}_{2}$-set. (22) illustrates this tripartite pattern.

(22) Tripartite alignment for third person in the perfect in J. Urmi

\begin{tabular}{|c|c|c|c|}
\hline INTR. ${ }^{+} q t i$ & & $\begin{array}{c}s \\
E_{1} \text {-set }\end{array}$ & \\
\hline TR. ${ }^{+}$qtil- & $\begin{array}{c}\text { A } \\
\mathrm{E}_{2} \text {-set }\end{array}$ & & $\begin{array}{c}\mathbf{P} \\
\mathrm{L}_{1 / 2} \text {-set }\end{array}$ \\
\hline
\end{tabular}

TRIPARTITE

Finally, there is one subtle aspect in which A is isolated in an ergative fashion. The resultative participle only agrees with $\mathrm{A}$, and this is only overt in the feminine singular. No such overt agreement is found for S and P. Morphologically speaking, the transitive construction betrays more differentiation for a than for $\mathrm{P}$, which is also distinct from $\mathrm{s}$ for feminine singular arguments. The difference is not visible for the masculine singular and the common plural. We may illustrate this with the first person coding. The $\varnothing$ symbol indicates that we observe no difference with the intransitive verbs here:

(23) 1ms. ' ${ }^{+} q t i l-\varnothing$-ón-wa-la ' 'I $\mathrm{M}_{\mathrm{M}}$ had killed her.'

${ }^{+} d m i x-\varnothing$-ən-wa ' 'I $\mathrm{I}_{\mathrm{M}}$ had gone to sleep.'

ipl. +qtil- $\varnothing$-áx-wa-la 'We had killed her.'

${ }^{+} d m i x-\varnothing-\partial x-w a \quad$ 'We had gone to sleep.'

Although the inflectional bases of transitive verbs is diachronically different from those of intransitives, i.e. resultative participle qțilá + enclitic copula as opposed to perfective qtil- + E-set, synchronically, they comprise a single system.

The feminine singular, by contrast, shows an additional / $t$-element, which originally reflect the resultative participle form ${ }^{+} q$ tal-ta 'killed', inflected like an adjective. This is distinct from intransitive verbs, for example: 


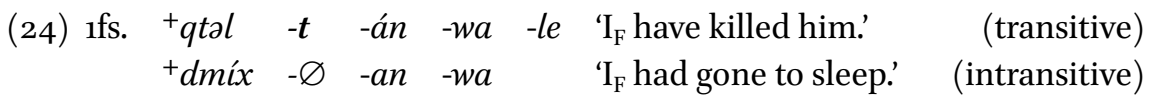

Hence, we observe an incidental special marking of A in the feminine singular. This agreement is not just gender-conditioned, but also conditioned by the A role. We observe, therefore, ergative agreement for the feminine singular, and accusative agreement for the masculine singular and the (common) plural. If this is correct, this would be an instance of a marked ergative agreement pattern. In the unmarked ergative type, only $\mathrm{S}$ and $\mathrm{P}$ trigger overt agreement (see $\S$ 4.2.1.2). By contrast, only A triggers overt participial agreement in gender here in Jewish Urmi.

\subsubsection{Sulemaniyya: Gender-Conditioned Ergativity}

The morphosyntax of compound verbal forms in Jewish dialects of Sulemaniyya and Halabja in NE Iraq is different from their Southeastern Trans-Zab peers in W Iran. The participle and copula mainly (though not always) undergo contraction in non-third person forms of the masculine singular and all forms of the plural. Which syllable is stressed, is an important cue to distinguish between these contracted perfect forms and their near-identical preterit counterparts (Khan 2004a, 99, 2005, 366):

\section{(25) smíx-ex 'We waited.' qțil- + E-suffixes \\ smix-éx 'We have waited.' qțila + enclitic copula}

The difference is more conspicuous in transitive constructions:
(26) šqál-lan 'We bought (sth.).'
qtil- + L-suffixes
šaqléx 'We have bought (sth.).' qțila + enclitic copula

Strictly speaking, the participial agreement is only apparent in uncontracted intransitive forms, which are the feminine and the third masculine singular, e.g.

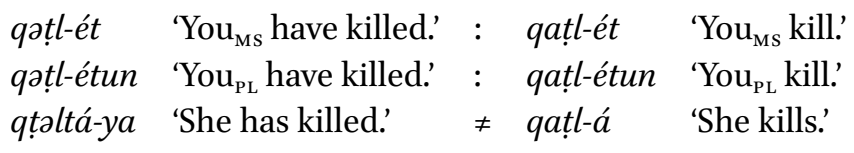

Other person indexes render the agreement obsolete as well, see (27) below for the full paradigm. 
(27) Perfect paradigms in J. Sulemaniyya (NE Iraq; Khan 2004a, 98; 2005) INTRANSITIVE TRANSITIVE

MS qțilá +COP qațlá +COP

3 smixá $-y$

2 smix-ét

'He has waited' šaqlá $-y$

'He has bought'

1 smix-ena 'You ${ }_{\mathrm{MS}}$ have waited' šaql-ét 'You ${ }_{\mathrm{MS}}$ have bought' 'I $\mathrm{M}_{\mathrm{M}}$ have waited' šaql-ena ' $\mathrm{I}_{\mathrm{M}}$ have bought'

FS qtiltá +COP qtaltá $+\mathrm{COP}$

3 smixta $-y a$ 'She has waited' šqalta -ya 'She has bought'

2 smixta $-y a t^{56}$ 'You ${ }_{\mathrm{FS}}$ have waited' śqalta $-y a t$ 'You ${ }_{\mathrm{FS}}$ have bought'

1 smixta -yan ' $\mathrm{I}_{\mathrm{F}}$ have waited' šqalta - yan ' $\mathrm{I}_{\mathrm{F}}$ have bought'

PL qtilé +COP qațlé +COP

3 smix-én 'They have waited' šaqlén 'They have bought'

2 smix-etun 'You $\mathrm{PL}_{\mathrm{PL}}$ have waited' šaql-etun 'You ${ }_{\mathrm{PL}}$ have bought'

1 smix-éx 'We have waited' šaql-éx 'We have bought'

Generally, the alignment is accusative in the perfect in J. Sulemaniyya. The participle and copula will agree with $\mathrm{A}$ and $\mathrm{s}$, and the object is marked independently, available for all persons just as in the progressive (see §3.3.2.3.), for example (Khan 2004a, 138)

qțilá-y 'all-óx 'He killed you.'

Dependent person markers may also be used as object indexes for the third person. The alignment is more complex, however. First of all, $\mathrm{P}$ is attached to the participle as a 'possessive' suffix, restricted to third person referents, e.g.

$\begin{array}{lllll}\text { 3ms. } & \text { qațl } & -e ́ w & \text { 'killed him' } & \text { (lit. killed his) } \\ \text { 3fs. } & \text { qațl } & -a ́ w & \text { 'killed her' } & \text { (lit. killed hers) } \\ \text { 3pl. } & \text { qațl } & -u & \text { 'killed them' } & \text { (lit. killed their) }\end{array}$

This parallels the marking of $\mathrm{P}$ in the preterit through the E-series. The copula in the perfect resembles the L-suffixes in the preterit. Compare the parallel sentences in preterit and perfect in (28) below.

56 The feminine singular forms in -yat and -yan may also contract, e.g. smixtá-yan > smixtán (Khan 2004a, 998). 
(28) J. Sulemaniyya (W Iran; Khan 2004a, 522 R:163)
$[\mathrm{P}]$
$[\mathrm{v}$
$-\mathrm{P}$
$-\mathrm{A}]$
a. ay-bratá
ma-ya
$m i \quad-t-a w$
$-y e t$ ?
DEM:FS-girl:FS what-COP:3FS bring:RPP -P:FS-P:3FS -A:2MS
'Why have you $_{\mathrm{MS}}$ brought this girl?'
b. aya ma-ya my $-\boldsymbol{a}$-lox?
DEM:FS what-COP:3FS bring ${ }_{\mathrm{PFV}}-\mathrm{P}: 3 \mathrm{FS}$-A:2MS
'Why did you $_{\mathrm{Ms}}$ bring her?'

These person indexes always pattern accusatively, the copula expressing $s$ and A. The resultative participle, however, can agree either with A or P in this construction. This depends on the gender(-number) hierarchy, given in (29) below.

\section{(29) Gender(-number) hierarchy \\ $\mathrm{FS}>$ non-FS (PL, MS)}

The participial agreement in gender and number with the feminine singular outranks the non-feminine irrespective of its role as either A or P. The masculine singular and the plural participial forms qațla and qațle coincide into qattlbefore the 'possessive' suffixes, which renders any distinction between the masculine singular and the plural obsolete. The main difference, then, is fs. qtal-tagainst non-fs. $q \partial t \underline{t}-\varnothing-$.

First of all, when all referents are non-feminine singular, participial inflection does not express anything other than non-feminine singular reference, so it could refer to either participant, as illustrated in (30). Forms like qatt-ewyex 'We have killed him' (3оa) and qatt-u-yet 'You ${ }_{\mathrm{ms}}$ have killed them' (3оc) are ambiguous with respect to their agreement with either A or P; their underlying declension could be qațla (ms.) or qațle (pl.) or no agreement at all. We simply cannot tell on the basis of these forms. The participial agreement of non-feminine singular forms is essentially neutral.

(30) Null agreement with the non-feminine singular $\mathbf{P} / \mathbf{A}$ (Khan 2004a)
$\mathrm{A} / \mathrm{P}=$ non-FS
$\mathrm{A} / \mathrm{P}=$ non- $\mathrm{FS}$
a. qațl $\quad-\varnothing \quad-e w \quad-y e x$
kill:RPP -NONFS -P:3MS -A:1PL
c. $q a t l l-\varnothing$
$-u ́ \quad-y e n a$
'We have killed him.'
kill:RPP -NONFS -P:3PL -A:1MS
'I $\mathrm{MS}_{\mathrm{S}}$ have killed them.'
$\left.\begin{array}{llllllll}\text { b. šmix } & -e ́ x & \left({ }^{*}-e ́\right. & -y e x) & \text { d. šmix } & \text {-ena } & \left({ }^{*}-a ́\right. & -y e n a\end{array}\right)$ wait:RPP -S:1PL $\quad$-S:PL $\quad$-S:1PL $\quad$ wait:RPP -S:1MS $\quad$-S:MS $\quad$-S:1MS 'We have waited.' ' ' $\mathrm{I}_{\mathrm{MS}}$ have waited.'


When feminine singular is involved, the participle will always express agreement with the feminine argument, irrespective of its role. Agreement with feminine singular arguments thus overrides agreement with non-feminine singular arguments (Khan 2004a, 137-138, 157).

When $P$ is feminine singular, the person markers align accusatively, but the participle agrees ergatively, grouping $\mathrm{s}$ and $\mathrm{P}$ in gender and number:

(31) Ergative agreement with $\mathbf{P}$ (Khan 2004a)

$$
\begin{aligned}
& \mathrm{P}=\mathrm{FS}>\mathrm{A}=\text { NONFS } \\
& \mathrm{P}=\mathrm{FS}>\mathrm{A}=\text { NONFS }
\end{aligned}
$$

b. šmix $\quad-t a \quad-y a$

wait:RPP -S:FS -S:3FS

'She has waited.'

When A is feminine singular, however, the participle groups $\mathrm{S}$ and $\mathrm{A}$ :

(32) Accusative agreement with A (Khan 2004a)

$$
\mathrm{A}=\mathrm{FS}>\mathrm{P}=\mathrm{NONFS} \quad \mathrm{A}=\mathrm{FS}>\mathrm{P}=\text { NONFS }
$$
a. $q$ țal $\quad-t \quad-e w \quad-y a$
c. $q$ țal $\quad-t \quad-u$
kill:RPP -A:FS -P:3MS -A:3FS
'She has killed him.'
'You ${ }_{\mathrm{FS}}$ have killed them.'
b. šmix $\quad-t a \quad-y a$
wait:RPP -S:FS -S:3FS
'She has waited.'
d. šmix $\quad-t a \quad-y a t$ wait:RPP -S:FS -S:2FS
'You ${ }_{\mathrm{PS}}$ have waited.' $-y a t$

kill:RPP -A:FS -P:3PL $\quad$-A:3FS

When all arguments are feminine singular, it is a moot point with which argument the participle agrees.

The same holds for the indexing of full NPs. When a full nominal P is not indexed, the participle agrees with $\mathrm{A}$, for example:

(33) Agreement with A like s (Khan 2004a, 490.72)
[A]
[P]
[v
$\left.\begin{array}{ll}-\mathrm{A} & -\mathrm{A}\end{array}\right]$
'ana noši... jullé kaldá xiț -ța -yan
I myself clothe:PL bride:FS sew:RPP -A:FS -A:IFS
'I $\mathrm{I}_{\mathrm{F}}$ myself (on my own) sewed the clothes of a bride.' 
When a full nominal $P$ is indexed, the gender determines participial agreement. A salient, feminine singular patient, such as ay-bratá 'this girl' in (34) below, may trigger overt participial agreement with $\mathrm{P}$.

(34) Agreement with P like s (Khan 2004a, 522.163)

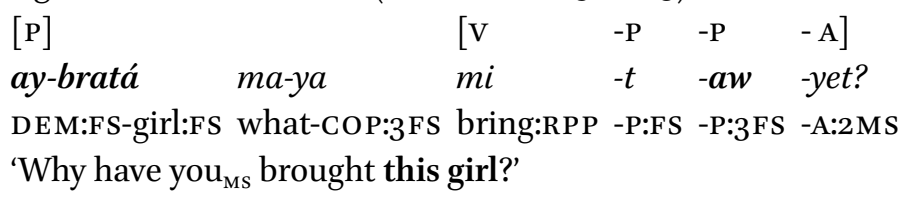

The alignment therefore depends on the properties of a co-argument. ${ }^{57}$ All functions S, A and P can trigger agreement. It only patterns either ergatively or accusatively, when a non-fs. argument is additionally involved. The nonfeminine singular arguments are ambiguous only in transitive clauses. Only non-feminine singular s triggers overt participial agreement, while A and P do not. The morphosyntax shifts in the direction of the morphologically more marked feminine singular, regardless of the function. Only A and P are treated differently depending on gender, while $s$ remains unaffected and the person indexes (i.e. the copula and the 'possessive' suffixes) remain accusative throughout.

We observed for J. Urmi that the overt gender agreement depends on both the argument type, i.e. feminine singular, and its grammatical function, i.e. A. In J. Sulemaniyya, however, it is the argument type, i.e. feminine singular, that triggers overt agreement, regardless of its grammatical function. Non-feminine singular arguments arguably do not trigger participial agreement in transitive clauses, since there is no overt morphology that distinguishes masculine singular or common plural. The resultative participle expresses agreement in gender and number with $\mathrm{P}$ only for the third person. The ergative grouping of $S$ and $P$, then, occurs only if $P$ is expressed as a dependent person form of the third person feminine singular and no competing feminine singular A is involved.

\subsubsection{Jewish NENA in West Iran: Ergative Third Person}

Southeastern Trans-Zab Jewish dialects of NENA in Iran, such as Sanandaj, Saqez and Kerend, differ drastically from those elsewhere in NENA, including Sulemaniyya and Halabja, which belong to the same Southeastern subgroup. The dialects differentiate between various moods and tenses of the perfect

57 See $\S$ 4.4.1.1. on this point raised by Witzlack-Makarevich et al. (2016). 
mainly by means of the verb hwy 'be'. Intransitive verbs can occur in all perfect constructions, for example:

(35) J. Saqez (W Iran; Israeli 1998, 110, 149) PRESENT PERFECT PAST PERFECT

REALIS dmixá-y

'He has fallen asleep'

IRREALIS dmixá $\varnothing$-hawé- $\varnothing$

'He may have fallen asleep' dmixēle < dmixáye-le

'He had fallen asleep' dmixá $\varnothing$-hawe- $\varnothing$-wa

'He would have fallen asleep'

Transitive perfect constructions are more restricted and peculiar. Both the copula and participle agree with the patient. This is a striking deviation from the more common pattern in the transitive realis perfects among NENA dialects. The copula always expresses the subject and agent in all of the NENA dialects except for these Jewish dialects in western Iran.

Consider the following hypothetical clauses in J. Urmi and J. Sulemaniyya. In J. Sulemaniyya, the participle agrees with the object only because of the gender hierarchy and the object is indexed by a 'possessive suffix' (see § 3.4.6, cf. $\S$ 2.2.5.1.). Nevertheless, the copula agrees with A regardless.

(36) Copula agrees with the agent

a. J. Urmi (NW Iran; Khan 2009, 7-8)

$\begin{array}{lllll}{[\mathrm{A}]} & {[\mathrm{P}]} & {[\mathrm{V}-} & -\mathrm{A} & -\mathrm{P}] \\ \text { šwaw-i } & \text { baxt-i } & \text { nšiq } & -e & -l l a\end{array}$
neighbor:MS-my woman:FS-my kissed:RPP -A:COP:3MS -P:3MS 'My neighbor has kissed my wife.' (lit. My neighbor is kissed her my wife)

b. J. Sulemaniyya (NE Iraq)

$\begin{array}{llllll}{[\mathrm{A}]} & {[\mathrm{P}]} & {[\mathrm{V}-} & -\mathrm{P} & -\mathrm{P} & -\mathrm{A}] \\ \check{s} \text { waw }-i & \text { baxt-i } & n s ̌ a q & -t & -a w & -y e\end{array}$
neighbor:Ms-my woman:FS-my kissed:RPP -P:FS -P:3FS -A:COP:3MS 'My neighbor has kissed my wife.' (lit. My neighbor is kissed hers my wife)

The corresponding sentence would be as follows in dialects in western Iran such as Sanandaj. Both the participle and the copula agree with the patient only. 
(37) J. Sanandaj (W Iran; Khan 20o9, 7-8)

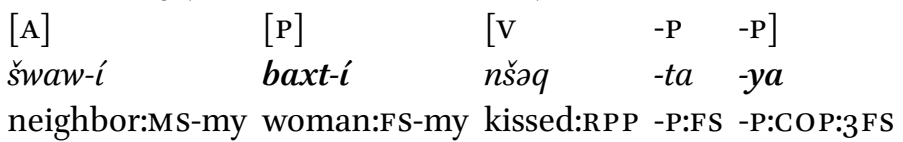

'My neighbor has kissed my wife.' (lit. My neighbor-my wife is kissed)

At the same time, in all three dialectal subgroups, pronominal P may be expressed by the 'al(l)-series (see $\S 3$.1.2.1), e.g.

$\begin{array}{lllll}\text { J. Urmi } & n s ̌ i q & -e & - \text { llax } & \text { 'He has kissed you }{ }_{\mathrm{Fs}} \text { ' } \\ \text { J. Sulemaniyya } & n ə \check{q} q a & -y & \text { 'วllax } & \\ \text { J. Sanandaj } & n ə \check{q} q a & -y & \text { 'alax } & \end{array}$

The perfect of Western Iranian Jewish dialects of NENA ${ }^{58}$ shows additional splits. Transitive clauses with two full NPs can freely occur in this construction, but pronouns are treated differently depending on person, showing, as we will see, ergative morphological marking for the third person and tripartite for the other persons. Furthermore, the trigger potential is also tripartite, with different degrees of possibility. $s$ agreement is obligatory and unconditioned, $\mathrm{P}$ agreement is possible, but conditioned, and A agreement is impossible. This, too, is linked with person in a horizontal way in that first/second person As and Ps are never expressed on this verbal form. Finally, contrasting with other dialects, the irrealis pendant of this construction patterns like the preterit.

\subsubsection{Verbal Person Marking in the Realis Perfect}

The marking of the patient is conditioned by person. Only the third person is overtly marked on the compound verbal form through the copula and participial agreement, much like the E-set in the preterit. Thus, the third person patterns ergatively only in the realis perfect:

(38) J. Saqez (W Iran; Hopkins 2002, 292)

[v-s]

a. dmix-ta-ya

(intransitive)

slept:RPP-FS-3FS

'She has slept.'

$5^{8}$ See Hopkins (2002) and Khan (2009, 90-92, 295-296, 323-326, 327-329). 

[A] $\quad[\mathrm{V}-\mathrm{P}]$
b. axonawal-i xzi-ta-ya
brother:PL-my seen-FS-3FS
'My brothers have seen her.'

(transitive)

The non-third person forms are necessarily expressed through a different set. This is the 'all-series of person markers, for example 'al-ax 'you' in J. Sanandaj (39b) below. Third person pronominals can also be expressed this way, e.g. băruxăwali garša-y 'al-ef 'My friends have pulled him', but they are not used in differential object indexing.

(39) Verbal vs. Prepositional marking (based on Khan 20o9, 324)

$$
\text { [A: fNP] [V-P: PRO 3] }
$$

a. băruxăwali grəš-te-ya- $\varnothing$

friend:PL-my pulled-P:FS-P:3FS

'My friends have pulled her/it $\mathrm{F}_{\mathrm{F}}$ '
[A: fNP $] \quad[\mathrm{v}]$
[P: PRO 1,2,3]
b. băruxăwali garša-y
'al-ax
friend:PL-my pulled(MS-3MS) OBJ-2FS
'My friends have pulled you $_{\mathrm{rs}}$ '.

If a speaker should wish to express an agent other than the third person, the simple form, which otherwise typically expresses the perfective past must be used instead of the compound verbal form (Khan 2009, 94). Thus, it is possible to say (41) below to convey either 'I saw the woman' (preterit) or 'I have seen the woman' (perfect), but it is not possible to include a non-third person agent in the compound form as illustrated in (40).
(40) **(aná) baxtaké xzita-ya
I woman:FS:DEF seen:FS-P:3FS
Intended: 'I have seen the woman.'

(41) (aná) baxtaké $\quad$ xazy-a-li
I woman:FS:DEF see PFV $^{-P: 3 F S-A: 1 S G}$
'I have seen the woman.' (or: 'I saw the woman.')

For third person agents as such, there are two distinct transitive constructions: garš- $a$-le 'He pulled her' for the preterit, i.e. perfective past, but grəštá-y '(He) has pulled her' for the realis perfect (J. Sanandaj, W Iran, Khan 2009, 94). For 
first and second person agents, the perfect must be expressed through a transitive qțil-construction, e.g. garš-a-li ‘I have pulled her' (Khan 2009, 284). The following variation in the realis perfect is found for a non-referential agent, an third person agent and a non-third person agent:

(42) Variation in agent-marking for the realis perfect (based on Khan 2009, 94)
INTRANSITIVE
$S$
a. Agentless:
$[1,2,3]$
grišté-yan 'I have been pulled'
TRANSITIVE
$P$
[3]
A
b. Agent 3rd person:
grəšt-é-y
[3]
$\varnothing \quad$ 'He has pulled her'
c. Agent 1st/2nd person: (qțil-based)
[3] A $[1,2]$ garš- $a \quad-l i \quad$ 'I have pulled her'

When we consider the person categories in isolation, there is an alignment split between ergative and tripartite. The qțil-based form necessarily also expresses the realis perfect for non-third person agents. The participial agreement and copula in the realis perfect align $\mathrm{S}$ and $\mathrm{P}$ ergatively for third person reference, while A is left unmarked $(\varnothing)$. The 'all-set attaches to qtalle expressing P for nonthird person reference, while $s$ is readily expressed through the construction based on the participle, so that each function is treated differently. The alignment pattern for non-third person arguments is therefore tripartite throughout (much as in the preterit).

(43) Ergative vs. tripartite alignment in the realis perfect (based on J. Sanandaj; Khan 2009)

FIRST/SECOND PERSON
TRIPARTITE

a. šmix-te-yan
'I $\mathrm{F}_{\mathrm{F}}$ have stood up'

b. grəš-li’al-ax

'I have pulled you ${ }_{\mathrm{FS}}$ '
THIRD PERSON ERGATIVE

c. šmix-te-ya

'She has stood up'

d. grəš-te-ya- $\varnothing$

'(They) have pulled her' (intransitive)

(transitive) 
In actual transitive clauses, the person categories are expressed differently depending whether they occur in A or P role. That is, there is both a person split in the coding of A and the coding of $\mathrm{P}$. The transitive form of the compound realis perfect as given in (43d) above is completely confined to the third person, both with respect to A and P. However, a third person agent may combine with a non-third person form of the all-series just as in the preterit, e.g. J. Sanandaj (Khan 2009, 324)

garša-y 'al-ax ' '(He) has pulled you ${ }_{\mathrm{Fs}}$ ' grəš-le 'al-ax 'He pulled you $\mathrm{Fs}^{\prime}$ '

\subsubsection{Full Nominals in the Realis Perfect}

The compound realis perfect freely combines with full NPs. When there is no overt agreement with either A or P, the verb takes an unmarked 3ms. form. Agreement with full nominal patients is only overtly expressed, when the NP is definite or referential indefinite (Khan 2009, 318-319, 326). In the following example, the indefinite $x a$ baxta in (44b) is salient and triggers overt agreement through both the participle and the copula, while baxta (44a) is not; and the lack of agreement is indicated by the non-referential dummy $3 \mathrm{~ms}$. verbal form.

(44) J. Sanandaj (W Iran; Khan 20o9, 326)
[A]
$[\mathrm{P}]$
[v]

a. tat-i

baxtá nəšqá-y

father:Ms-my woman:Fs kissed(:MS-3Ms)

'My father has kissed a woman.'
$[\mathrm{A}]$
b. tat $-i^{-}$
$[\mathrm{P}]$
[V-P]
father:MS-my one woman:FS kissed-P:FS-P:3FS
'My father has kissed a certain woman.'

By contrast, the agent NP never triggers agreement. This may be expected for ergative agreement morphology ${ }^{59}$ The zero realization of the agent is typologically unmarked for ergative agreement. ${ }^{60}$

\footnotetext{
59 One may be tempted to consider this form rather like a passive, since the agreement potential of A is even less than that of P. See $§ 3.5 \cdot 3$. for arguments why these clauses should not be treated as passive.

6o See Subsection 4.2.1. on typological markedness and ergativity in relation to NENA dialects.
} 


\subsubsection{The Irrealis Perfect}

Turning to other moods and tenses of the perfect, the same pattern occurs in the irrealis perfect. In the past realis perfect, the preterit of the (weak) verb hwy 'to be' is inflected with $\mathrm{L}_{1}$ - suffixes (yele 'He was') and is employed to expressed a past tense copula, the past counterpart to the enclitic copula $(-y(e)$ 'He is'). The past copula is employed in intransitive perfect constructions, but this cannot be employed in a transitive pluperfect construction, cf. J. Saqiz (Israeli 1998, 110,149 )

baxtaké dmaxtá-yela 'The woman had slept.'

**baxtaké xzitá-yelan intended: 'We had seen the woman'

There is therefore no past tense counterpart to the present perfect.

There is, however, an equivalent irrealis perfect. Instead of the copula, the subjunctive of $h w y$ 'be', i.e. $\varnothing$-hawe- 'may be' against realis base $k$-we- 'is, shall be', is combined with the resultative participle, e.g. dmaxtá-hawy-a 'She would have slept' (J. Saqez, Israeli 1998, 119). The two elements often have phonetically reduced contracted alternants, fusing into one conjugational form through elision, compare rqilé-hawen(i) and rqilá-wen(i) 'They would have danced' (J. Kerend, Hopkins 2002, 291 ff.). ${ }^{61}$ The irrealis transitive perfect is based on the same morphological elements, but freely allows agent-marking through the use of $\mathrm{L}_{1}$-suffixes to the subjunctive $h w y$ in the same way as the preterit, e.g. graštáhawy-a 'pulled her' + -le 'he' > graštáwy-a-le 'He would have pulled her' (lit. Him may be pulled she). The person indexes consist of the $\mathrm{L}_{1}$-series to mark A and the $\mathrm{E}_{1}$-series ${ }^{62}$ to mark $\mathrm{S}$ and $\mathrm{P}$. Table 17 below offers an overview.

The functional distribution of the $\mathrm{E}_{1}$-set and the $\mathrm{L}_{1}$-set in the irrealis perfect is equivalent to that in the preterit. The morphosyntax is once again ergative in the expression of the third person, which is all the more striking given that the inflectional base $\varnothing$-hawe 'may/would be' is, in fact, ultimately a qatal-form. Other NENA dialects that have similar coding devices in an irrealis perfect construction have an alignment as fully accusative as qațl-. In J. Urmi, for example, graštá-hawy-a-le would mean 'She may have pulled him' (Khan 20o8b, 142), not 'He may have pulled her'. Thus we observe the following contrast:

61 Cf. Khan (2009, 92) for J. Sanandaj.

62 The inflection is, nonetheless, based on the paradigm of final-y verbs as expected for the verb hwy. 


\begin{tabular}{|c|c|c|c|c|}
\hline & \multicolumn{4}{|c|}{ INTRANSITIVE } \\
\hline & BASE & s & & \\
\hline & qțila + hawe & $\mathrm{E}_{1}$-SET & & \\
\hline \multirow{6}{*}{$\begin{array}{l}3 \mathrm{MS} \\
3 \mathrm{FS} \\
3^{\mathrm{PL}}\end{array}$} & rqil-awe & $-\varnothing$ & & 'He may have danced' \\
\hline & rqilt-awy & $-a$ & & 'She may have danced' \\
\hline & rqil-áwe & $-n(i)$ & & 'They may have danced' \\
\hline & \multicolumn{4}{|l|}{ TRANSITIVE } \\
\hline & BASE & $P$ & \multicolumn{2}{|l|}{ A } \\
\hline & qoțla + hawe & $\mathrm{E}_{1}$-SET & \multicolumn{2}{|l|}{$\mathrm{L}_{1}-\mathrm{SET}$} \\
\hline $3 \mathrm{MS}$ & garš-áwe & $-\varnothing$ & $-l e$ & 'He may have pulled him' \\
\hline $3 \mathrm{FS}$ & grošt-áwy & $-a$ & $-l e$ & 'He may have pulled her' \\
\hline $3 \mathrm{PL}$ & garš-áwe & $-n i$ & $-l e$ & 'He may have pulled them' \\
\hline
\end{tabular}

DATA BASED ON HOPKINS (2002)

(45) Contrasting the irrealis perfects of J. Urmi and J. Saqiz
J. Urmi (Khan 2008b)
J. Saqiz (Israeli 1998)

ACCUSATIVE

ERGATIVE

a. ${ }^{+}$dməx-tá-hawy-a

'She may have slept.'

c. dmax-tá-hawy-a

'She may have slept.'

b. graš-tá-hawy-a-le

d. grəš-t-áwy-a-le

'She may have pulled him.'He may have pulled her.'

The two irrealis perfect constructions in the two distinct Jewish dialects mirror each other's morphosyntax. It would seem that the ergative coding of qtil- lies at the base of the irrealis inflectional base qatlawe- in Southeastern Trans-Zab Jewish dialects in western Iran like Kerend, while in Northern Trans-Zab Jewish dialects in northwestern Iran like Urmi the construction is based on qațal-. Both can be accounted for on system-internal grounds.

Table 18 at the end of this subsection below gives a brief overview of the ergative patterns attested in the Western Iranian dialects. Morphologically 
speaking, the three TAM-categories preterit, irrealis perfect and realis perfect constitute a separate uniform subsystem, which operates according to principles non-existent in other TAM morphology within these dialects. There is a primary distinction between intransitive and transitive inflectional bases for sound verbs throughout. The two perfects are based on allomorphs of qțil- in the preterit along with its accompanying ergative morphosyntax. Finally, the coding associated with $\mathrm{S}$ and $\mathrm{P}$ is directly linked with this aspectual stem and marked as close as possible to the verbal base.

Interestingly, it is the realis perfect that is morphosyntactically less transitive than the irrealis, while, semantically, realis mood is said to be a key feature of ergative transitive constructions (e.g. Hopper and Thompson 1980). Although both essentially employ a verbal adjective, the irrealis incorporates the copula verb hwy into a new inflectional base that can be conjugated like the preterit. This facilitates the use of $\mathrm{L}_{1}$-suffixes to mark the agent.

The realis transitive perfect (qatlá-y) is the most restricted of the three in not permitting the expression of non-third person arguments as either P or A. Although this is reminiscent of the passive voice, it otherwise qualifies as an active transitive construction (see $\$ 3 \cdot 5 \cdot 3$ ). Absence of overt A coding could be explained by the unique nature of the construction itself. Since both the participle and the copula always agree with P, no agreement morphology is available for the agent, while the copula would always express A in other dialects. Moreover, the copula is not mobile in these realis perfect forms and cannot be combined with the $\mathrm{L}_{1}$-suffixes, the $\mathrm{L}_{2}$-series or the 'all-series to encode $\mathrm{A}$, so that the following forms are impossible:

$$
\begin{array}{lll}
\text { ***nqəšté-ya } & -l i & \text { intended: 'I have kissed her.' } \\
\text { **slí } & \text { nqəšté-ya } & \text { (lit. Me is kissed she) }
\end{array}
$$

This may be blocked because of system-internal pressure from the differential prepositional marking with ('al)l-. Nevertheless, one would expect that the copula would become available as an agent index, when it need not mark the patient. This is not what we find. Instead, even when the patient coding attaches to the compound verbal form, the unmarked 3ms. is still preferred, leaving the agent unexpressed, e.g. J. Saqez (W Iran; Israeli 1998, 117)

nəšqa-y -li '(He/she/they) have kissed me' 
TABLE 18 Ergativity in Jewish NENA in the preterit and beyond

\begin{tabular}{llll}
\hline & Base $_{\mathbf{P F V}}$ & $\mathbf{S} / \mathbf{P}$ & $\mathbf{A}$ \\
\hline & & {$[3]$} & {$[1,2,3]$} \\
PRETERIT & $\begin{array}{l}\text { rqil- } \\
\text { qțal-/qațl- }\end{array}$ & $\mathrm{E}_{1}$-SET & \\
& & $\mathrm{E}_{1}$-SET & $\mathrm{L}_{1}$-SET \\
& & {$[3]$} & {$[1,2,3]$} \\
IRREALIS PERFECT & $\begin{array}{l}\text { rqiláwe } \\
\text { qațláwe }\end{array}$ & $+\mathrm{E}_{1}$-SET & \\
& $+\mathrm{E}_{1}$-SET & $\mathrm{L}_{1}$-SET \\
& & & \\
& & {$[3]$} & {$[3]$} \\
REALIS PERFECT & rqilá & $+\mathrm{COP}$ & \\
& qațlá & $+\mathrm{COP}$ & $\varnothing$ \\
\hline
\end{tabular}

DATA BASED ON KHAN (2009, 94) AND HOPKINS (2002, 297)

\subsection{Ergativity and Transitivity: Argument Omission and Valency Alternations}

Maintaining our focus on Southeast Trans-Zab Jewish varieties, we have observed that most intransitive verbs are inflected like P only in the third person, the first and second person being treated differently. Many of intransitive verbs with coding distinct from A generally express a situation oriented towards a single participant that registers

- a state or (dis)position, such as zade- $\varnothing$ 'be afraid';

- a transitory state, e.g. naxip- $\varnothing$ 'be ashamed', kanip- $\varnothing$ 'become hungry';

- or an uncontrolled process, such as pil- $\varnothing$ 'fall', mil- $\varnothing$ 'die', šare- $\varnothing$ 'slip' (Khan 2004a, 298-305).

Not all intransitive constructions, however, follow this pattern; others take Lsuffixes like A. Placing this within a typology of transitivity alternations, can we predict when a verb takes either E-suffixes or L-suffixes, respectively, when the referentiality of the patient or agent is reduced or completely omitted? As it happens, many verbs can take both, and this is reminiscent of fluid subject marking, i.e. semantic alignment, where verbs take $s_{P}$ or $s_{A}$ coding. In these NENA dialects, however, this only applies to the third person. For practical considerations, I will speak in terms of $s_{P}$ or $s_{A}$ coding. Nevertheless, I remain non-committal to the view that considers this a system sui generis. It seems to 
me consistent with the cross-linguistic typology of transitivity that is largely determined by lexical semantics rather than the presence of a syntactic object. The difference in subject coding unfolds because A in the perfective past or qțil- is distinguished from A in the imperfective or qațal-, while $\mathrm{s}$ is treated alike in both systems. Where ergative alignment is found cross-linguistically, the salience of the patient can be reduced either through morphosyntactically intransitive constructions, such as the antipassive, or through morphosyntactically transitive constructions, such as an anti-impersonal construction. The patient is oblique or completely omitted in the antipassive ${ }^{63}$ as the counterpart to the oblique or absent agent in the passive. An anti-impersonal construction is the counterpart to the impersonal passive: the referentiality of $P$ is reduced, but some third person morphology and/or transitive coding is maintained. ${ }^{64}$

\subsubsection{Patient Omission: Lexical Transitivity}

Some languages that betray ergative morphosyntax opt for intransitive coding even though the orientation remains directed towards the agent (cf. Comrie $1978,358 ; 1975,118)$. In Samoan (a Polynesian language), for example, verbs that allow the dropping of the patient, such as 'eat', conform to the coding of other intransitive predicates, including agent-oriented intransitives, such as 'run away'.

(1) Samoan (Polynesian, Samoa; Mosel and Hovdhaugen 1992, 108, glossing adapted)

$[\mathrm{v}] \quad[\mathrm{A}] \quad[\mathrm{P}]$

a. $S \bar{a}$ 'ai $e$ le teine $\varnothing$ le i'a

PST eat ERG the girl ABS the fish

'The girl ate the fish.'

$[\mathrm{v}] \quad[\mathrm{s}]$

b. $S \bar{a}$ 'ai $\varnothing$ le teine

PST eat ABS the girl

'The girl ate.'

$[\mathrm{v}] \quad[\mathrm{s}]$

c. $S \bar{a}$ sola $\varnothing$ le teine $\quad$ (agentive intransitive)

PST run.away ABS the girl

'The girl ran away.'

63 See Givón (199o, 624-628), Cooreman (1994), Payne (1997, 220).

64 See Lazard $(1998,137)$. Cf. Comrie $(1978,118)$. 
Often, however, languages that exhibit non-accusative alignment will also have a set of verbs that take A-like subject marking within their system, reminiscent of split-s systems. In Basque, for example, when an otherwise transitive verb 'eat' occurs in an intransitive construction, it may maintain A-like subject coding. The 3 sg. is the unmarked form of the verb and therefore non-referential in the meaning of 'Martin ate', but it indicates that morphosyntactically some transitivity is preserved (Comrie 1978, 118):

(2) Basque (Comrie 1975, 118, 1978, 333, 358)

$$
[\mathrm{ABS} \rightarrow \mathrm{S}] \quad[\mathrm{v}]
$$

a. Martin ethorri da.

Martin-ABs came AUX-3sG:S

'Martin came.'

$$
[\mathrm{ERG} \rightarrow \mathrm{S}(\mathrm{A})][\mathrm{V}]
$$

b. Martin-ek jan du.

Martin-ERG ate AUX-3SG:A(-3SG:P)

'Martin ate.'

Generally, Southeastern Trans-Zab Jewish nena fits the profile of Basque, maintaining transitivity coding in allowing for some verbs to be lexicalized like transitives. Effective transitive verbs, such as ' $x l$ 'eat' and $p q y$ 'shoot', may omit the patient, while the coding of the agent remains the same. In (3a-b), for example, the patient tfanga may be freely omitted and the L-suffix encodes the agent:

(3) J. Sulemaniyya (NE Iraq; Khan 2004a, 297, 301)

$$
[\mathrm{P}] \quad[\mathrm{V}-\mathrm{A}]
$$

a. tfanga pqe-le

rifle:FS shoot ${ }_{\mathrm{PFV}} \mathrm{A}: 3 \mathrm{MS}$

(patient specified)

'He shot a gun.'

$$
[\mathrm{V}-\mathrm{S}(\mathrm{A})]
$$

b. pqe-le

shoot $_{\mathrm{PFV}}-\mathrm{A}: 3 \mathrm{MS}$

(patient unspecified)

'He shot.'

Since agent-like marking can be maintained for lexicalized transitive verbs, the dividing line between ergative alignment and split-s marking is not always clear, although fluid- and/or split-s marking systems are sometimes character- 
ized as an alignment type sui generis (e.g. Mithun 1991). Comrie (2005, 399) considers that, when it is only a small number of verbs that take A-like subject coding, the pattern instantiated by the majority of verbs is the basic alignment at least for comparative purposes. Indeed, there seems to me no reason to conclude that the transitivity alternation displayed by languages like J. Sulemaniyya, or like Basque in (2) above for that matter, renders their ergative morphology more 'split-ergative' than that in languages like Samoan, which display the alternation illustrated in (1). By contrast, some scholars consider the latter a kind of split conditioned by the nature of the object. In her survey of these alternations, Woolford (2015), for instance, argues that the types like (2) and (3) are more fully ergative than the types like (1) conditioned on the object, and that it remains questionable whether ergative patterns exist that are purely grounded in transitive syntax rather than in additional semantic factors. Each approach depends on what type one considers more basically ergative than the other, though we have no a priori reason to consider (2) and (3) more 'superficially ergative' than (1), perhaps except for the fact that (2) and (3) remind us of the similar alternation in accusative patterns.

Thus, while one could consider SE Trans-Zab Jewish displaying a type of semantic alignment, for all other purposes, they show ergative verbal person marking in the third person. As we will observe in $\S 3.5 .2$, some causative/ inchoative alternations (Haspelmath 1993b) follow the opposite pattern reminiscent of the antipassive in (lb), i.e. P-like subject coding. By contrast, the stronger the implication of a patient, the more likely A-like coding. Those verbs that are most likely to receive agent-like coding (i.e. the L-set) in SE Trans-Zab Jewish are those that at least imply a change in a patient-like argument, even when no such patient argument is expressed explicitly. These include transitive verbs of which the patient may be omitted, e.g. xal-le 'He ate', in which the ergative coding of A is retained. As Khan points out (2009, 303):

The use of the transitive inflection for these verbs, therefore, can be explained by the fact that there is an implied 'latent' affectee of the action, although this is not necessarily specified.

Complex predicates or light verb compound constructions (sometimes also termed phrasal verbs) also involve reduced referentiality of the patient, but may still maintain transitive coding. This is a typical feature of Iranian languages, but also occurs in several NENA varieties, in many cases due to contact with neighboring languages (Kapeliuk 2002). In such light verb constructions, a non-referential dummy nominal element is incorporated in the verbal con- 
struction as a single constructional unit. In Vafsi (Tati, Northwestern Iranian; p.c. Stilo), for example, the verb $d a$ - 'give' may combine with the NP sezne 'sneeze' to convey the meaning of 'sneeze' (lit. 'to sneeze-give'). The choice of $s_{A}$ or $\mathrm{s}_{\mathrm{P}}$, however, is largely determined by the light verb and may be semantically arbitrary (Creissels 20o8b; Haig 2008, 11). The verb gen-/kcett- 'fall', for example, may combine with the NP rá 'road' to convey the meaning of 'set off' (lit. 'to road-fall') and takes $\mathrm{s}_{\mathrm{P}}$ coding despite its agentive semantics. By contrast, less controllable or uncontrollable situations, such as cerceq kcerd- 'sweat', take $\mathrm{s}_{\mathrm{A}}$ coding because of the otherwise transitive light verbs, such as kcerd- 'do' or da'give'.

Such complex predicates or light verb constructions where the verb takes a dummy full NP also occur in NENA, most of which are replicated either in material or pattern from Persian and/or Kurdish combining with ' $w l$ 'do' or $x \varnothing r$ 'become' (e.g. Khan 20o9, 153), e.g.

J. Sanandaj

'ila

hand

\section{Central Kurdish}

$\begin{array}{ll}\text { dast }-\hat{\imath} & \text { kird 'He began' } \\ \text { hand-A:3Ms } & \text { did }\end{array}$

The verb itself determines $\mathrm{s}_{\mathrm{A}}$ coding or lack thereof. A light verb construction may also involve non-Iranian material, such as milá 'circumcision' from Hebrew, and can also combine with additional object coding on the verb or on the nominal element, e.g. (Khan 2009, 154, 160-161)

$\begin{array}{lll}\text { milá } & \text { xir- } \varnothing & \text { 'He was circumcised.' } \\ \text { tahdíd } & \text { wil-a-le } & \text { 'He threatened her.' } \\ \text { da'wăt-óx } & \text { wi-le } & \text { 'He invited you }{ }_{\mathrm{Ms}} .\end{array}$

Animal noises or sound emission verbs, such as 'bark', more or less controllable bodily responses, such as 'sneeze' and 'laugh', and manner of motion verbs, such as 'dance' and 'run', are a common exception in taking agent-like/transitive coding in languages with ergative constructions (Lazard 1998, 136-139). They typically include verbs whose lexical aspect belongs to situations that are called semelfactive (Comrie 1976, 42). This term is used to distinguish a punctual atelic predicate involving an instantaneous event, i.e. happening only once, from an iterative atelic one with a serial meaning, i.e. happening in a series. Lazard $(1998,139)$ suggests that such verbs tend to take $\mathrm{s}_{\mathrm{A}}$ coding, because they imply a single, instant, manifestation impressing on a perceiver via the senses that is, morphosyntactically, realized in the reduced referentiality of the patient. Some of the verbs in dialects like J. Sulemanniya that are semantically 
intransitive, but combine with $\mathrm{s}_{\mathrm{A}}$ coding belong to semantic fields of the antiimpersonal constructions mentioned by Lazard $(1998,139)$, e.g. J. Sulemaniyya (Khan 2004a, 583)

$\begin{array}{llll}\text { tiffe } & \text { di-le } & \text { 'spit' } & \text { (lit. spit-hit) } \\ \text { cirike } & \text { di-le } & \text { 'shout' } & \text { (lit. shout-hit) } \\ \text { bora } & \text { di-le } & \text { 'low, bellow (cow)' } & \text { (lit. bora-hit) }\end{array}$

Indeed, such semelfactive verbs do tend to take $\mathrm{s}_{\mathrm{A}}$ coding in these dialects. This includes animate and inanimate sound emissions and bodily emissions and reactions such as phr 'yawn', šhl 'cough', and so forth. They are not equivalent in all dialects (see further below). In J. Sulemaniyya, all such semelfactive verbs are inflected like A:

(4) Semelfactives (J. Sulemaniyya; Khan 2004a, 300, 2007a, 151; transcription adapted)

a. kalbá nwax-le 'The dog barked.'

b. 'ewá gargam-le 'The cloud thundered.'

The implied effect is morphosyntactically realized in an implicit $\mathrm{P}$ that that triggers transitive coding. This can be made explicit through cognate objects much like xalá xal-le 'He ate food', for example:

c. (tapoltá) tpal-le 'He sneezed (a sneeze).'

Another possible reason why these verbs tend to take $\mathrm{s}_{\mathrm{A}}$ coding is they correspond to local Central Kurdish complex predicates composed of kirdin 'do' and an indefinite noun phrase (Khan $2007 \mathrm{~b}$ ), which are lexically transitive.

In omitting the patient, a particular set of verbs pertaining to grooming and putting on may take transitive coding, but invoke a reflexive meaning contrasting with the aforementioned verbs:

\section{(5) J. Sulemaniyya (NE Iraq)}
$[\mathrm{P}]$
[V-P-A]
a. jal-éf lawš-i-le
(patient specified)
clothes:PL-his dress ${ }_{\mathrm{PFV}}-\mathrm{P}: 3 \mathrm{PL}-\mathrm{A}: 3 \mathrm{MS}$
'He put on his clothes.' (Khan 2004a, 303) 

$\left[\mathrm{V}-\mathrm{S}_{\mathrm{A}}\right]$
b. lwaš-le
dress $_{\mathrm{PFV}}-\mathrm{A}: 3 \mathrm{MS}$
'He got dressed (i.e. dressed himself).' (ibid. 258)

(patient unspecified)

This reflexive meaning is semantically restricted; thus, a verb such as $x ə l-l a$ 'She ate' would not be considered reflexive without further specification. Such a reading would require an explicit reflexive pronoun, such as noš- $a w$ 'herself' (; Khan 2004a, 300). While the agent of reflexive verbs is much more so affected than other verbs such pqe-le 'shoot' and $x a l$-le 'eat' that have an implicit patient, one could view the explicit patient in $(5 \mathrm{a})$ as a supplementary extension of a self-oriented action. That is, clauses like jal-éf lawš-i-le 'He put on his clothes' literally mean 'He dressed (in) clothes'. There is indirect evidence for this in the corresponding derived causative of this verb, where the additional object is also semantically secondary but more object-like, e.g.

\section{c. jullé labl-i-wa julle malbiš-i-wa-le}

clothes:PL take ${ }_{\mathrm{PFv}}-\mathrm{A}: 3 \mathrm{PL}-\mathrm{PST}$ clothes:PL III:dress ${ }_{\mathrm{PFV}}-\mathrm{A}: 3 \mathrm{PL}-\mathrm{PST}-\mathrm{P}: 3 \mathrm{MS}$ 'They took his clothes and dressed him in clothes' (Khan 2004a, 566.13), lit. 'they used to dress him clothes'.

Another possibility is that the transitive coding is influenced by the Kurdish equivalent complex predicate, e.g. jil nān 'to put on clothes', lit. 'clothes-do'.

Purely morphological factors can also be important determinants. As expected, the absence or presence of object coding can result in A-like coding. First, there are intransitive verbs that exhibit dummy, non-referential 3 fs. object coding, compare $(6 \mathrm{a}-\mathrm{b})$ below. Lazard $(1998,137)$ calls this an anti-impersonal construction. The referentiality of $\mathrm{P}$ is reduced, but some third person morphology is maintained. A-like subject coding is used, because the E-suffixes are reserved for the non-referential P. Hence, a verb like $g x k$ 'laugh' in (6a) is generally treated differently from $b x y$ 'cry'. A single lexeme ' $r q$ in (6b) can express a semantic distinction between 'flee' and 'run' that is reflected in the type of inflection. ${ }^{65}$ The verb $g x k$ 'laugh' can also occur without transitive coding to express an incidental occurrence of laughter (Khan 2009, 308).

65 Semantically, verbs that exhibit a dummy object typically belong to the middle voice (cf. Mengozzi 2005). See Kemmer (1993) on the semantics of the middle voice. 
(6) Verbs with non-referential 3 fs. object (J. Sanandaj; Khan 20o9, 307-308)

a. gaxk-a-le 'He laughed' vs. baxe- $\varnothing$ 'He wept'

b. 'arq-a-le 'He fled' vs. riq- $\varnothing$ 'He ran'

When such verbs take a prepositional complement, the coding remains A-like, e.g. gaxk-a-le ga-i 'He laughed at me' (Khan 20o9, 515). Dialects may differ in this respect; compare $p s x^{\prime}$ 'rejoice' in Jewish Saqez and Sanandaj:

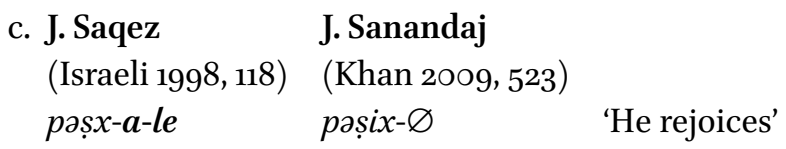

The same verb $p s ̦ x$ 'rejoice' takes A-like coding and combines with a prepositional complement in Jewish Sulemaniyya:

\section{(7) J. Sulemaniyya (NE Iraq; Khan 2004a, 582) \\ $[\mathrm{V}-\mathrm{S}(\mathrm{A})] \quad[\mathrm{OBL}]$ \\ pșax-le ba'-éu 'He was happy with him'}

The verb hwy 'be' takes A-like subject coding in all these dialects. This is most likely morphologically motivated, as the L-suffixes are presumably a means to express the past. A paradigm based on the E-series would have been morphologically identical to the present copula forms. Compare the forms for J. Sulemaniyya (Khan 2004a) below:

\begin{tabular}{llll} 
(8) PAST & \multicolumn{3}{c}{ PRESENT } \\
-ye-le & 'He was' & $-y e-\varnothing$ & 'He is' \\
-ye-la & 'She was' & $-y-a$ & 'She is' \\
-ye-lan & 'We were' & $-y-e x$ & 'We are' etc.
\end{tabular}

Finally, agent coding may also occasionally be extended to intransitive verbs when they co-occur with a transitive verb. The L-suffixes that mark the agent of a transitive verb are attracted to an immediately preceding intransitive verb. Normally, the intransitive verb zyl 'go' is inflected with E-suffixes, but in (9) below it takes an L-suffix to index the subject argument due to the following transitive verb:
(9) 'ay-zíl-wa-la
mír-wa-la
baqa Marza Xănăká
she-go PFV -PST-S:3FS say ${ }_{\text {PFV }}$-PST-A:3FS DAT PRN PRN 
The majority of intransitive verbs, however, will not take $\mathrm{s}_{\mathrm{A}}$ forms in Southeastern Trans-Zab Jewish dialects. They do not show the same coding as the agent in the corresponding transitive valence pattern, if it exists. Khan (2004a, $\left.{ }^{295}{ }^{-305}\right)^{66}$ explains such exceptions on the basis of transitivity in a broader semantic sense, to which we turn in the following subsection.

\subsubsection{Agent Omission: Ergative and Antipassive Typology}

Transitive and intransitive verbs can show causative/inchoative alternations (Haspelmath 1993b), where both verbs express a similar situation, but the intransitive pendant omits a cause, denoting a spontaneous process; hence the term inchoative as the process of entering into a state, such as 'break' in English My leg broke in the sense of 'become broken'. When transitive and intransitive morphosyntax differ in a transitivity alternation, the intransitive pendant of a valence alternation will show distinct subject coding from the agent in the transitive counterpart through what is called the antipassive voice. This is considered to be a hallmark of ergative typology (e.g. Keenan 1976, 313; Comrie 1988, 18-19).

Cognitive linguists have indicated several tendencies in linguistic typology that seem to point to a correlation between reduced semantic or less prototypical transitivity and reduced or less prototypical morphosyntactic transitivity. At the same time, such valence alternations marked by voice show constructionspecific and language-specific properties.

\subsubsection{Ergativity: Causative/Inchoative Alternations}

The omission of A can still yield well-formed sentences in languages that otherwise exhibit an ergative pattern (cf. Keenan 1976, 313; Comrie 1988, 18-19). For instance, Samoan, a Polynesian language, allows the absence of agent coding for most transitive verbs, such as 'hit' in (10) below (Mosel and Hovdhaugen $1992,104)$. The agent of the corresponding active transitive clause is omitted in $(1 \mathrm{ob})$, and the resulting construction is similar to the passive in that an impersonal agent may still be implied. The agent, therefore, is more loosely integrated in the clause in being freely omitted and unspecified, much like oblique agents in the passive, but there is no special verbal morphology indicating a voice shift.

66 Cf. Khan (2007a, 148-152, 2008b, 73-75, 2009, 302-308). 
(10) Samoan (Polynesian, Samoa; Mosel and Hovdhaugen 1992, 416, 421; glossing adapted)

[v] [ERG $\rightarrow \mathrm{A}] \quad[\mathrm{P}]$

a. $S \bar{a}$ sasa $e$ le teine $\varnothing$ le maile (specified agent)

PST hit ERG the girl ABS the dog

'The girl hit the dog.'

[v] [s/P?]

b. $S \bar{a}$ sasa $\varnothing$ le maile (agentless/unspecified agent)

PST hit ABS the dog

'The dog was hit.' / 'Someone hit the dog.'

Naturally, the coding is indistinct from the $s$ in intransitive constructions, such as 'fall' in (10c), because of ergative alignment:

$[\mathrm{v}] \quad[\mathrm{s}]$

c. $S \bar{a}$ pa'ū $\varnothing$ le teine

PST fall ABS the girl

(intransitive)

'The girl fell.' (Mosel and Hovdhaugen 1992, 108)

An alternation that does not involve a change in verbal morphology is considered labile. A valency alternation for an ambivalent verb like open in English, for example, does not involve a change in morphological marking. Ambitransitive verbs like English open can have transitive and intransitive uses.

Anticausatives may be distinguished from passives through special morphology. Samoan, for example, shows an anticausative alternation for verbs such as 'break', as illustrated in (11) below. The anticausative morpheme ma is added to the verb to detransitivize the event, shifting the viewpoint to an affectee of a spontaneous process rather than an action performed by an agent (Mosel and Hovdhaugen 1992, 738).

(11) Samoan (Polynesian, Samoa; Mosel and Hovdhaugen 1992, 738, glossing adapted)

$[\mathrm{P}] \quad[\mathrm{A}]$

a. $S \bar{a}$ fa'i $\varnothing \quad l=o=' u \quad$ nifo $e$ le föma'i.

PST break ABS the $=$ POSS=1SG tooth ERG the doctor

'The doctor pulled my tooth out.' (causative) 
$[\mathrm{s}]$

b. 'ole'a $m a=f a$ 'i nifo!

FUT DTR=break tooth

'My teeth are about to break off!' (inchoative)

In some languages where ergative morphosyntax predominates (such as Lezgian, Haspelmath 1993a), however, there is no distinction in verbal morphology between verbs that freely omit the agent and spontaneous events.

Weak verbs show such labile alternations in Southeastern Trans-Zab Jewish varieties, though, naturally, the ergativity is limited to the third person. The agentless form generally denotes a spontaneous event, which indicates that the agent may be completely absent as with a patientive intransitive verb (such as pil- $\varnothing$ 'He fell'). In (12) below, a verb like $p q y$ 'shoot, burst' can lack agent indexing. The agent agreement is present and the L-suffixes mark the agent in (12a). The verb takes no agent index in (12b) and the agent is left unspecified.

(12) J. Sulemaniyya (NE Iraq; Khan 2004a, 297)

$[\mathrm{P}] \quad[\mathrm{V}-\mathrm{P}-\mathrm{A}]$

a. tfangăké paqy-a-le

(specified agent, causative)

rifle:FS:DEF shoot $_{\mathrm{PFV}}-\mathrm{P}: 3 \mathrm{FS}-\mathrm{A}: 3 \mathrm{MS}$

'He fired the rifle.'

$[\mathrm{s}] \quad\left[\mathrm{v}-\mathrm{S}_{\mathrm{P}}\right]$

b. tfangăké paqy-a

(agent unspecified/inchoative)

rifle:FS:DEF shoot ${ }_{\mathrm{PFv}}-3 \mathrm{FS}$

'The rifle was fired (by sb.).'

'The rifle exploded.'

At a first glance, agent coding seem to be simply deleted, so that forms like paqy-a ' $\mathrm{It}_{\mathrm{F}}$ exploded' are to some extent analyzable as truncated transitive forms conveying '(Somebody) fired the rifle'. In leaving the agent unexpressed, the question arises whether the construction is morphosyntactically still transitive or not (cf. Keenan and Dryer 2007, 330). Is the patient-like argument in $p a q y-a$ an $\mathrm{S}$ or $\mathrm{P}$ ? There are grammatical and morphological reasons to treat such constructions as intransitive inchoative that may more strongly imply an agent as a passive rather than as a transitive construction where the unspecified agent has been deleted.

First of all, while the inflectional base of transitives is identical to that of the intransitive in the case of weak verbs, it not the same as that of intransitives for strong verbs. Intransitive verbs constitute a special class of verbs with 
a different inflectional base consistently maintaining the long vowel /i/ (see $\S$ 3.1.3.1.). This modification suggests we are not dealing with lability in the strict sense, ${ }^{67}$ but perhaps with what Haspelmath (1993b, 91-92) calls an equipollent alternation, where both transitive and intransitive stems are derived from the same abstract root with a subtle difference in stem modification. As illustrated in (13) below, the intransitive counterpart of ambitransitive verbs morphologically follows the pattern of all basic strong intransitive verbs. This is an indication that the patient argument is S and not $\mathrm{P}$, since the intransitive counterpart is morphologically distinguished even within the same stem formation.

(13) Transitive and intransitive bases (J. Sulemaniyya, NE Iraq; Khan 2005) TRANSITIVE

$\begin{array}{lll}3^{\mathrm{MS}} & \text { bšal- } \varnothing-l e & \text { 'He cooked } \mathrm{it}_{\mathrm{M}} \text { ' } \\ 3^{\mathrm{FS}} & \text { bəšl- } a-l e & \text { 'He cooked it }{ }_{\mathrm{F}} \\ 3^{\mathrm{PL}} & \text { bəšl- }-\mathrm{i}-l e & \text { 'He cooked them' }\end{array}$

INTRANSITIVE

INTRANSITIVE

\begin{tabular}{|c|c|c|c|}
\hline 3Ms bšil- $\varnothing$ & 'It $\mathrm{M}_{\mathrm{M}}$ cooked' & smix $-\varnothing$ & 'He waited' \\
\hline bšill-a & 'It ${ }_{\mathrm{F}}$ cooked' & smix- $a$ & 'She waited' \\
\hline L $\quad b$ šil $-i$ & 'They cooked' & smix $-i$ & 'They waited' \\
\hline
\end{tabular}

Transitive verbs can naturally also alternate in valency through different stem formations. Several intransitive verbs, such as tym 'finish', are transitivized in stem III derivations:

(14) J. Sulemaniyya (NE Iraq; Khan 2004a, 299)
a. tim- $\varnothing$
(inchoative, stem I)
finish $_{\mathrm{PFV}}-\mathrm{S}: 3 \mathrm{MS}$
'It $\mathrm{M}_{\mathrm{M}}$ inished.'

b. ktebăké mtim-a-le

(causative, stem III)

book:FS:DEF finish ${ }_{\mathrm{PFV}}-\mathrm{P}: 3 \mathrm{FS}-\mathrm{A}: 3 \mathrm{MS}$

'He finished the book.'

67 This was pointed out to me by M. Kossmann. 
Khan observes for Jewish Sanandaj (W Iran), closely related to Jewish Sulemaniyya (NE Iraq), that the agentless counterpart of transitive verbs is generally conditioned by telicity, i.e. "telic actionality with an inherent endpoint constituting a change of state" (Khan 2009, 309). Transitive verbs that have a definitive, lasting effect, such as 'kill', e.g. mamí qțil- $\varnothing$ 'My uncle was killed', ${ }^{6}$ have an agentless counterpart, but transitive verbs without a definitive, lasting effect on the patient-like argument, such as 'see' or 'hit', cannot occur in such a construction. The passive of such verbs has to be expressed differently, for example by the resultative participle and the copula or hwy, e.g. xiya $\varnothing$-hăwe$\varnothing$ 'He may have been seen' (Khan 2009, 310).

Khan's observations imply that practically all effective transitive verbs can occur in causative/inchoative transitivity alternations. Regardless of morphological modification in inflectional base or not, both forms like bšil-a ' $\mathrm{It}_{\mathrm{F}}$ cooked' and paqy- $a$ ' 'It $\mathrm{F}_{\mathrm{F}}$ exploded' are essentially inchoative (Khan 2009, 309). They denote an uncontrolled process arising spontaneously, where the origin is less salient to the course of the event.

The agent, however, could also be more strongly implied, in which case the meaning is similar to that of an agentless passive: qtill-a 'She was killed (by somebody)'. The passive construction essentially follows the pattern of spontaneous events, but a cause is more easily contextualizable because of the nature of the event. Inchoatives do not exclude that a speaker is unaware of any causal origin and may add a causal phrase (e.g. The door opened because of the wind; Croft 1994b, 110), but the cause is otherwise not as strongly implied as in the prototypical passive.

Similarly, overt expression of the agent is not altogether avoided. An additional oblique agent is possible (Khan 2004a, 297, 2009, 309). The agent is introduced by the source preposition man- 'of' as in the following example:

\section{(15) J. Sanandaj (W Iran)}
$[\mathrm{s}]$ [v-s]
[OBL]
a. mam-i $\quad q t ̦ i l-\varnothing$ mən-laga sarbazé (overt agent) uncle-my kill $_{\mathrm{PFv}}$-s:3Ms from-side soldiers 'My uncle was killed by the soldiers.' (Khan 2009, 309)

The same preposition marks the indirect cause (i.e. 'because of') and can be added to any intransitive predicate 
[OBL]

b. mən-qardá ret- $\varnothing$

(overt agent)

from-cold:Fs shake $\mathrm{IPFv}-\mathrm{S}: 3 \mathrm{MS}$

'He is shaking because of the cold.' (ibid. 585)

The agent complement in (15) is also typical for denoting the indirect cause of events that are construed as spontaneous. If thus understood, (15) would be akin to English 'My uncle got killed because of the soldiers' rather than a passive.

All else being equal, therefore, intransitive valence patterns that alternate with a transitive valence pattern of the same basic verb allow for an interpretation where the event unfolds spontaneously, consistent with the higher degree of saliency on the part of the patient for inchoatives (cf. Croft 2001, 317). Most intransitive verbs are inflected with E-suffixes and pattern as such. There are, however, a number of relevant exceptions, to which we turn in the following subsection.

\subsubsection{Ergativity: Transitive Semantics and Antipassives}

Ever since Hopper and Thompson's (1980) seminal article, functional typologists ${ }^{69}$ have argued that the prototypical transitive semantics of the event as a whole contributes to the preference for more transitive morphosyntax in constructional splits and alternations. The intransitive valence pattern tends to be used for the semantically less transitive situation..$^{70}$ Agent-like or patient-like arguments are treated more like $\mathrm{s}$ or more like oBL, respectively. ${ }^{71}$

Languages have various valence-reducing devices that downgrade the patient (cf. Payne 1997). Alternative constructions, such as the antipassive voice, are favored when the effect on the patient is reduced (e.g. Cooreman 1994). Cross-linguistically, the antipassive and comparable constructions are largely uniform in expressing reduced semantic transitivity and marginalizing the effect on the patient (e.g. Hopper and Thompson 1980; Tsunoda 1981). In Samoan, for example, a transitive verb such as 'eat' occurs in an intransitive

69 See inter alia Lakoff (1977), Comrie (1978, 1989), Hopper and Thompson (1980), DeLancey (1984, 1987), Givón (1984a, 1985a), Langacker (1987, 1991a-b), Croft (1990, 1991), Lazard (1998, 2002), de Swart (2006), and Næss (2007).

$70 \quad$ E.g. Hopper and Thompson (1980), Tsunoda (1981), Givón (1984a, 1985).

71 A rather extreme view found in the literature is that ergative alignment itself is even conceptually based on transitivity (e.g. Cooreman et al. 1984; Givón 1985a) and its effects, therefore, are predicted to characterize any split between ergative and other constructions (e.g. Givón 1984a, 153-163). 
construction in (16b), where the agent is expressed as $\mathrm{s}$. The patient equivalent to the transitive counterpart in (16d) is expressed as the oвL with the locative-directional case, used to denote a partially affected undergoer (Mosel and Hovdhaugen 1992, 108).

(16) Samoan (Polynesian, Samoa; Mosel and Hovdhaugen 1992, 105, 108, 429, glossing adapted)

$[\mathrm{v}] \quad[\mathrm{s}]$

a. $S \bar{a}$ pa'ū $\varnothing$ le teine

(patientive intransitive)

PST fall ABS the girl

'The girl fell.'

$[\mathrm{v}] \quad[\mathrm{s}]$

b. $S \bar{a}$ 'ai $\varnothing$ le teine

(patientless antipassive)

PST eat ABS the girl

'The girl ate.'

$[\mathrm{v}] \quad[\mathrm{s}] \quad[\mathrm{OBL}]$

c. $S \bar{a}$ 'ai $\varnothing$ le teine $i$ le i'a

(antipassive)

PST eat ABS the girl LOC the fish

'The girl ate some fish.' (lit. The girl ate at the fish)

$[\mathrm{v}] \quad[\mathrm{A}] \quad[\mathrm{P}]$

d. $S \bar{a}$ 'ai $e$ le teine $\varnothing$ le i'a

PST eat ERG the girl ABS the fish

(transitive)

'The girl ate the fish.'

The affectedness or change of state of $\mathrm{P}$ is arguably the most fundamental feature that contributes to the transitivity overall. When the patient is totally affected, the change of state is completed, the endpoint of the event is clearly delimited and the transitive construction is preferred. When the patient is not totally affected and/or the change of state is incomplete, the delimitations become vaguer. The most important of these shared properties can be summed up as follows:

(17) ANTIPASSIVE

less transitive imperfective partial affectedness of $P$ atelic
ERGATIVE

more transitive

perfective

complete affectedness of $\mathrm{P}$

telic 


$\begin{array}{ll}\text { ANTIPASSIVE } & \text { ERGATIVE } \\ \text { durative } & \text { punctual } \\ \text { stative } & \text { dynamic }\end{array}$

The intransitive construction is favored when the effect on the patient is less salient and the activity is more central. In Hopper and Thompson (1980)'s model, this is the reduction of transitivity.

Similarly, some transitivity alternations in Trans-Zab Jewish dialects do evince a distinction in the coding of $\mathrm{A}$ and $\mathrm{s}$ that are arguably reminiscent of the antipassive voice. The less definitive the effect, the more likely the verb will not take $\mathrm{s}_{\mathrm{A}}$ coding.

To illustrate, the intransitive alternant of $(18 \mathrm{a})$ in $(18 \mathrm{~b})$ is patientless, but takes subject coding distinct from A.

(18) J. Sanandaj (W Iran; Khan 2009, 522)
[A]
[v-A]
[P]
a. hangăké nqas-la 'al-í
(active)
bee:FS:DEF prick ${ }_{\mathrm{PFV}}-\mathrm{A}: 3 \mathrm{FS}$ OBJ-1SG
'The bee stung me.'
[s] [v-s]
b. xmatá nqis-a
needle:FS:DEF prick ${ }_{\mathrm{PFV}}-\mathrm{S}: 3 \mathrm{FS}$
'The needle pricked.'
(patientless antipassive)

Such an antipassive may also be extended with an oblique patient. This is typical of bivalent verbs that combine with prepositional complements and generally involve an aimer and a target as participants.
$[\mathrm{s}]$
$[\mathrm{v}-\mathrm{s}]$
[OBL]
c. xmatá
nqis-a
ga-ili-i
needle:FS:DEF prick $\mathrm{PFv}_{\mathrm{PV}}$-S:3FS at-hand-my
'The needle pricked (lit. at) my hand.'

Similarly, the alternation between (19a) and (19b) below depends mainly on whether the patient is more definitively affected or not. In (19a), the less affected patient is encoded as oblique with the preposition $b a$-. Here the patient yalaké is only partially affected and the verb literally conveys 'became attached to' (Khan 2004a, 304). The direct counterpart to this is (19b). The patient is completely affected and this is expressed in the primary transitive morphosyntax. 
(19) OвL opposed to P (J. Sulemaniyya; Khan 2004a, 304)

$[\mathrm{s}] \quad[\mathrm{V}-\mathrm{s}] \quad[\mathrm{OBL}]$

a. hanga dwiq-a bă-yalaké (овL, less affected)

'The bee stung the child.'

$[\mathrm{P}] \quad[\mathrm{V}-\mathrm{P}-\mathrm{A}]$

b. yalăké $d w a q-\varnothing-l a$

(P, more affected)

'She seized the child.'

Variation in s-marking is also partly conditioned by properties of the situation or event as a whole, i.e. aspect. This concerns punctuality and dynamism. In (20) below, for instance, the difference in punctuality plays a role, and in (21), the degree of dynamism (Khan 2008b, 73-74).

(20) Punctual (A-like) vs. durative (P-like) (J. Sulemaniyya; Khan 2004a, 305) a. torá lip-le 'He learnt Torah.'

(A, punctual)

b. ga-maktáb lip- $\varnothing$ 'He learnt at school.'

$\left(\mathrm{S}_{\mathrm{P}}\right.$, non-punctual $)$

Khan (2004a, 301) explains that the patient-like form of $y / p$ 'learn' in (2ob) refers to a "more diffuse, durative activity, spread over a long period of time, although presented perfectively as a unitary whole." Hence, the disfavor of agent-like coding depends on the durativity of the action.

The $\mathrm{s}_{\mathrm{A}}$ construction therefore seems to be disfavored for durative and stative situations in accordance with Hopper and Thompson's transitive semantics. Khan (2004a, 304) also attributes the difference between prq 'finish' and $b d y$ 'begin' in (21) to action-dynamics. prq 'finish' in (21b) expresses the cessation (endpoint) of an activity resulting in an enduring state of completion (i.e. durative and stative) and hence aligns with P. bdy 'begin' entails the initiation of an event with a greater degree of dynamism and, hence, aligns with $\mathrm{A}$.

(21) Active-dynamic (A-like) vs. stative (P-like) (J. Sulemaniyya; Khan 2004a, 301)
a. haštá (m)parq-a-le 'He finished the work.'
(stem II transitive)
b. prriq- $\varnothing$ m-xalá
'He finished eating.'
$\left(\mathrm{s}_{\mathrm{P}}\right.$, more stative)
c. bde-le b-xalá
'He started eating.'
$\left(\mathrm{s}_{\mathrm{A}}\right.$, more dynamic $)$

Antipassives may also correlate with reflexives (Comrie 1978, 361-362). A few intransitive constructions that are understood as reflexive reveal coding distinct from A in NENA, such as sxy and xpy conveying 'wash (oneself)', for example: 
(22) J. Sulemaniyya (NE Iraq; Khan 2004a, 300; 2007a, 150)

$$
[\mathrm{P}] \quad[\mathrm{V}-\mathrm{P}-\mathrm{A}]
$$

a. bronăké xip- $\varnothing$-la

child:MS:DEF wash PFV $-\mathrm{P}: 3 \mathrm{M} \mathrm{S}-\mathrm{A}: 3 \mathrm{FS}$

'She washed the child.'

$$
\text { [v-s] }
$$

b. xip-a

(antipassive)

wash $_{\mathrm{PFv}}-\mathrm{S}: 3 \mathrm{FS}$

'She washed.'

The intransitive valence pattern of verbs like xip-a 'She washed' is thus not simply agentless and does not convey the meaning 'She was washed (by sb. else)'. This is in contrast to reflexive verbs of dressing and grooming that are lexicalized as transitive, where the corresponding from that lacks $\mathrm{s}_{\mathrm{A}}$ coding leaves the agent unspecified, e.g.
lwaš-le 'He got dressed'
(by himself)
lwiš- $\varnothing$ 'He was dressed'
(by somebody else)

There are known counterexamples, however: for example, it is possible that the antipassive marks precisely the opposite, a highly individuated and affected patient much like differential object marking (cf. Comrie 1978, 362-363). Similarly, many dynamic and/or punctual verbs are not $\mathrm{s}_{\mathrm{A}}$ verbs in NENA, such as

$$
\begin{array}{llr}
\text { paqe } \varnothing \text { ' } & \text { 'explode' } & \text { (dynamic, punctual, telic) } \\
\text { rqil- } \varnothing & \text { 'dance' } & \text { (dynamic, durative, atelic) }
\end{array}
$$

Moreover, the relationship between transitivity and the properties of the agent (i.e. control, intention, animacy) is even more controversial (e.g. Fauconnier 2011B, 2012). Not all scholars (e.g. Tsunoda 1981) consider the degree of agentivity a significant factor in contributing to transitivity as conceived by Hopper and Thompson (1980)..$^{72}$ Studies such as those of Fauconnier (2011a-b, 2012 $)^{73}$ have shown, for instance, that less transitive morphosyntax is ultimately the result of the anticausativization of a verb denoting an uncontrolled event, which, being intransitive and conceived as spontaneous, is generally not com-

72 Cf. Croft (1984), Malchukov (2006).

73 Cf. Kittilä (2005), Shibatani (2006), Fauconnier and Verstraete (2014). 
patible with A. It is also generally a lexically intransitive verb that primarily determines the A-like or P-like marking of $\mathrm{s}$ and not the transitive semantics per se (Creissels 2008b; Haig 2008, 11).

Cross-linguistically, the most typical agent-like intransitive verbs are controlled activities such as 'dance' (Croft $1998,5^{2-53}$ ). It is striking, then, that the prototypically agent-like intransitive subjects, such as raqil- $\varnothing$ 'He danced', are treated unlike A in Southeastern Trans-Zab Jewish dialects of NENA. This is a noteworthy exception to agentivity as a contributing semantic factor. Khan $(2007 \mathrm{a}, 15 \mathrm{O})$ points out that such verbs lack an implicit patient and do not have a labile counterpart with a transitive valence pattern. Clearly, however, such verbs could potentially take an object, $\mathrm{cp}$. English We danced the tango, and some of them do, for example, $y / p$ 'learn' in (2O) above, perhaps shifting to the more transitive coding simply because of the presence of an object.

Several dialects in NW Iran seem to differentiate on the basis of agentivity. The subject's agentive properties do come into play here. In J. Qarah Hasan, for instance, (23a) 'bark' as an animal noise verb is distinct from (23b) 'sneeze' as a bodily action, presumably viewed as an uncontrolled process, like pil- $\varnothing$ 'fall', instead. The subject of $t p l$ 'sneeze' in $(23 \mathrm{~b})$ is more patient-like than the subject of $n w x$ 'bark' in (23a) due to lack of control.

(23) J. Qarah Ḥasan (W Iran; Khan 2009, 306)

a. nox-le ' $\mathrm{It}_{\mathrm{M}}$ barked.'

$\left(\mathrm{s}_{\mathrm{A}}\right.$, controlled $)$

b. tpil- $\varnothing$ 'He sneezed.' $\left(\mathrm{s}_{\mathrm{p}}\right.$, uncontrolled)

Such instantaneous bodily reactions are known to lead to ambiguity in the degree of control of $s$ (Khan 2009, 305; cf. Sorace 2000, 877).74

In the related dialect of J. Sanandaj, animacy plays a role. If the subject is inanimate, the verb is categorized as intransitive and takes E-suffixes, compare:

(24) J. Sanandaj (W Iran; Khan 2009, 294, 304-306)

$[\mathrm{s}] \quad\left[\mathrm{V}-\mathrm{s}_{\mathrm{A}}\right]$
a. $x$ mara sre-le
donkey:Ms bray brv- $^{-3 \mathrm{MS}}$
'The donkey brayed.'



[s] $\quad\left[\mathrm{v}-\mathrm{s}_{\mathrm{P}}\right]$
b. 'ewá gargám- $\varnothing$
$\left(\mathrm{s}_{\mathrm{P}}\right.$, inanimate $)$
cloud:Ms thunder $\mathrm{PFv}^{-3 \mathrm{MS}}$
'The cloud thundered.'

The inanimate subject 'ewá 'cloud' of grgm 'thunder' in (24b) is inherently more patient-like than the animate subject $x$ mara 'donkey' in (24b). Again, the animal noise verb is $s_{A}$. Note that the inanimate subject in $(24 b)$ is not necessarily less instigating than $\mathrm{A}$, so that the choice of an $\mathrm{s}_{\mathrm{A}}$ from depends on animacy in J. Sanandaj and not instigation/agentivity.

The coding of the verb nqs 'prick' in (25) below also differs depending on whether the subject is animate or inanimate. When the subject is inanimate and instigating, the verb does not receive $\mathrm{s}_{\mathrm{A}}$ coding; if it is human and instigating, it receives $\mathrm{s}_{\mathrm{A}}$ coding (Khan 2009, 304).

(25) Animate (A-like) vs. inanimate (P-like) s (J. Sanandaj; Khan 20o9, 304, 543)
[s]
[V-s]
[OBL]
a. baxtăké
nqas-la ga-'il-í
woman:FS:DEF prick PFv $^{-3}$ FS at-hand-my
'The woman pricked (lit. at) my hand.'
$\left(\mathrm{s}_{\mathrm{A}}\right.$, human $)$
b. xmatá nqis-a ga-'il-í
needle:FS:DEF prick PFv 3 Fs at-hand-my
'The needle pricked (lit. at) my hand.'

$\left(\mathrm{s}_{\mathrm{P}}\right.$, non-human $)$

Note that in the case of J. Sanandaj ( $25 \mathrm{~b})$, the meaning of the verb is only slightly different, but it seems that xmatá nqis- $a$ in $(25 \mathrm{~b})$ is agent-oriented and does not imply an agent other than 'the needle'.

Transitivity alternations are known to lead to ambiguity in orientation in languages where ergativity predominates (e.g. Drossard 1998). The intransitive valence pattern of the verb $y / p$ seems to be agent-oriented in Jewish Sulemaniyya in (20) above. In the closely related dialect of Sanandaj (W Iran), it is oriented towards a patient-like affectee. Khan $(2009,304)$ argues that verb $y l p$ 'learn' manifests an alternation depending on control. In this instance it does matter whether another cause is being implied; the $s_{A}$ form cannot be used because of the anticausativization of the event. The A-like coding entails that the human subject learnt something through its own deliberate effort (controlled), whereas lack of A-like coding entails that the human subject learnt something by being taught by somebody else (uncontrolled). 
(26) Controlled (A-like) vs. uncontrolled (P-like) (J. Sanandaj; Khan 20o9, $304,543)$

a. 'ó rába məndixané ylap-le (compatible with $\mathrm{A}$ ) he many thing:PL learn $\mathrm{PFv}^{-} 3 \mathrm{MS}$

'He learnt many things (by himself).'

b. 'ó rába mandixané yálip- $\varnothing$ (incompatible with A) he many thing:PL learn ${ }_{\mathrm{PFV}}-3 \mathrm{MS}$

'He learnt many things (from somebody else).'

All in all, the distinction in subject-marking does neither evince a neat split between agentive and patientive verbs nor between the presence or absence of objects. This does not mean that semantic or syntactic transitivity is completely irrelevant (cf. Khan 2004a, 304). Inanimate and/or noncontrolling arguments sometimes do not seem compatible with the $\mathrm{s}_{\mathrm{A}}$ construction.

\subsubsection{Agent Omission in Compound Verbal Forms in West Iranian Jewish Dialects of NENA}

Particular types of arguments are not compatible with the A function in the compound verbal form in Southeastern Trans-Zab Jewish dialects of NENA in western Iran. In fact, there is no overt inflection of the agent in such compound verbal forms (Hopkins 2002; Khan 2009, 92), which is a major difference from other NENA dialects. Also, given the lack of agent indexes, the compound verbal form itself is unspecified for an agent, which has to be inferred from the context and can never be a highly topical argument such as the first or second person. Thus, a hypothetical clause like (27) below is not possible.
$[\mathrm{A}] \quad[\mathrm{P}] \quad[\mathrm{V}-\mathrm{P}]$
(27) **aná baxtí
nšaq-ta-ya
I woman:FS-my kissed-P:FS-P:3FS
Intended: 'I have kissed my wife.'

The agent NP does not trigger agreement even when it is a full and definite nominal, such as bratí 'my daughter' in (28), and even when the patient is omitted, for example:

$[\mathrm{A}] \quad([\mathrm{P}])[\mathrm{v}]$

(28) brat-í

(Ø) qaryá-y

daughter:Fs-my studied(:MS-3MS)

'My daughter has studied (lit. it $\mathrm{M}_{\mathrm{M}}$ )' (Khan 2009, 325) 
Conversely, the prominent patient retains overt agreement when the agent is still referential, but unexpressed:

$$
\text { [A] }[\mathrm{P}] \quad[\mathrm{V}-\mathrm{P}]
$$

(Ø) mašinăké lbalte-ya

he car:FS:DEF taken:P:FS-P:3FS

'He ${ }^{75}$ has taken the car.' (Khan 2009, 518)

The realis perfect is similar to the passive, since the agent is obligatorily zero and incompatible with higher ranking agents. The agent in the passive construction is limited to the third person and may be omitted in some languages of the world (Jelinek and Demers 1983; Croft 2001, 288-290 ${ }^{76}$ ). The passive cannot be used when the agent outranks the patient. That is, when the agent is non-third person and the patient is third person (either pronominal or full nominal), a different construction must be used instead in such languages.

Nevertheless, there are good reasons to analyze this construction as transitive, i.e. ergative, and not passive. All things considered, it will be demonstrated that the transitive realis perfect (garšá-y) in Iranian Jewish dialects of NENA is not a passive voice construction. This is supported by the morphological and syntactic properties of the patient (differential marking), of the agent (lacking oblique case-marking, occupying initial position, co-referential deletion) and the verbal form itself (distinct inflectional base for transitives and intransitives). It still remains a restricted and largely impersonal construction, namely in limiting both $\mathrm{A}$ and $\mathrm{P}$ to the third person.

\subsubsection{Differential Object Marking}

The marking of the patient is sensitive to definiteness in the realis perfect, which is typical of objects. Agreement, for instance, is only manifested, when the patient argument is salient. Otherwise the compound verbal form is in the unmarked masculine singular form, e.g. garšá-y, and does not agree, just as in the preterit, e.g. $\operatorname{gr} \check{s}(-\varnothing)$-li 'I pulled' (Khan 20o9, 326). Although it is not uncommon for passives to disfavor non-third person arguments to occur as the oblique agent, it is typical of passives to favor them as the patient. The compound verbal form that concerns us here, however, is not compatible with non-third person arguments as either agent or patient. The person constraint

\footnotetext{
75 This is Khan's translation; the agent's identity, i.e. he/she/it/they, is context-dependent, however.

76 Cf. DeLancey (1981), Haspelmath (2007, 94).
} 
on the patient, however, is not typical of a passive, but is similar to the ergative preterit. A first person form, for example, cannot be expressed as the patient, as shown in the following hypothetical clause:

(1) šulțaná ** nšaqta-yan

king:MS kissed:P:FS-P:1Fs

Intended: 'The king has kissed $\mathrm{me}_{\mathrm{F}}$ '.

In addition, it is the patient argument that may receive (differential) prepositional marking by means of ('al)l-, for example:

(2) Differential prepositional marking
[A]
[DOM $\rightarrow \mathrm{P}]$
$[\mathrm{v}]$
a. šulțaná
al-ganawá
qațlá-y
king:MS
Dom-thief:Ms
killed
'The king has killed the thief.' (J. Saqez, W Iran; Israeli 1998, 229)
b. tat $-i^{\prime}$
hal-baxtaké
garšá-y
father:Ms-my Dom-woman:the:Fs pulled
'My father has pulled the woman.' (J. Sanandaj, W Iran; Khan 2009, 329)

Similarly, the realis perfect freely combines with independent object person markers, for example:

(3) J. Sanandaj (W Iran; Khan 20o9, 324)
[A]
$[\mathrm{v}]$
$[\mathrm{P}]$

a. brat-í

garšá-y 'al-éf

girl:Ms-my pulled овј-3мs

'My daughter has pulled him.'

b. $\varnothing$

$$
\text { garšáà 'əl-í }
$$

A:3 pulled овJ-1SG

'(He/she/it/they has/have) pulled me.'

Dependent person markers of the $\mathrm{L}_{1}$-suffixes or $\mathrm{L}_{2}$-series may attach to the immediately preceding verbal form in J. Saqez just as it does in the preterit (Israeli 1998, 117), e.g.

nišqá-y -lan '(He/she/it/they has/have) kissed us' 
First and second person patients are never expressed by the participial agreement or the copula when the perfect is transitive. This is a type of person constraint also attested for the preterit of these dialects. One would expect for a passive that participle and copula would agree with a highly topical patient just as it would agree with s, but they do not. The patient coding of the perfect mimics that of objects in the preterit (cf. Khan 2009, 323).

One would expect the agent to be prepositional in a passive, but prepositional marking of the agent does not appear to be possible in these dialects for the realis perfect, so that clauses like (4) below do not occur.

$$
\begin{aligned}
& \text { **al-brat-í garša-y 'alí } \\
& \text { DAT-daughter:Fs-my pulled P:1SG } \\
& \text { 'My daughter has pulled me.' }
\end{aligned}
$$

\subsubsection{Full Expression of the Agent and Word Order}

The unmarked word order of full NPs in the perfect is consistent with other transitive clauses. Compare the perfect in (5a) with an equivalent preterit clause in $(5 \mathrm{~b})$ in the Jewish dialect of Saqez:

(5) J. Saqez (W Iran; Israeli 1998, 103)

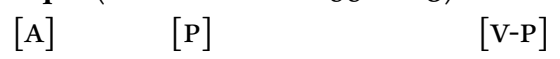

a. brat-év axonowal-áv la xəzy-én girl:Fs-his brother:PL-her NEG see:RPP:P:PL-P:3PL 'His daughter has not seen her brothers.'

$[\mathrm{A}] \quad[\mathrm{P}] \quad[\mathrm{V}-\mathrm{P}-\mathrm{A}]$

b. ahmád xalist-év xazy-a-le

PRN sister-his see ${ }_{\mathrm{PFV}} \mathrm{P}: 3 \mathrm{FS}-\mathrm{A}: 3 \mathrm{MS}$

'Ahmad saw his sister.'

The agreement is entirely limited to the patient in the realis transitive perfect (5a) contrasting with the preterit, where the agent is also indexed (i.e. the Lsuffixes). The agent NP in (5a) occupies the typical position of A in the clause. Indeed, the agent nominal is similarly zero-marked. It is never oblique, as we would expect for a passive.

\subsubsection{Referential Continuity}

Moreover, co-referential deletion is not expected to be possible for the (oblique) agent in a passive prototype, but only for s (see $§ 4.2 .2$ ). In the following examples, however, an intransitive construction is combined with a 
transitive one, both in the realis perfect. The agent in the conjoined clause is the same referent as $s$. The $-\varnothing$ affix indicates that agent agreement is not overtly expressed.

(6) J. Kerend (W Iran; Hopkins 2002, 292)
$\left[\mathrm{s}_{\mathrm{i}}\right]$
a. hy-a-y
$\left[\mathrm{A}_{\mathrm{i}}=\mathrm{S}_{\mathrm{i}}\right]\left[\mathrm{P}_{\mathrm{j}} \neq \mathrm{S}_{\mathrm{i}}\right]$
come:RPP-S:MS-S:3MS and 3MS money:Ms-his
$[\mathrm{V}-\mathrm{P}](-[\mathrm{A}])$
labl-á-y $(-\varnothing)$
taken-P:MS-P:3MS-A:3
' $\mathrm{He}_{\mathrm{i}}$ has come and (he $\mathrm{i}_{\mathrm{i}}$ has) taken his $\mathrm{i}_{\mathrm{i}}$ money.'
$\left[\mathrm{s}_{\mathrm{i}}\right]$
$\left[\mathrm{A}_{\mathrm{i}}=\mathrm{S}_{\mathrm{i}}\right]\left[\mathrm{P}_{\mathrm{j}} \neq \mathrm{S}_{\mathrm{i}}\right]$
b. h-ita-ya

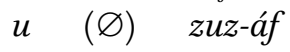
come:RPP-S:FS-S:3FS and 3 FS money:MS-her
$[\mathrm{V}-\mathrm{P}](-[\mathrm{A}])$
labl-á-y(-Ø)
taken-P:MS-P:3MS-A:3
'She ${ }_{\mathrm{i}}$ has come and ( she $_{\mathrm{i}}$ has) taken her ${ }_{\mathrm{i}}$ money.'

The s of the intransitive verb hyy 'come' shows full agreement. It has the same referent as the agent of the following transitive clause. The transitive verb $l b l$ 'take' agrees with the definite patient NP, which is zuza 'money'. In each case there is a distinct reference for the agent as indicated by the possessor on $z u z a$, and this subject reference is the same as the preceding $s$ of the intransitive verb. Other than contextualization, such as the possessor pronoun, and the subject in the preceding intransitive clauses, the agent is not expressed. Accordingly, forms like lablá-y 'taken her' still imply agreement with a third person agent, so that a feature [A:3] is arguably part of the construction (cf. Hopkins 2002). Transitive forms like xəzyá-y '(A:3) seen him' and paltá-y '(A:3) taken him out' are active two-argument instances of the realis perfect.

In same-subject complements, modal verbs like 'by 'want' (cf. 'abe-le 'he wanted') take the agentless transitive form, while the following subjunctive verb in the complement clauses expresses overt subject agreement, for example:

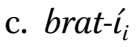
’abyá-y- $\varnothing$
$\varnothing_{i} \varnothing$-hiy-á
daughter:FS-my wanted:RPP(:M S-3MS)-A:3
SBJ-come $_{\text {IPFV }}-\mathrm{S}: 3 \mathrm{FS}$
'My daughter wanted to come.' (Khan 2009, 326) 


\subsubsection{Lexical Transitivity}

In addition, if the patient is omitted, the verb remains referential to the agent, even when it takes the unmarked 3 ms. form (Khan 2009, 325). Thus where the patient is less salient to the event, an agent-orientation may be maintained, such as with qry 'study' in (7a). Similarly, intransitive $\mathrm{s}_{\mathrm{A}}$ verbs, such as šhl 'cough' in $(7 \mathrm{~b})$, which take transitive coding in the perfective past, also retain an agentorientation (Khan ibid.). A passive interpretation is completely ruled out. This contrasts with most intransitive verbs, such as 'come', which always show agreement. This would be consistent in analyzing the $\mathrm{s}_{\mathrm{A}}$ verbs, such as šhl 'cough', as basically lexically transitive.

(7) J. Sanandaj (W Iran; Khan 20o9, 325)
a. brat-i
qaryá-y
: qre-le (transitive coding)
daughter:FS-my studied:RPP(:MS-3MS)
'My daughter has studied.'
b. baxt-i šahlá-y : šah-le $77 \quad$ (transitive coding) woman:Fs-my coughed:RPP(:Ms-3Ms)
'My wife has coughed.'
c. baxt-i
hi-ta-ya
: hiy-a
(intransitive coding)
woman:FS-my come:RPP-S:FS-S:3 FS
'My wife has come.'

\subsubsection{Different Inflectional Bases}

Finally, the difference between agent- or patient-orientations is also reflected in the inflectional base; not for weak verbs like $x z y$ 'see' in (5) above, but for sound verbs like grš 'pull'. Sound verbs differentiate between transitive and intransitive predicates. They differ in the vowel template of the participle similarly to qtil-. Transitive verbal forms have a vowel before the second radical in the masculine and plural base, which is a reduced /ə/:

\section{(8) Transitive bases}

ms. garšá 'pulled'

pl. garšé

fs. grašté

Intransitive verbs, such as $\operatorname{smx}$ 'stand, wait', have a full /i/ and a stable vowel template. This also applies to the intransitive form of transitive verbs: 
(9) Intransitive bases

$\begin{array}{llll}\text { ms. } & \text { smixá } & \text { 'waited' } & \text { grišá } \\ \text { pl. } & \text { smixé } & \text { grišé } & \\ \text { fs. } & \text { smixté } & \text { grišté }\end{array}$

Thus intransitive verbs show a stable inflectional base:

$\begin{array}{ll}\text { smix-á-y } & \text { 'He has stood' } \\ \text { smix-te-ya } & \text { 'She has stood' } \\ \text { smix-én } & \text { 'They have stood' }\end{array}$

Virtually all verbal roots that have transitive stems as shown in (8) can also have intransitive stems as shown in (9). There is a subtle morphological distinction between intransitive and transitive stems, which corresponds to their use with intransitive and transitive morphosyntax, respectively. The transitive valence pattern is qațlá, where an agent is still implied, against the intransitive qțilá, e.g. J. Saqez (Israel 1998, 107)

$$
\begin{array}{lll}
\text { palt } & -a ́ a-y & \text { '(They) have taken him out' } \\
\text { plit } & -a ́-y & \text { 'He has gone out' } \\
\text { grrš } & -a ́-y & \text { '(They) have pulled him' } \\
\text { griš } & -a ́-y & \text { 'He has been pulled' }
\end{array}
$$

(causative) (inchoative) (causative) (inchoative)

\subsubsection{Transitivity and Alternations in Northwest Iranian Jewish Dialects of NENA}

The more western and northern Trans-Zab Jewish dialects are similar to the core of NENA varieties (see Chapter 4) with the following noteworthy differences. Jewish dialects in NW Iran and villages such as Rustaqa and Koy Sanjaq in NE Iraq do use qțil- with E-suffixes. Forms corresponding to $\mathrm{S}_{\mathrm{A}}$ coding express the perfective past, whereas the form with E-suffixes expresses the inchoative pendant with result state focus in these dialects, which is reminiscent of the same form in Southeast Trans-Zab dialects used in the perfective past.

Consider, for instance, plix- $\varnothing$ and plax-le in J. Urmi in (1) below.

(1) J. Urmi (NW Iran)
$[\mathrm{P}] \quad[\mathrm{V}-\mathrm{P}]$
a. tar-é palx-i-le
(causative, perfective past)
door-PL open ${ }_{\mathrm{PFv}}$-P:3PL-A:3MS
'He opened (lit. them) the doors.' (Garbell 1965, 150) 

$[\mathrm{s}] \quad\left[\mathrm{v}-\mathrm{s}_{\mathrm{P}}\right]$
b. tara plix- $\varnothing$
(inchoative, realis perfect)
door:Ms open ${ }_{\mathrm{PFV}}-\mathrm{S}: 3 \mathrm{MS}$
'The door has opened.' (Khan 2008b, 294)
$[\mathrm{s}] \quad\left[\mathrm{v}-\mathrm{s}_{\mathrm{A}}\right]$
c. labb-ew plax-le
(inchoative, perfective past)
heart:Ms-his open ${ }_{\mathrm{PFv}}-\mathrm{S}: 3 \mathrm{MS}$
'His heart opened (= He cheered up).' (Khan 20o8b, 459)

Thus the subject of the intransitive valence pattern that corresponds to the patient in the transitive valence pattern is coded in a patient-like or agent-like fashion depending on aspect (perfect or resultative-stative vs. perfective past). They both denote a spontaneous event, not a passive. The passive has to be expressed differently in Jewish Urmi, for example by the resultative participle and the copula, e.g. o-naša +qtil-ele 'The man is killed' (Khan 20o8b, 83). The same construction also occurs in the closely related dialect of Arbel, where an oblique agent can be added:

(2) J. Arbel (NE Iraq; Khan 1999, 285)
$[\mathrm{s}]$
[RPP
gaw-kaxtá
kliw
$-\mathrm{COP}]$
[OBL]
inside-letter:MS written:s:NONFS -S:COP:3MS from-hand-LK angel:PL
'(He sees) the content of the letter is written by (the hand of) angels.'

Consequently, the argument coded like the patient in forms such as (lb) should be analyzed as $\mathrm{S}$ and not $\mathrm{P}$.

There are notable differences between which intransitive verbs are compatible with transitive coding in Southeastern Trans-Zab Jewish varieties and Northern Trans-Zab Jewish varieties like Urmi. Table 19 below compares the use of qtil- with E-suffixes for the two dialects of Sulemaniyya and Urmi: the preterit forms for J. Sulemaniyya and the perfect forms for J. Urmi.

A few intransitive verbs are inflected differently in the perfect in J. Urmi and are compatible transitive coding, including those denoting a controlled activity, such as $r q l$ 'dance', where forms like ${ }^{* *} r q i l-\varnothing$ 'He has danced' are impossible. Instead the verbal person marking is the same as that of compound verbal forms expressing the transitive realis perfect (see $\S 3.1 .3 .3$. and $\S 3.4 .5$.). The transitive counterpart of plix- $\varnothing$ in (1b) above, for example, would be plix-é 'He has opened' from plixa, the resultative participle, and -ile 'He is'. Thus, an intransitive verb like $r q l$ 'dance' can occur only with the morphosyntax of the 
TABLE 19 Comparison of subject-marking in J. Sulemaniyya and J. Urmi

\begin{tabular}{|c|c|c|c|}
\hline & & J. Sulemaniyya & J. Urmi \\
\hline & & $\begin{array}{l}\text { Preterit } \\
\text { (Khan 2004a) }\end{array}$ & $\begin{array}{l}\text { Perfect } \\
\text { (Khan 20o8b) }\end{array}$ \\
\hline state & 'be afraid' & $z \partial d e-\varnothing$ & $z a d e-\varnothing$ \\
\hline change of state & 'become hungry' & kpin- $\varnothing$ & kpin- $\varnothing$ \\
\hline uncontrolled process & 'explode’ & pəqe- $\varnothing$ & páqe-Ø \\
\hline \multirow[t]{7}{*}{ controlled activity } & 'dance' & rqil- $\varnothing$ & rqil-é \\
\hline & 'jump’ & nande- $\varnothing$ & nandy-é \\
\hline & 'ride' & $r k i w-\varnothing$ & $r k i w$-é \\
\hline & 'come out' & plit- $\varnothing$ & ${ }^{+}$plit- $\varnothing$ \\
\hline & 'go' & $z i l-\varnothing$ & $z i l-\varnothing$ \\
\hline & 'arrive' & mațe- $\varnothing$ & ${ }^{+}$mate- $\varnothing$ \\
\hline & 'finish' & priq- $\varnothing$ & priq- $\varnothing$ \\
\hline \multirow[t]{4}{*}{ sound emission } & 'bark' & nwax-le & $n w i x-\varnothing$ \\
\hline & 'yawn' & phar-re & phir- $\varnothing$ \\
\hline & 'sneeze' & tpal-le & tpil- $\varnothing$ \\
\hline & 'thunder' & gargam-le & gargím- $\varnothing$ \\
\hline \multirow[t]{3}{*}{ inherently reflexive } & 'wash' & səxe- $\varnothing$ & sáxe-Ø \\
\hline & 'undress' & šlax-le & šlix- $\varnothing$ \\
\hline & 'dress' & lwaš-le & lwiš-é \\
\hline
\end{tabular}


transitive realis perfect, e.g. rqil-é 'He has danced'. This is in contrast to the other Trans-Zab Jewish varieties, where such intransitives are not compatible with transitive coding, e.g. J. Sulemaniyya rqil- $\varnothing$ 'He danced'.

Contrasting with J. Sulemaniyya, J. Urmi treats atelic verbs that denote a controlled activity, such as rqil-é 'dance', as transitive, consistent with the control hierarchy of Croft $\left(1998,5^{2-53}\right)$. Conversely, semelfactives receive transitive coding in J. Sulemaniyya (nwax-le), but intransitive in J. Urmi (nwix- $\varnothing)$. Other verbs that denote a controlled activity like $m t y$ 'arrive' and $p r q$ 'finish' are treated the same in both dialects. Interestingly, J. Urmi differentiates between the putting on (lwiš-é) and the taking off of clothes (šlix- $\varnothing)$, which is presumably simply an idiosyncrasy. Possibly, the distinction is similar to J. Urmi bašlamís widé 'begin' (a light verb construction consisting of 'beginning' + 'do') and priq- $\varnothing$ 'finish' in terms of dynamism, i.e. begin vs. stop wearing. Khan (2008b, 74) offers a likely explanation for the differences: punctuality is more fundamental in dialects like J. Sulemaniyya due to the perfective past sense of the preterit, whereas a resultant state is more fundamental to the J. Urmi perfect, which is not readily available for (atelic) activity verbs like rql 'dance'.

\subsection{Conclusion: Construction-Specific, Not Alignment-Specific Factors}

In general, transitive and intransitive constructions show morphosyntax independent of the argument groupings we identify for the Trans-Zab Jewish dialects of NENA. S, A and P cannot be grouped coherently in several inflectional systems, except for the 'imperfective', i.e. qațal-, and the imperative. Alignment patterns are confined grammatically to the same extent as transitive and/or intransitive constructions are restricted.

Consequently, ergativity is a highly restricted morphological phenomenon in Southeastern Trans-Zab Jewish varieties because of third person restrictions on the transitive constructions based on qțil-, i.e. the perfective, and/or qțila, i.e. the resultative participle. Speaking in terms of "antidotes" (Barotto 2015) or "repair mechanisms" (Khan 2017) in order to resolve ergativity in accordance with prominence hierarchies like Silverstein (1976) presupposes that ergativity is inherently unstable in these NENA dialects and overlooks the fact that the ergative cross-indexing is conditioned by higher ranking full NPS, which goes against this prominence hierarchy. Indeed, the identification of a person split does not immediately mean we are dealing with ergativity. Person restrictions can be found also in other constructions, where neither qțil-nor ergativity plays a role, possibly because of analogical affix orders elsewhere in the system. Rather it is particular transitive constructions that are restricted, not ergative 
TABLE 20 Person marking for qțil- in Trans-Zab Jewish dialects

\begin{tabular}{|c|c|c|c|c|c|c|c|c|}
\hline & \multicolumn{4}{|c|}{ SE Trans-Zab } & & \multicolumn{3}{|c|}{ Other Trans-Zab } \\
\hline & \multicolumn{2}{|c|}{ Third only } & \multicolumn{2}{|c|}{ All persons } & & Third only & \multicolumn{2}{|c|}{ All persons } \\
\hline A & \multicolumn{2}{|c|}{ L-set } & \multicolumn{2}{|c|}{ L-set } & A & \multicolumn{3}{|c|}{ L-set } \\
\hline S & E-set & L-set & E-set & L-set & $\mathrm{s}$ & \multicolumn{3}{|c|}{ L-set } \\
\hline$P$ & \multicolumn{2}{|c|}{ E-set } & \multicolumn{2}{|c|}{ 'al- } & $\mathrm{P}$ & E-set & 'วl- & L-set \\
\hline
\end{tabular}

alignment in itself. The same third person restriction, for example, results in an accusative pattern in Western Trans-Zab Jewish varieties on the Arbel Plain, since the intransitive constructions differ from their Southeastern peers. While person splits are common for splits between ergative (third) and non-ergative (first/second) alignment, it has been shown that person restrictions occur irrespective of the intransitive constructions and thus irrespective of the grouping of $s$ and $\mathrm{P}$ that characterizes ergative alignment or irrespective of any grouping whatsoever.

Table 20 above summarizes our findings for Trans-Zab Jewish NENA in the inflection of qțil-, generally used to express the perfective past. The person split is rather an incidental constructional split common to all the Trans-Zab Jewish varieties irrespective of their alignment in the perfective past.

The variation in Trans-Zab Jewish dialects therefore reflects two common strategies for differential object marking, namely with a verbal object index, the preposition 'all- or both. The incidental combination of differential object indexing alongside differential object flagging results in ergative verbal person marking, but accusative nominal marking. The strategies selected in transitive morphosyntax are thereby independent of those in the corresponding intransitive constructions, which show a greater degree of differences across the dialects.

Indeed, the SE Trans-Zab dialects show variation to what extent the subject of intransitive clauses are also compatible with transitive coding, which is determined lexically. Some NENA specials ascribe great significance to this as a type of split-s marking and being distinct from the canonical type of ergativity (e.g. Coghill 2016, 90-100, 250-264; Khan 2017). The split intransitivity in the 'perfective' is striking only because it is not apparent in the 'imperfective'. If we were to subsume this pattern under a semantic alignment system, however, 
this would require us to rethink ergativity altogether, as the basic alignment of third person marking is arguably as ergative as well-known ergative systems (cf. Comrie 2005, 399). The split intransitivity in these NENA varieties is not less typical of ergative morphosyntax, since ergative systems are known to opt for either A-like and/or P-like s-marking in various constructions, such as patient omission constructions. There is no reason to presuppose that one of these strategies is more canonical than the other. In fact, this typology of NENA is generally similar to that of other languages in the area that show lexical-semantic motivations for ergative morphology as well as languages with predominantly ergative morphosyntax such as Basque. When the patient is omitted, yielding a syntactically intransitive construction, the morphosyntax remains nondistinct from the equivalent transitive construction, especially when there is the implication of an effect. This is different from languages with ergative constructions like Samoan, where the ergative case is not used in the absence of a referential object. In some cases, however, the Trans-Zab dialects do show situations incompatible with transitive coding, such as inanimate arguments or human arguments lacking control.

Moreover, when we consider tense-aspect, several Jewish dialects in the northwest use forms with E-suffixes (qim- $\varnothing$ 'He has/is risen') for the resultative and/or perfect rather than the preterit in the southeast ('He rose'). It seems plausible that this reflects the historical development from stative $>$ resultative $>$ perfect and later preterit of the form with E-suffixes (see §6.1.2 and Noorlander forthcoming). The transitive counterpart or the usage of compound verbal forms from formerly resultative constructions is resolved differently for each dialect. The Jewish dialects in western Iran exhibit ergative third person marking both in the simple qțil-, typically denoting the perfective past, and in the compound verbal forms based on qtila, which typically expresses the perfect, which is consistent with the TAM scale of Malchukov (2015). The transitive compound perfect is limited to third person arguments in general. In other respects the NENA data go against this tendency: the perfective past can pattern accusatively, while the perfect and/or resultative patterns ergatively. The dialect of Rustaqa, for instance, incidentally has ergative morphological marking limited to the third person in non-perfective uses of qțil alongside a preverbal TAм strategy. We also observed that ergativity is not peculiar to simplex verbal forms, when one considers the feminine gender agreement in the paradigms of the compound perfect in Jewish dialects of Sulemaniyya and Iranian Azerbaijan. The ergative morphology in the compound verbal forms is summarized in Table 21 below.

The role of language contact requires further investigation, since the TransZab Jewish dialects, especially the Southeastern cluster, show considerable 
TABLE 21 Ergative agreement in compound verbal forms in Trans-Zab Jewish NENA

\begin{tabular}{|c|c|c|c|c|c|c|}
\hline & \multicolumn{2}{|c|}{ Sulemaniyya (Northeast Iraq) } & \multirow{2}{*}{\multicolumn{2}{|c|}{$\begin{array}{c}\text { Northwest Iran } \\
\text { Fem only }\end{array}$}} & \multirow{2}{*}{\multicolumn{2}{|c|}{$\begin{array}{l}\text { West Iran } \\
\text { Third only }\end{array}$}} \\
\hline & Non-fem $>$ fem & Other & & & & \\
\hline A & $\varnothing$ & $\operatorname{AGR}(-t)$ & A & $-t$ & A & $\varnothing$ \\
\hline S & $-t$ & $\operatorname{AGR}(-t)$ & $\mathrm{s}$ & $\varnothing$ & $\mathrm{S}$ & $\operatorname{AGR}(-t)$ \\
\hline $\mathrm{P}$ & $-t$ & $\varnothing$ & $\mathrm{P}$ & $\varnothing$ & $\mathrm{P}$ & $\operatorname{AGR}(-t)$ \\
\hline
\end{tabular}

convergence with local Iranian languages (e.g. Noorlander 2014). It is likely, for instance, that contact with Gorani and Kurdish led to the grammaticalization of intransitive forms inflected with E-suffixes from resultative to perfective past in Southeastern Trans-Zab in contradistinction to Western and Northern Trans-Zab dialects, where the same form expresses the resultative or perfect. ${ }^{78}$ Moreover, convergence with Iranian and the replication of light verb constructions may partly account for the distribution of transitive coding in the Southeastern dialects, especially verbs denoting sound emission (Khan 2007b, 209). Furthermore, the ergative pattern of the compound perfect in these dialects is presumably also due to convergence with Kurdish (Khan 2007b, 204-205). The system found only in Jewish dialects of NENA in West Iran, where the copula agrees with P only, is most likely a pattern replication of the compound perfect in local Iranian languages such as Gorani-Hawrami (MacKenzie 1966, 51), where the copula also agrees with P. The Iranian languages in Northeast Iraq and West Iran, however, generally use clitics to express A, which attach to the full nominal object. The $\varnothing$ expression of A in the local Jewish varieties of NENA could be due to the lack of such a corresponding clitic in their Aramaic speech and, perhaps for communicative reasons, such $\varnothing$ expression is disfavored for first and second person arguments.

In the end, the morphosyntactic microvariation in Trans-ZabJewish dialects of NENA is not driven by underlying functional, cognitive principles in order to avoid ergativity per se, but rather by system-internal and/or cross-dialectal motivations, such as the development of new strategies to mark TAM, the pressure from the main inflectional system qațal-and the restrictions on combi-

$7^{8}$ Khan $(2017,898)$ reaches a similar conclusion. 
nations of dependent person markers to express A and $\mathrm{P}$ in a particular order (cf. Mengozzi 2002b, 45, fn. 144). This presumed cross-system pressure is even more apparent in other dialects, which will be discussed in more detail in the following chapter. 